\title{
AD-A166 106
}

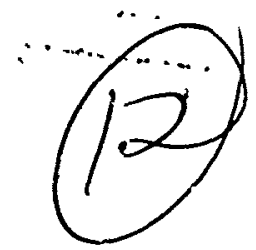

DNA-TR-85-149

\section{FREQUENCY DOMAIN ANALYSIS OF HIGH EXPLOSIVE SIMULATION TECHNIQUE FIDELITY}

\author{
Barry L. Bingham \\ Applied Research Associates, Inc. \\ 4300 San Mateo Bivd NE \\ Suite A220 \\ Albuquerque, NM 87110
}

30 March 1985

Technical Report

CONTRACT NO. DNA 001-82-C-0098

Approved for public release; distribution is unlimited.

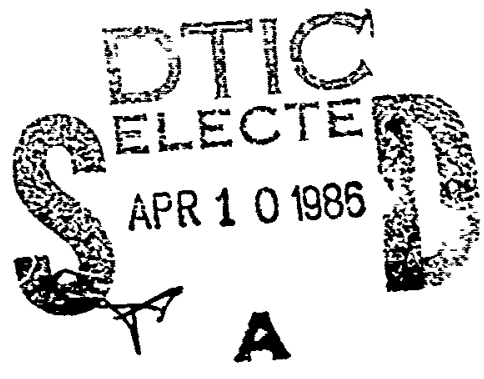

THIS WORK WAS SPONSORED BY THE DEFENSE NUCLEAR AGENCY UNDER RDT\&E RMSS CODE B344.082466 Y990AXSDG0020 H2590D.

Prepared for

Director

DEFENSE NUCLEAR AGENCY

Washingion, DC 20305-100C 
Destruy this report when it is no longer needed. Do not return to sender.

PLEASE NOTIFY THE DEFENSE NUCLEAR AGENCY, ATTN: STTI, WASAINGTON, DC 20305-1000, IF YOUR ADDRESS IS INT,ORRECT, IF YOU WISH IT DELETED FROM THE DIS [RIBUTION LIST, OR IF THE ADDRESSEE IS NO LONGFA EMPLOYED BY YOUR ORGANIZATION.

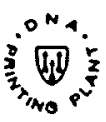


UNCLASSIFIED

SECURITY C'ASSFFICATION OF THIS PAGE

AD. A $16610^{6}$

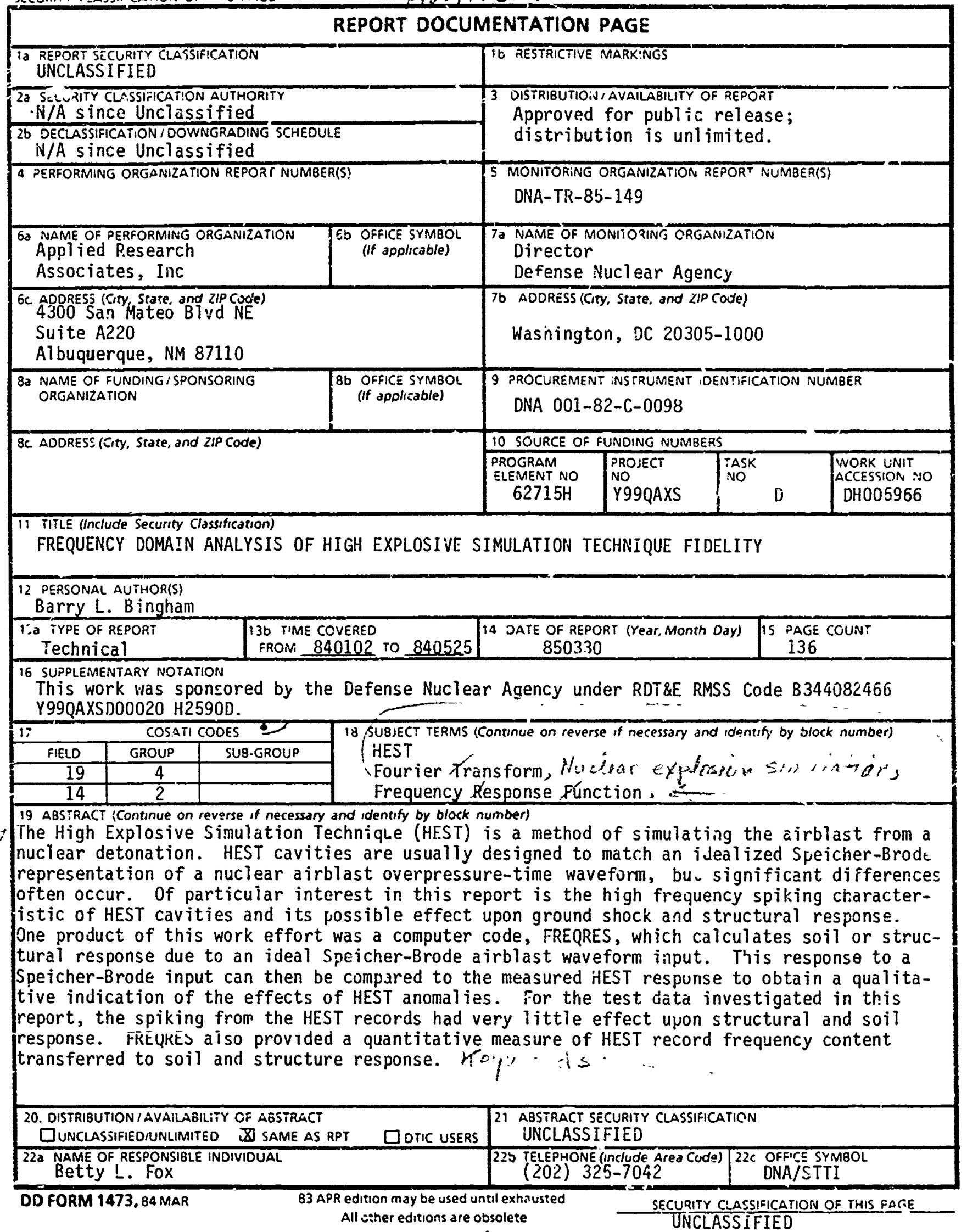




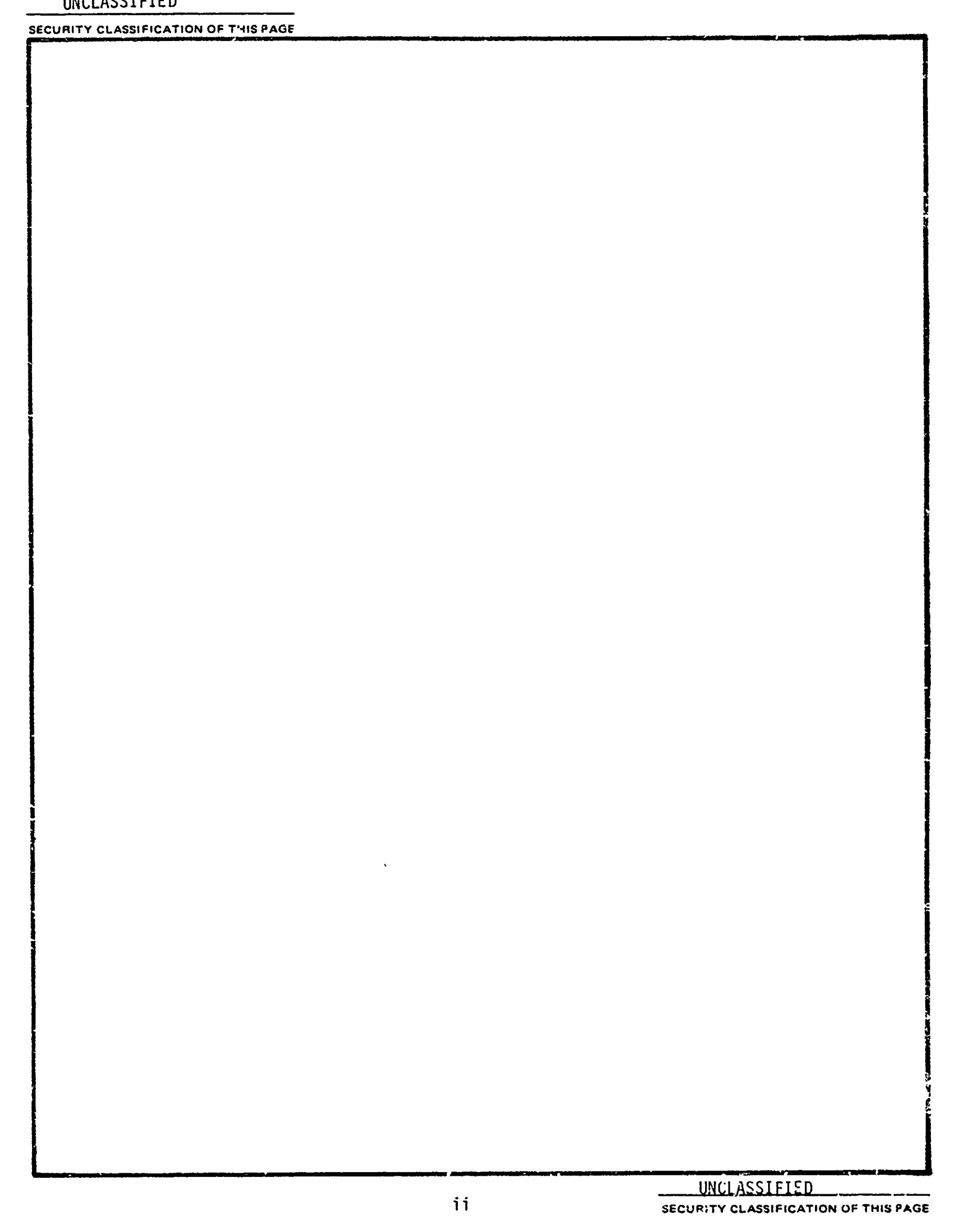




\section{PREFACE}

The analysis presented herein was performed as part of work conducted during the period May 1984 to September 1984 on Contract DNA 001-82-C-0098, Investigation of Scaling, Simulation, and Assuciated Requirements for the STP-3 Combined Effects Program.

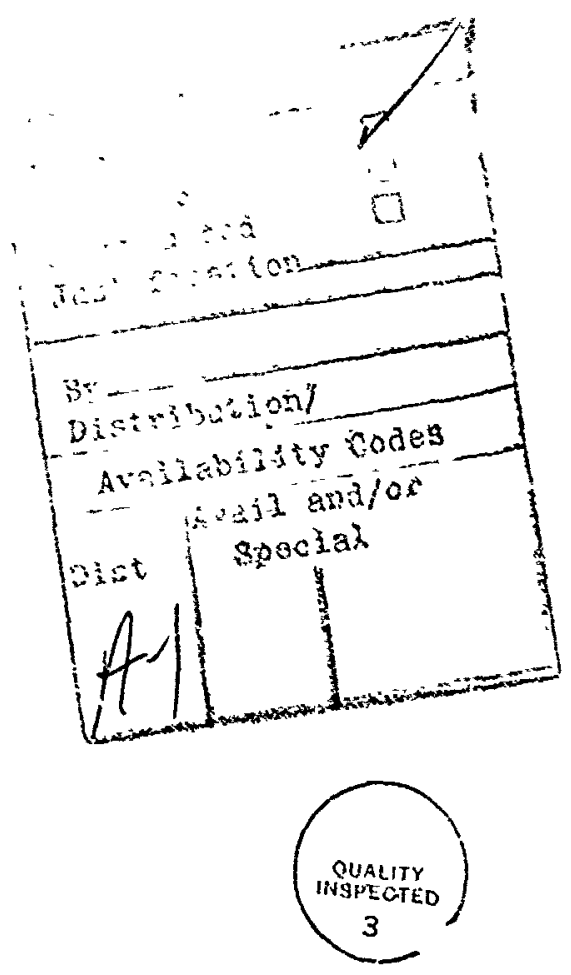


Conversion factors for U.S. customary to metric (SI) units of measurement.

\begin{tabular}{|c|c|c|}
\hline To Convert From & To & Muitıply By \\
\hline angstrom & meters (m) & $1.000900 \times E-10$ \\
\hline atmusphere (normai) & kılo pascal (kPa) & i. $01325 \times E+2$ \\
\hline $\operatorname{tar}$ & kılo pascal ( $(\mathbf{P a})$ & $1.000000 \times \mathrm{E}+2$ \\
\hline barm & meter $r^{2}\left(m^{2}\right)$ & $1000000 \times 5 .-28$ \\
\hline British thermal unit (thermochemical) & joule (J) & $1.054350 \times \mathrm{E}+3$ \\
\hline calorie (the rmochemical) & joule (J) & 4.184000 \\
\hline cal (the rmochemical) $/ \mathrm{cm}^{2}$ & mega joule $/ \mathrm{m}^{2}\left(\mathrm{MJ} / \mathrm{m}^{2}\right)$ & $4184000 \times E-2$ \\
\hline curie & "giga becquerel (GBq) & $3700000 \times E+1$ \\
\hline dcgree (angle) & radian (rad) & 1. $745329 \times \mathrm{E}-2$ \\
\hline degree Fah:enhett & degree kelvin (ii) & $t_{x}=\left(t^{*} f+459.67\right) / 1.8$ \\
\hline electron volt & joule (J) & $160219 \times E-19$ \\
\hline eng & joule $(j)$ & $1000000 \times \mathrm{E}-7$ \\
\hline $\mathrm{erg} / \mathrm{second}$ & watt (W) & $1.000000 \times E-7$ \\
\hline foot & meter $(m)$ & 3. $048000 \times \mathrm{E}-1$ \\
\hline foot-pound-force & joule $(\mathrm{J})$ & 1355818 \\
\hline gallon (ti $s$ liquit) & $\operatorname{meter}^{3}\left(\mathrm{~m}^{3}\right)$ & $3785412 \times \Sigma \cdot 3$ \\
\hline inch & meter (m) & 2. $540000 \times E_{t}-2$ \\
\hline jerk & joule $(J)$ & $1.000000 \times E+9$ \\
\hline $\begin{array}{l}\text { joule/kilog ram }(\mathrm{J} / \mathrm{kg}) \text { (radation dose } \\
\text { absorhed) }\end{array}$ & Gray (Gy) & 1. 000000 \\
\hline kılotons & terajoules & 4.183 \\
\hline kıp $(1000 \mathrm{Bb})$ & newton (N) & $4.448222 \times \mathrm{E}+3$ \\
\hline hep/inch ${ }^{2}(k s 1)$ & kilo pascal $\left(k r_{\hat{n}}\right)$ & $6894757 \times E+3$ \\
\hline ktap & $\begin{array}{l}\text { newton-second } / \mathrm{m}^{2} \\
\left(\mathrm{~N}-\mathrm{s} / \mathrm{m}^{2}\right)\end{array}$ & $1000000 \times E+2$ \\
\hline micron & meter $(m)$ & $1000000 \times E-6$ \\
\hline mil & meter $(m)$ & $2.540000 \times \mathrm{E}-5$ \\
\hline mile (international) & $\operatorname{meter}(m)$ & i. $609344 \times \mathrm{E}+3$ \\
\hline ounce & hlogram (kg) & $2.834952 \times E-2$ \\
\hline pound-force (lbe ator mlupots) & newton $(\mathbb{N})$ & 4.448222 \\
\hline pound-foree nch & nexton-meter $(\mathrm{N} \cdot \mathrm{m})$ & 1. $129348 \times \mathrm{E}-1^{-1}$ \\
\hline pound-force/unch & newton/meter $(\mathrm{N} / \mathrm{m})$ & $1751268 \times \mathrm{E}+2$ \\
\hline pound -force/foot ${ }^{2}$ & hito pascal (kPa) & $478 \triangleleft 026 \times E-2$ \\
\hline pound-force/ $\mathrm{unch}^{2}$ (psi) & hilo pascal ( $\mathrm{kPa}$ ) & 5894757 \\
\hline pound-mass (lbm avoi riupots) & kılogram (kg) & $4535924 \times E-1$ \\
\hline pound-mass-foot ${ }^{2}$ (moment of inertia) & $\begin{array}{l}\text { hulogram-meter } \\
\left(\operatorname{tr} \cdot \mathrm{m}^{2}\right)\end{array}$ & $4214011 \times$ E -2 \\
\hline pound-mass $/$ foot ${ }^{3}$ & $\underset{\left(\log / \mathrm{m}^{3}\right)}{\operatorname{kilog} \mathrm{ram} / \mathrm{meter}^{2}}$ & $1601846 \times E+1$ \\
\hline rud (raìation dose absorbed) & $\bullet G, a_{2}(G y)$ & i $000000 \times \mathrm{E}-2$ \\
\hline roeritgen & $\begin{array}{l}\text { coulornb/hilogram } \\
(\mathrm{C} / \mathrm{kg})\end{array}$ & $2579760 \times \mathrm{E}-4$ \\
\hline shathe & second (s) & $1000000 \times E-8$ \\
\hline slug & kilogram (kg) & $1459390 \times E+1$ \\
\hline $\operatorname{torr}\left(\mathrm{mm} \mathrm{Hg}, 0^{\circ} \mathrm{C}\right)$ & kilo pascal (kPa) & 1. $33322 \times$ E - 1 \\
\hline
\end{tabular}

The becquere! (Bq) is the Sl unti of radioncturity; $1 \mathrm{~Bq}=1$ event $/ \mathrm{s}$. - The Gray (Gy) is the Sl umit of absorbed radiation.

A more complete listing of conversions mat be fount in "Metrie Practice Gude $\Sigma$ 380-74," Americus Society for Testing and Materials 
TABLE OF CONTENTS

Section

Page

Preface......................

Conversion Table ................... iv

List of Illustrations ................ . vi

List of Tables ................... ix

1 INTRODUCTION

1.1 Orjective ..................... 1

1.2 Background.................... 1

2 THEORETICAL DEVELOPMENT

2.1 Sause-Effect Relationship . . . . . . . . . . 3

2.2 Fast Fourier Transform . . . . . . . . . . . . 4

2.3 Inverse Fast Fourier Transform . . . . . . . . . . 6

2.4 Frequency Response Function . . . . . . . . . . \&

.5 FOURFIT ................. . . . .

2.6 Mocified Output Response . . . . . . . . . . 9

3 PROGRAM RESULTS

3.1 Program FREQRES ................. 11

3.2 Test Data ................... 11

3,3 FOURFIT Resuits ................. 11

3.4 Frequency Response Functions . . . . . . . . . . . . *

3.5 Fast Fourier Transform Comparisons . . . . . . . . 1.

3.6 Time History Comparisons . . . . . . . . . . 17

4 CONCLUSIONS AND RECOMMENDATIONS . . . . . . . . . 18

Appendices

A Listing oi Program FOURFIT . . . . . . . . . . . 21

B Program FREQRES User's Manual . . . . . . . . . . 43

c Listing of rrogram FREQRES . . . . . . . . . . . 51

D Listing of Program FREPLT . . . . . . . . . . . 65 


\section{LIST OF ILLUSTPATIONS}

Figure

Page

1 Linear cause-effect relationship between two data

72 records.

2 Constant time history and its Fourier transform.

3 Illustration of an original time history, an FFT, and an inverse FFT.

4 Comparison of the original record number 6 and an offset inverse FFT.

5 Record number 2, HEST pressure on the structure.

6 Record number 4, HEST pressure on the soil.

7 Record number 5, soii pressure at $0.5^{\prime}$ depth.

8 Record number 6, soil pressure at $0.5^{\prime}$ depth. 79

9 Record number 7, soil pressure at 5.21' depth. 80

10 Record number 8, vertical structure acceleration at 81 $0.83^{\prime}$ depth.

11 Record number 9, vertical structure acceleration at 3.2.8' depth.

12 Record number 10 , vertical soil acceleration at 5.21 ' depth.

13 Record number 11, vertical soil acceleration at $12.21^{\prime}$ depth.

14 Record number 12 , vertical structural strain at $1.29^{\prime}$ depth.

15 Record number 13, vertical structural strain at $1.29^{\prime}$ depth.

16 Record number 14, vertical structural strain at. $3.33^{\prime}$ depth.

17 Record number 15, vertical structural strain at 5.21 ' depth. 
18 Record number 16, vertical structural strain at 12.21 ' depth.

1.9 Record number 17, vertical structural strain at $18.71^{\prime}$ depth.

20 Record nuriber 18, structural hoop strain at $1.29^{\prime}$ depth.

21 Record number 19, structural hoop strain at $5.29^{\prime}$ depth.

22 Record number 20, structural hoop strain at $12.21^{\prime}$ depth.

23a FFT fit comparison for test data record number 2.

23b Time history comparison of Speicher-Brode waveform to 95 HEST record number 2.

23c Impulse time history comparison for record number 2.96

24a FFT fit comparison for test data record number 4 . 97

24b Time history comparison of Speicher-Brode waveform to 98 HEST record number 4 .

24c Impulse time history comparison for record number 4.

$25 \quad F R F^{\prime}$ s for vertical soil stress (0.5' and 5.21'). 100

26 FRF's for vertical soil velocity (5.21' and 12.21'). 101

$27 \quad$ FRF' $^{\prime}$ s for vertical structural velocities $10.83^{\prime} \quad 102$ and $3.28^{\prime}$ )

28 FRF's for vertical structural strains (1.3', 5.2', and $\left.18.7^{\prime}\right)$.

$29 \mathrm{FRF}^{\prime}$ s for structural hoop strains $\left(1.3^{\prime}, 5.3^{\prime}\right.$, and $12.2^{\prime}$ ).

30 Comparison of original FFT to FFT with Speicher-Brode influence for record number 6 . influence for record number 18 . 


\section{LIST OF ILLUSTRATIONS (Concluded)}

Figure

Page

32 Record number 5 time history comparison.

107

33 Program FREQRES flow chart.

108

viij 
1 Description of example test data.

2 FREQRES input file variable list and description.

3 Sample output listing from FREQRES calculation.

4 Input file variable specifications for each data record.

5 Summary of the total impulse, first FFT value, and inverse FFT offset for the test data.

FREQRES input files.

119 
SECTION 1

INTRODUCTION

\subsection{OBJECTIVE}

The main objective of this work was to investigate the effects of high frequency spiking characteristics of the High Explosive Simulation Technique (HEST) upon testbed and rest article resporise. Spiking is the high pressure, high frequency deviation of a HEST loading from a design nuclear airblast waveform. This investigation provided a qualitative and quantitative evaluation of how well the loading from a HEST cavity simulates the idealized airblast overpressure of a nuclear detonation. A secondary objective was to determine how the frequency content of a HEST ciata record influences measured structure/soil response data.

\subsection{BACKGROUND}

HEST cavities are designed to match Speicher. Brode representations of airblast overpressure-time waveforms, but significant differences often occur between the recorded data and predictions. Due to the discrete, ratiner than continitious application of pressure from the det-cord and the numerous reflections which occur within a HEST cavity, a HEST record is strongly characterized by high frequency (greater than $1000 \mathrm{~Hz}$ ) and sometimes high magnitude pressure spikes. A HEST record can also experience lower frequency, low magnitude deviations from the design 
Speicher-Brode pulse, but this anomaly is less common. It has long been of concern how these HES, deviations from an ideal airblast time history affect soil media and structure response within a testbed. Is the high frequency content of a HEST record filtered out as the load transfers through soil media and/or a structure? Or does the high frequency input content excite high frequency response modes? These questions are difficult to answer in the time domain. Frequency domain anaiysis tools such as the Fast Fourier Transform (FFT), Frequency Response Function (FRF), and the inverse FFT are ideal for investigating these questions, and were used in this effort to obtain a qualitative and quantitative determination of HEST fidelity in simulating a Speicher-Brode nucleir environment.

1. Speicher, S.J. and Brode, H.L., Airblast Overpressure Analytic Expressions for Burst Height, Range and Time--Over an Ideal Surface, PSR Note 385, Facific-Sierra Research Corp., Los Ange?es, CA, November 198i, as modified for time of arrival at high overpressures by memo from S.J. Speicher, Pacific-Sierra Research Corp., 7 June 1982. 
SECTION 2

THEGRETICAL DEVELOPMENT

\subsection{CAUSE-EFFECT RELATIONSHIP}

The fundamental assumption in the analysis which follows is that there is a linear cause-effect relationship between two sets of corresponding data records. A linear cause-effect relationship necessarily means that there is an input and an output, related by a linear transfer function (see Figure 1). The input, $x(t)$, may be a HEST overpressure-time waveform, and the output, $a(t)$, may be a soil or structure response-time waveform. Any test data waveform pair, $x(t)$ and $a(\dot{x})=$ will contain a certain amount of data acquisition system noise. This analysis will ignore the presence of noise and assume that $x(t)$ and $a(t)$ are actual loading and response behavior. This analysis procedure should, therefore, not utilize records containing high levels of noise. Steps should be taken to remove noise content or, if this is not possible, the record should be discarded.

The actual transfer function hetween an input data record and an output data record may be highly nun?inear. Iontinearities may result from concrete crushing and cracking, steei yielding, and soil media deforming inelastically, or from undefined soil-silo interactions. However, a linear assumption may be acceptable when investigating changes in output resulting from slight variations in input, such as might be the case when considering the di-corence between a HEST record and a best-fit 
Speicher-Brode nuclear airblast waveform. If there are significant variations between different input data records, the assumed linear transfer function may cause some alterations in output which are erroneous. The amount of variation in the iriput which can be allowed, without causing significant erroneous alterations in the output, is currently indeterminate.

\subsection{FAST FOURIER TRANSFORM}

The Fourier transform is a way of representing a time domain function, $x(t)$, in the frequency domain. If $X(\omega)$ is the Fourier transform of $x(t)$, then $x(t)$ and $x(w)$ are called a Fourier transform pair.

$$
\begin{aligned}
& x(t) \Leftrightarrow X(\omega) \\
& X(\omega)=\int_{-\infty}^{\omega} x(t) e^{-i \omega t} d t
\end{aligned}
$$

where $t=$ time $(\mathrm{sec})$

$$
\begin{aligned}
& \omega=\text { frequency }(\mathrm{rad} / \mathrm{sec}) \\
& i=\sqrt{-1}
\end{aligned}
$$

If $X(t)$ is a real continuous function of infinite duration, then $X(\omega)$ is a set of complex numbers

$$
X(\omega)=a(\omega)+i b(\omega)=[A(\omega)] e^{i \phi(\omega)}
$$

which define both the amplitude and phase associated with each frequency, $\omega$, of the function $x(t)$. The amplitude, $A$, and phase angle, $\phi$, associated wi th each point of $X(w)$ are:

$$
\begin{aligned}
& A(\omega)=\sqrt{[a(\omega)]^{2}+[b(\omega)]^{2}}=|x(\omega)| \\
& \phi(\omega)=\operatorname{\tau an}^{-1} \frac{\dot{b}(\omega)}{a(\omega)}
\end{aligned}
$$

The amplitudes, A, are all real numbers and the resulting fourier transform amplitude is a real function which will be referred to as $|X(\omega)|$. 
One time domain function of particular concern is the dc component, which is constant with time (see Figure 2). The Fourier transform of a dc component is a single value at zero frequency, known as a Dirac-delta function. The significance of this Fourier transform pair will be addressed in the next subsection.

The analysis presented in this report utilizes real test data records. These records are of finite duration and are finely digitized sets of points with a constant time step. Therefore, this anaiysis must use the Discrete Fourier Transform (DFT):

$$
x(n / N T)=\frac{1}{N} \sum_{K=0}^{N-1} x(K T) e^{-i 2 \pi n K / N}
$$

where $x(K T)=$ discrete time series

$$
\begin{aligned}
K & =0,1,2, \ldots,(\mathrm{N}-1) ; \text { time domain counter } \\
n & =0, \pm 1, \pm 2, \ldots ; \text { frequency domain counter } \\
T & =\text { time step } \\
N & =\text { total number of time steps } \\
N T & =T_{0}=\text { signal duration }
\end{aligned}
$$

The DFT has to be scaled to approximate the continuous integral transform:

$$
X_{c}(n / N T)=T_{0} X(n / N T)
$$

where $X_{c}(n / N T)=$ scaled DFT.

The Fast Fourier Transform (FFT) is a computationally efficient algorithm for calculating the DFT. The FFT algoritrm reduces the computation of the DFT of an $N$ point time series from $N^{2}$ operations to $N \log _{2} N$ operations. If $N$ is : $: i \cdots ?^{\prime}$ large the savings in the number of operations can be very significant. For example, if the number of points in a time series is 4096 , Equation (3) requires $16,777,216$ operations, while the FFT requires onty 49,152 . 
The number of points in the FFT array is one half the number of points in the original time series. The first FFT value is defined at zero frequency; the second FFT value is defined at the fundamental frequency:

$$
f_{0}=\frac{1}{\text { record duration }}
$$

and the third FFT value is defined at twice the fundamental frequency, $2 f_{0}$, and so on. The final FFT value is defined at the Nyquist frequency:

$$
f_{c}=\frac{1}{2(\text { data record time step) }}
$$

The Nyquist frequency, $f_{C}$, should be greater than or equal to the highest frequency of concern in any subsequent analysis.

One further step is application of a "weighting" function or "window" to a discrete time series before it is transformed. It is best that a discrete time sories start and end up at zero in order to prevent

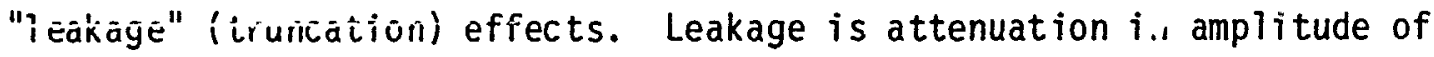
the primary frequency component, and magnification of cther secondary frequency components. "Weighting" functions or "windows" are usf to gradually bring the beginning and end portions of a data trace back to zero. Most test data traces start at zero, but most do not return to zero at the end. For the analysis in this report, a cosine squared spline was applied to the final 15 percent of all data traces to return them to zero.

\subsection{INVERSE FAST FOURIER TRANSFORM}

The original discrete time series, $x(K T)$, can be reconstructed from the inverse of the DFT.

$$
x(K T)=\sum_{n=0}^{N-1} x(n / N T) e^{i 2 \pi n K / N}
$$


Again, an inverse FFT algorithm is used for computational efficiency. The new resultant time series differs slightly from the original time series. As an example, notice the three plots in Figure 3. An original discrete time series is shown in Figure $3 a$. The FFT amplitude spectrum is shown in Figure $3 \mathrm{~b}$ and the inverse FFT is shown in Figure $3 c$. If there were no inaccuracy in the FFT algorithm, the plots in Figures $3 a$ and $3 c$ would be identical. An obvious difference is that the inverse FFT appears to be offset from the time axis. The of fset appears to be constant with time, since the final portion of the inverse FFT ends up at the same level as tne beginning. A constant offset with time indicates the presence of a dc component in the inverse FFT time history. As was discussed in the previous subsection and shown in Figure 2, a dc component in a time history is caused by the value of the FFT at zero frequency. The FFT in Figure $3 b$ does in fact have a value at zero frequency. But zero frequency is related to an infinite duration in the time domain and the original discrete time series in Figure $3 a$ is of finite duration. Due to the finite time duration, the value of the FFT at zero frequency must be erroneous, and is therefore the reason for the offset in Figure $3 c$. If the $d c$ component is removed from the inverse FFT, it becomes neariy identical to the original discrete time series (see Figure 4 ). The inverse FFT removes some of the high frequency spiking present in the original time history due to the reduced number of points defining the new record. The value of the offset is equal to twenty times the value of the full integral of the original discrete time series. The absolute value of the full integral of the original discrete time series is also equal to the value of the FFT aniplitude spectrum at zero frequency. 


\subsection{FREQUENCY RESPONSE FUNCTION}

The formulation of a frequency response function (FRF) requires an input-output relationsnip described in Section 2.1. An FRF is a transfer function in the frequency oma in which completely defines the dynamic characteristics of a linea! system. Again, using the same nomenclature as wa's used in Section $\left.2.1, x^{\prime} t\right)$ reprosents an input time history and $a(t)$ represents an output time history. The Fourier transfonns of $x(t)$ and $a(t)(X(\omega)$ and $A(\omega)$, respectively) are a set of complex numbers. The FRF, $H(\omega)$, is simply the Fourier transform of the output divided by the Fourier transform of the input, and is also a set of compiex numbers.

$$
H(\omega)=A(\omega) / X(\omega)
$$

At each individual frequency an FRF describes the output response of a linear system subjected to an input defined by a crostant amplitude sine wave of fixed frequency. The input is of the form:

$$
x(t)=x_{0} \sin \omega t
$$

The output response will be a sine wave at the same frecuency, w, fixed amplitude, $a_{0}$, and phase difference, $b$ :

$$
a(t)=a_{0} \sin (\omega t-b)
$$

Froin Reference 2:

Information about the amplitude ratio $a / x$ and the phase angle $\phi$ defines the transmission characteristics of transfer function of th: system at the fixed frequency w. The FRF $H(\omega)$ results $i \hat{r}$ the ampi itude ratio and phase angle can be plotted as a function of frequency...

Insteand of thinking of amplitude ratio and phase angle as two separate quantities, it has become customary in vibration theory to use a single complex number to. represent both quantities. This is $H(\omega)$ which is defined so that its magnitude is equal to the amplitude ratio and the ratio of its imaginary part to its real part is equal to the tangent of the phase angle.

2. Stearns, S.D., Digital Signal Analysis, Hayden Book Co., Rochelle Park, NJ, 1975. 


$$
H(\omega)=B(\omega)+i C(\omega)
$$

then

$$
\begin{aligned}
& |H(\omega)|=\sqrt{B^{2}+C^{2}}=a_{0}(\omega) / x_{0} \\
& \emptyset(\omega)=\tan ^{-1} \frac{C}{B}
\end{aligned}
$$

The FRF amplitude ratio, $|H(\omega)|$, is a useful tool in determining how much of the HEST pressure records gets through to soil and structural response at à given frequency.

\subsection{FOIJRFIT}

Reference 3 discusses the purpose, use and theory of the program FOURFIT. It is basically a program which will examine a HEST pressure record and determine the yield and peak overpressure of a "best-fit" Speicher-Brode ideal nuclear airblast waveform, using irequency domain analysis. The ideai airbiast waveform can be substituted for a HEST pressure record as input in order to determine new response data. A listing of FOURFiT is presented in Appendix A with slight modifications for savifig the "best-fit" airblast waveform.

\subsection{MODIFIED OUTPUT RESPONSE}

Since the FRF is a linear transfer function which completely describes the dynamic characteristics of a linear system, varied input waveforms can be applied to the system to get new outputs. As long as changes in the input are relatively minor, the linear assumption remains

3. jteedman, D.W. and Partch, J.C., FOURFIT--A Computer Code for Determining Equivalent Nuclear Yield and Peak Overpressure by a Fourier Spectrum Fit Method, as yet unpublished DNA report, Applied Research Associates, Inc., Albuquerque, NM, May 1984. 
valid (see Section 2.1). Repeating Equation (8) the FRF $H(\omega)$ is defined as:

$$
H(\omega)=A(\omega) / X(\omega)
$$

Rearranging this equation one obtains:

$$
A(\omega)=H(\omega) * X(\omega)
$$

The original input time history is $x(t)$. A new input time history $x^{\prime}(t)$ can be fourier transformed to ohtain $X^{\prime}(\omega)$. This new Fourier transform can be substituted into Equation (12) to oitain a new output Fourier transform, $\mathcal{R}^{\prime}(\omega)$ :

$$
A^{\prime}(\omega)=H(\omega) * X^{\prime}(\omega)
$$

$A^{\prime}(\omega)$ can be inverse Fourier transformed to obtain a new output response time history, $a^{\prime}(t)$. 


\section{SECTION 3}

PROGRAM RESULTS

\subsection{PROGRAM FREQRES}

Program FREQRES calculates an FRF for a given pair of input and output time histories. Using the defined FRF, the program will calculate a new output time history for any new input time history the user wants to specify. A user's manual for FREQRES is presented in Appendix B, and a listing of the program is presented in Appendix $C$.

\subsection{TEST DATA}

Data from a HEST test of a surface flush vertical silo surrounded by soil were analyzed using the program FREQRES. Both the silo and the surrounding soil were loaded by the HEST cavity. The test data had a duration of $49.85 \mathrm{msec}$ and were recorded at a digitizing rate of $200,000 \mathrm{~Hz}$. This resulted in a time step of $5 \times 10^{-6} \mathrm{sec}$, and a total of 9970 digitized points. Figures 5 through 22 present plots of the 18 data records used in this analysis. Table I presents a brief description of each of the plots.

\subsection{FOURFIT RESULTS}

A FOURFIT analysis was performed on the two HEST pressure time histories, test data record number 2 on the structure and record number 4 on the free field soil. Three plots result from a FOURFIT calculation: (1) a frequency domain plot comparing the FFT of the test data to the FFT of the "best-fit" Speicher-Brode ideal nuclear waveform, (2) a time history comparison of the pressure waveforms, and (3) a tine history comparison of the resulting impulse curves. Figures 23a, 23b, and $23 \mathrm{c}$ present these three plots for HEST record number 2 on the structure and 
Figures $24 a, 24 b$, and $24 c$ present the three plots for HEST record number 4 on the free field soil. The "best-fit" Speicher-Brode ideal nuclear waveform to HEST record number 2 is a $19.08 \mathrm{kt}$ yield surface burst with a peak overpressure of $20,280 \mathrm{psi}$. For HEST record number 4 it is a $7.83 \mathrm{kt}$ yield surface burst with a peak overpressure of $14,620 \mathrm{psi}$. The above results indicate substantial variation in the effective yield and peak overpressure across the testbed, and between measurements on the structure and on free field soil.

\subsection{FREQUENCY RESPONSE FUNCTIONS}

If the system represented by the FRF transfer function is linear, the absolute magnitude of the FRF amplitude ratio has significance. For example, if one specifies a pressure record in psi as an input data record and a velocity time history in $i n / s$ as an output data record, then the amplitude ratios of the FRF can be multiplied by a constant $\rho c$ is is the density of the material in the linear system and $c$ is the loading wave velocity) to normalize the FRF. In a normalized amplitude ratio FRF, a value of 1.0 at a particular frequency represents perfect transmission of power at that frequency. A value of less than 1.0 represents a decay in power and a value greater than 1.0 represents an amplification of power. In a reinforced concrete silo $\rho c$ is fairly constant, and therefore can be used to normalize the FRF. For soil response oc may vary significantly with depth and time and, therefore, a constant does not exist to normalize the FRF. For other input/output combinations, different constants of proportionality exists. If the input is pressure and the output is strain, then the constant will be a stiffness modulus. If the input is pressure and the output is stress, then no constant of proportionality is 
necessary since the input and output are already in the same units and the FRF is al ready normalized.

Figure 25 show's two $\mathrm{FRF}^{\prime} \mathrm{s}$ for vertical soil stress response at $0.5 \mathrm{ft}$ and $5.21 \mathrm{ft}$ depths. Notice that at the $0.5^{\prime}$ depth, power transmission from the HEST pressure loading to the soil stress response is strong at most frequencies from 0 to $3000 \mathrm{~Hz}$. In fact there is significant power transmission at $1700 \mathrm{~Hz}, 2200 \mathrm{~Hz}$, and $2800 \mathrm{~Hz}$ (relatively high frequencies). The reason for this could be: (1) noise in the data record at the three frequencies mentioned above, or (2) exitation of natural frequencies in response. Notice from Figure $23 a$ that the input power content at frequencies between $1700 \mathrm{~Hz}$ and $2800 \mathrm{~Hz}$ is very low compared to input power at frequencies less than $100 \mathrm{~Hz}$. Since the HEST contains low power at the higher frequencies, strong power transmission at these frequencies still results in ralatively low power for the FFT amplitude spectrum of soil stress response (see Figure 3). Al so note from Figure 25 that power transmission at all frequencies greater than $1000 \mathrm{~Hz}$ is dramatically reduced when going from the $0.5 \mathrm{ft}$ depth to the $5.21 \mathrm{ft}$ depth. The power transmission between 100 and $1000 \mathrm{~Hz}$ is also significantly reduced, but not to the degree evident at higher frequencies. This suggests that by $5 \mathrm{ft}$ depth, the soil has significantly filtered out the high frequency characteristics of the HEST pressure loading.

Figure 26 shows two FRF's for vertical soil velocity response at $5.21 \mathrm{ft}$ and $12.21 \mathrm{ft}$ depths. The FRF at the $5.21 \mathrm{ft}$ depth is very simiiar in shape to the FRF at the same depth in Figure 25. There is a constant decay in power transmission between $100 \mathrm{~Hz}$ and $1000 \mathrm{~Hz}$. At the 
$17.21 \mathrm{ft}$ depth, power transmission is even further reduced between 100 and $1000 \mathrm{~Hz}$. At this depth power transmission is relatively low at all frequencies above $350 \mathrm{~Hz}$. Soil is a very good attenuator of the high frequency power of a HEST cavity, starting with the higher frequencies.

Figure 27 shows two FRF's for vertical structural velocity response at $0.83 \mathrm{ft}$ and $3.28 \mathrm{ft}$ depths. The FRF amplitude ratio can be normalized through application of the proportionality constant, $\mathrm{pC}$. Assume the density ci concrete to be 4.7 slugs $/ \mathrm{ft}^{3}$ and the loading wave velocity to be $10,000 \mathrm{ft} / \mathrm{s}$.

$$
\begin{aligned}
\rho C & =\left(4.7 \text { slugs } / \mathrm{ft}^{3}\right)(10,000 \mathrm{ft} / \mathrm{s})\left(\mathrm{ft}^{3} / 1728 \mathrm{in}^{3}\right) \\
& =27.2 \mathrm{lb}-\mathrm{s} / \mathrm{in}^{3}
\end{aligned}
$$

Multiplying this constant times the amplitude ratio scale of 0.0 to 0.03 in Figure 27 results in a normalized scale of 0.0 to 0.82 . A noticcable large frequency pnwer transmission (75 percent on the normalized scale) exists at approximately $250 \mathrm{fiz}$. This is related to the natural frequency of axial response of the vertical cylinder test article. The structure was approximately $21.5 \mathrm{ft}$ in length. At the $0.83 \mathrm{ft}$ depth the time it took the axial stress wave to reach the bottom of the cylinder and reflect back up is (assuming shock wave velocity in concrete $=10,000 \mathrm{ft} / \mathrm{s}$ ):

$$
\frac{2(21.5 \mathrm{ft}-0.83 \mathrm{ft})}{10,000+\mathrm{t} / \mathrm{s}}=4.13 \times 10^{-3} \mathrm{sec}
$$

The frequency asscciated with $4.13 \times 10^{-3} \mathrm{sec}$ is $1 / 4.13 \times 10^{-3} \mathrm{sec}$ which equals $242 \mathrm{~Hz}$. At the 3.28 depth the travel time and associated frequency ars $3.64 \times 10^{-3} \mathrm{sec}$ and $274 \mathrm{~Hz}$, respectively. The FRF's in Figure 27 also show a decay in power transmission with depth, similar to that for soil response. Comparing Figures 25 and 27 , the decay with depth is not as dramatic in the structure as it is in the soil. 
The FRF's for structural axial strains and hoop strains (see Figures 28 and 29 i show no clear pattern of power transmission decay with depth. This indicates that the structure tends to transmit most of the power from a HEST pressure time waveform over the broad frequency range of 0 to $3000 \mathrm{~Hz}$. The normalizing proportiorality constant for structura? strains is assumed to be the constrained modulus for concrete, since the concrete in the structure is confined with a high percentage of steel. Assume a constrained modulus of $5.16 \times 10^{6} \mathrm{psi}$. The strain test data are in units of micro-strain, such that $1 \times 10^{6}$ has to be factored out of the proportionality constant. The resulting constant is 5.16. Multiplying this constant times the amplitude ratio scales of 0.0 to 0.8 in Figures 28 and 29 results in a normalized scale of 0.0 to 4.13 . A normalized amplitude ratio of 1.0 corresponds approximately to 0.2 on the scales in Figures 28 and 29. There are two characteristics common to buth Figures 28 and 29. At the $5.2 \mathrm{ft} / 5.3 \mathrm{ft}$ depth there is strong power transmission (335 per cent on the normalized scale) at $150-200 \mathrm{~Hz}$. At the $1.3 \mathrm{ft}$ depth there is also strong power transmission (181 percent on the normalized scale) at $1200-1600 \mathrm{~Hz}$. Why the $150-200 \mathrm{~Hz}$ strong power transmission is peculiar to the $0.2 \mathrm{ft} / 5.3 \mathrm{ft}$ depth is currently unclear. The only structural response mode wi th a natural frequency as low as $150-200 \mathrm{~Hz}$ is the axial response of the cylinder associated with the axial stress wave traveling back and forth down the entire length of the cylinder and reflecting off each end. But if this were the cause of the strong frequency power transmission at the $5.2 \mathrm{ft} / 5.3 \mathrm{ft}$ depth, then it should alsc occur at the other depths as well. It does not. The $1.3 \mathrm{ft}$ depth in the cylinder occurs in a thick walled portion of the cylinder cailed the 
headworks. Hoop expansion of the cylinder due to passage of the axial compressive wave, and also hoop compression due to large ground shock stresses surrounding the cylinder are very strong near the surface. Hoop expansion and compression are associated with the brealting inode response of a cylinder. The natural frequencies for the breathing mode response of a cylinder are (Ref. 4, pg. 298, Table 12-1):

$$
f_{i}=\frac{\lambda_{i}}{2 \pi R}\left(\frac{E}{\mu\left(1-\nu^{2}\right)}\right)^{1 / 2}
$$

where $i_{i}=i$ th natural frequency

$i=$ response mode $(=0$ for breathing mode)

$E=$ roung's Modulus

$\mathrm{R}=$ cylinder radius to midsurface

$\mu=$ density of shell material

$v=$ Poisson's ratio

$\lambda_{i}=\left(1+i^{2}\right)^{1 / 2}=1$ for $i=0$

The following values are substituted into Equation $(16)$ to determine the lowest breathing mode natural frequency of the headworks:

$$
\begin{aligned}
\mathfrak{i}= & 0 \\
E= & 5.77 \times 10^{6} \mathrm{psi} \text { (effective Young's Modulus including } \\
& \text { concrete and steel contributions) } \\
R= & 20.0 \text { inches } \\
\mu= & 2.25 \times 10^{-4} \text { ib s } 2 / \mathrm{in}^{4} \\
\nu= & 0.2 \\
\lambda_{0}= & 1
\end{aligned}
$$

The result is $1300 \mathrm{~Hz}$. Notice that this falls within the $1200-1600 \mathrm{~Hz}$ range of strong power transmission for the $1.3 \mathrm{ft}$ depth in both Figures 28 and 29. 4. Blevins, R.D. Formul as for Natural Frequency and Mode Shape,
Van Nostrand Reinhoid Co., New York, NY, 1979. 


\subsection{FAST FOURIER TRANSFORM COMPARISONS}

Figure 30 shows a comparison of the original FFT amplitude spectrum for test data recoró number 6 and the FFT amplitude spectrum after the Speicher-Brode wayeform influence has been included (see Section 2-6). The FFT with Speicher-Brode influence has higher power at most frequencies between 100 and $3000 \mathrm{~Hz}$. Notice that the same is true when comparing the Speicher-Brode "best-fit" waveform FFT to HEST record number 4 FFT in Figure 24a. In fact the higher power in the Speicher-Brode "best-fit" waveform FFT is the cause of the higher power in the FFT with Speicher-Brode influence in Figure 30. But this higher power has very little effect upon the inverse FFT time history, as will be illustrated in the next section. For lest record number 18 which used HEST record number 2 instead of $Q$ as the input data record in FREORES, the increased power is only evident above $800 \mathrm{~Hz}$ (see Figure 31). Notice that the same is true in Figure 23a in which the fit between 100 and $700 \mathrm{~Hz}$ is very good.

\subsection{TIME HISTORY COMPARISONS}

For records 5 through 20, there is no visible difference between the original record time histories and the response time histories had the surface pressure loading been an ideal Speicher-Brode nuclear waveform. As an example, Figure 32 presents record number 5 and its Speicher-Brode input comparison waveform. The high frequency spiking characteristic of HEST pressure records has negligible effect upon soil and structure resporse. 


\section{SECTION 4}

\section{CONCLUUSIONS AND RECOMMENDATIONS}

Analysis of the test data presented in this report indicates that the high frequency spiking characteristic of HEST pressure records has negligible effect upon testbed and test article response when compared to ioading frum a "best-fit" ideal Speicher-Brode nuclear airblast waveform. The high frequency power content of a HEST pressure loading atteriuates with depth in both soil and structure. The power decay is more dramatic in soil and is evident in both stress and motion response. Structural strain records show little power transmission decay with depth. This indicates that structural strain response tends to transmit most of the power content of HEST pressure-time waveforms. Beyond the $2000-3000 \mathrm{~Hz}$ range the power content in a HEST pressure-time waveiorm is very low compared to that in the lower frequencies, so that power transmission at the higher frequencies is insignificant.

Strong power transmission is evident in structural response FRF's at natural response moce frequencies. Natural modes are excited by the broad frequency range of power content of a HEST pressure loading, such that the FRF amplitude ratio becomes magnified at the modal frequencies.

The HEST pressure records used in this report (Figures 5 and 6) were very good pressure waveforms, in which the Speicher-Brode "best-fits" from the FOURFIT program matched the pressure and impulse-time waveforms very closely (see Figures 23b, 23c, 24b, 24c). It would be interesting to run this analysis wi th HEST records from a test which do not provide such good 
representations of $i$ deìl Speicher-Brode nuclear airblast waveforms. In this case there might be greater variation in output response comparisons. Also, another interesting use of this analysis procedure would be to determine what testbed and test article response would have been, hâd the HEST loading been exactly as original design. Instead of using the "best-fit" Speicher-Brode waveform to a HEST record, have the FREQRES program read in the original design waveform.

The analysis procedure outlined in this report can be used to investigate the fidelity of any nuclear airblast simulation technique. It is not restricted to HEST. 
APPENDIX A

LISTING OF PROGRAM FOURFIT

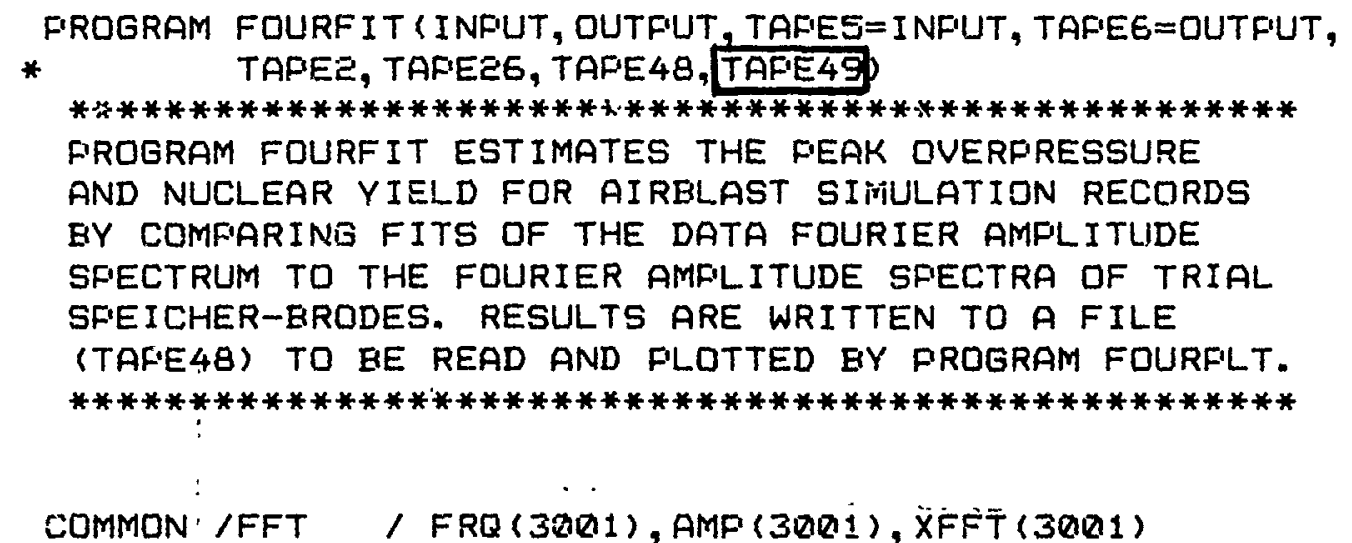

COMMON / ITERAT/ $W(5), F(5), D E L T A W(5)$, DELTAF (5), YLD (5)

COMMON /THIST / TTIM(GQQQ), FRESS (12QDQ), TIMP (E999), FIMP (2999),

* FFILT (EQRQ)

COMMON /IMF / I IMF, DTD, DTE, TPEE, DTEN

COMMON /FO?NTS/ NEPTS, NEFTS, NI: NEF, NEF

COMMON /ESTIM / FSOI, WI, FF, W13, FSOF, WF, FSQ

COMMON /PEAK / DF, TA, FSO, ALFF

COMMON /SECONS/ RSKFT, YS, S, XM

COMMON /FILT / IFILT,FLD(7), FFDMX (7), FFEMX (7)

COMIMON /FLOTV / ITL (B), ISTL (B), IDE

COMMON /UNITS / IUNITS, JUNITS

COMMON /COUNT / ICOUNT, IOPT, LFILT

COMFLEX XFFT

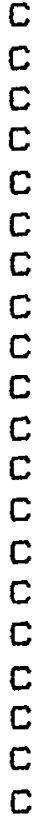

TAFEE CONTAINS INFUT PARAMETERS

NEFTS = NO. OF FOINTS TO EE READ FROM TAPE

IUNITS=1 FOR TAPE INFUT FRESSURE IN FSI

$=-1$ FOR TAFE INPUT FRESSURE IN MPA

JUNITS=1 FOR TAFE INPUT TIME IN MILLISECONDS

$=-1$ FQR TAFE INFUT IN SECONDS

FSOI = INITIAL FEAK QVERFRESSURE ESTIMATE IN MFA

WI = INITIAL NUCLEAR YIELD ESTIMATE IN KT

IOFT=1: FITTING ROUTINE TO EE DONE

IOPT=E: JUST FOURIER TRANSFORM THE DATA

IOFT $=3$ : JUST FOURIER TRANSFORM THE SFEICHER-BRODE.

DEFINED EY FSOI, WI

IFILT=1 FOR FILTER TO EE EXECUTED

IFILT $=-1$ FOR NO FILTER

FLQ=LOW END CUTOFF FREQUENCY (UP TO 7 ALLUWED)

(NOTE:FOR LESS THAN 7 FILTERS, FLO

MUST BE SET TO Q. TO ESCAPE THE LUOF.; 


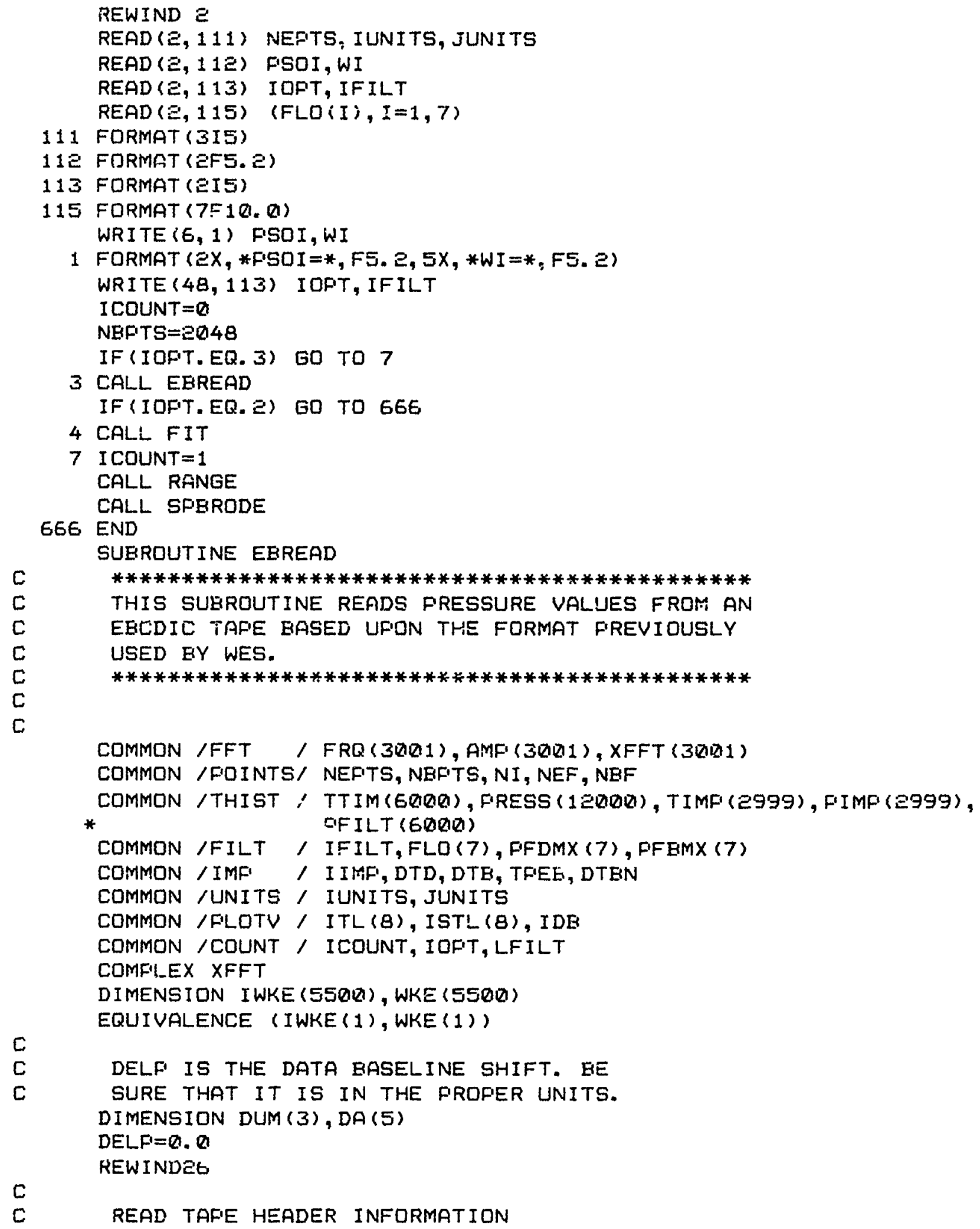


C

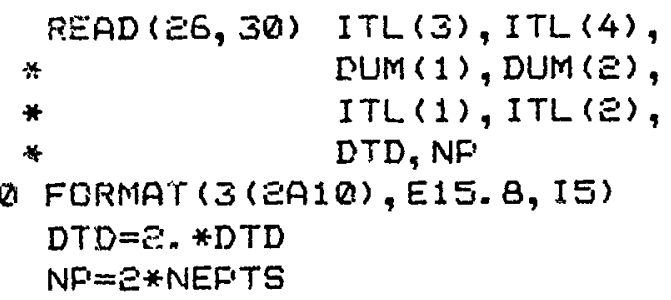

c

ITL (5) $=1$ QH FRESSURE

ITL $(E)=I$ DHHISTORY

$\operatorname{ITL}(7)= \pm D H$

ITL $(9)=10 \mathrm{H}$

WRITE $(49,35)$ (ITL (L), $L=1,8$ )

35 FORMAT (BAIQ)

DO $\Xi 0 \quad I=1$, NEFTS

TTIM I $;=Q$.

FRESS $(I)=0$.

QA CONTINUE

IF (EOF (2द) $\quad 900,901$

c

$=$

c

\section{SET UF DATA UNITS CONVERSIONS;}

MSEC TO SEC AND FSI TO MFA.

901 IF (JUNITS. GE, 1 ) DTD=DTD* . DQ1 1

FFACT $=$. QU16854757

IF (IUNITS. LT. Q) FFACT=1.

IF $=1$

TIME $=Q$.

NL I NE $=N F / 5$

RL INE=FLCAT (NF); $/ 5$.

IF (PLINE. GT. NL TNE) NLINE=NLINE+1

c

C

C

$$
\text { READ F'RESSLRE VALUES }
$$

DO $4 D \mathrm{~J}=1$, NLINE

$$
\text { READ }(E 6,5 D) \text { (DA }(J J), J J=1,5)
$$

50

FORMAT (SE16.8)

IF (EDF (EE)) $\quad 900,902$

$30 E D O$ SQ $K=1,5$

$$
\begin{aligned}
& F=D A(K) \\
& F \cdot R E S S\left(J F^{\prime}\right)=(F * F F A C T)-D E L F
\end{aligned}
$$

$$
I \tilde{r}=I \mathrm{~F}+1
$$

EQ CONTINUE

40 CONTINUE

$$
I M=Q
$$

TIME $=Q$.

DO $11 M=E, N F, e$ $I M=I M+1$

TTIM (IM) $=$ TIME

FRESS $(I M)=($ RRESS $(M)+$ FRESS $(M-1)) / E$. 


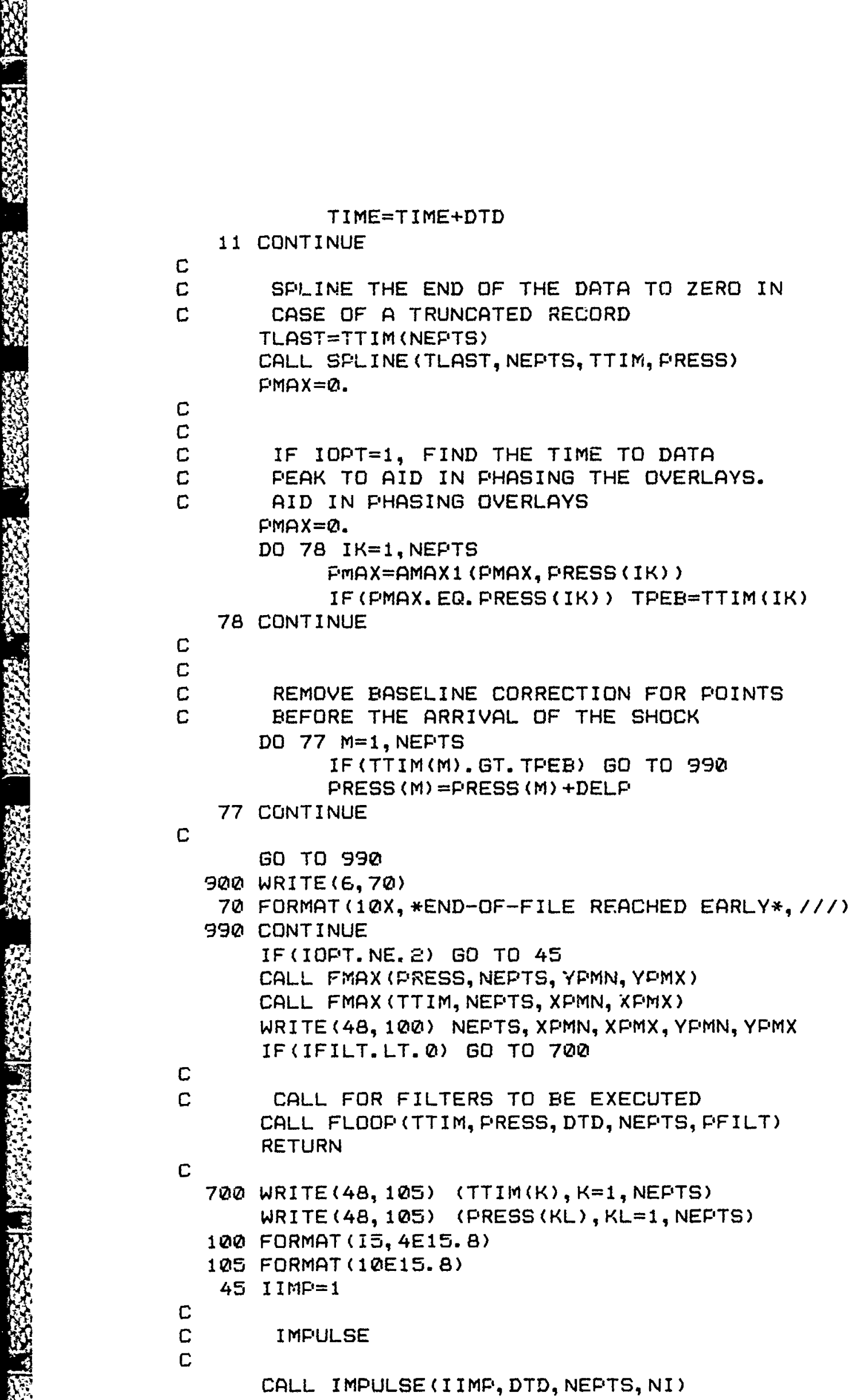

$T I M E=T I M E+D T D$

11 CONTINUE

C

C SFILINE THE END OF THE DATA TO ZERO IN

C CASE OF A TRUNCATED RECORD

TLAST $=$ TTIM (NEF'TS)

CALL SFLINE (TLAST, NEFTS, TTIM, F'RESS)

FMAX $=0$.

$c$
$c$
$c$
$c$
$c$

78 CONTINUE

IF IOPT=1, FIND THE TIME TO DATA

FEAK TO AID IN FHASING THE QVERLAYS.

AID IN FHASING DVERLAYS

$F M A X=Q$.

DO 78 IK $=1$, NEFTS

FMAX $=A M A X 1$ (FMAX, FRESS (IK))

IF (PMAX. EQ. FRESS (IK)) TFEB $=$ TTIM (IK)

C

c

C REMOVE EASELINE CORRECTION FOR FOINTS

C EEFORE THE ARRIVAL OF THE SHOCK

DO $77 M=1$, NEFTS

IF (TTIM(M). GT. TFEB) GD TD 990

77 CONTINUE

FRESS $(M)=$ FRESS $(M)+D E L F$

c

GO TO $99 Q$

TQQ WRITE $(E, 70)$

70 FORMAT ( $1 Q X, * E N D-O F-F I L E$ REACHED EARL $Y *, / 1 /$ )

$99 Q$ CONTINUE

IF (IDFT. NE. E) GO TO 45

CALL FMAX (FRESS, NEFTS, YFMN, YOMX)

CALL FMAX (TTIM, NEFTS, XFMN, XFMX)

WRITE (48, 1QQ) NEFTS, XFMN, XFMX, YFMN, YFMX

IF(IFILT.LT.Q) GO TO 700

C

C CALL FOR FILTERS TO EE EXECUTED

CALL FLDOF' (TTIM, F'RESS, DTD, NEF'TS, F'FILT)

RETURN

C

7Q0 WRITE (48, 105) (TTIM (K), K=1, NEFTS)

WRITE ( 48,105 ) (FRESS (KL), KL=1, NEFTS)

1QQ FORMAT (I $\$, 4 E 15.8)$

105 FORMAT (10E15.8)

45 IIMFt=1

C

C IMFULSE

C

CALL IMPULSE (I IMF, DTD, NEPTS, NI) 
IF (IOFT. NE. $₹$ ) GO TO 110

ITL (S) $=1 Q H$ IMPULSE $H$

$I T L(E)=1$ QHISTORY

WRITE $(48,115)$ ITL (5), ITL (6)

CALL FMAX (TIMF, NI, XIMN, XIMX)

CALL FMAX (FIMF, NI, YIMN, YIMX)

WRITE (48, 100) NI, XIMN, XIMX, YIMN, YIMX

WRITE $(48,105)$ (TIMP (IH), IH=1,NI)

WRITE $(48,105)$ (FIMF (JH), JH=1,NI)

c

115 FORMAT (ŻA1Q)

C

C

110 TTOT $=D T D * N E F T S$

c

FREQUENCY INCREMENT

DFE $=1$. /TTOT

FQE $=0$.

C

FOURIER TRANSFORM

CALL FFTRC (FRESS, NEFTS, XFFT, IWKE, WKE)

$X R E=R E A L(X F F T(1)) /(2 * N E F T S)$

$X I E=A I M A G(X F F T(1)) /(2 * N E F T S)$

$F Q E=F Q E+D F E$

$F R Q(1)=F Q E$

C AMFLITUDE SPECTRUM

$\operatorname{AMF}(1)=S Q R T(2 . *(X R E * X R E+X I E * X I E)) * T T Q T$

$N E F=N E P T S / E+1$

DO $8 Q \mathrm{JK}=\Omega, N E F$

$F Q E=F Q E+D F E$

$F R Q(J K)=F Q E$

$X R E=R E A L(X F F T(J K)) / N E P T S$

$X I E=A I M A G(X F F T(J K)) / N E F T S$

$A M F(J K)=S Q R T(X R E * X R E+X I E * X I E) * T T O T$

BQ CONTINUE

C

IF (IOFT. NE. Z) RETURN

ITL $(5)=1$ QH FOURIER A

ITL $(6)=1$ QHMFLITUDE $S$

ITL $(7)=1$ QHF'ECTRUM

CALL FMAX (FRQ, NEF, XFMN, XFMX)

CALL FMPX (AMF, NEF, YFMN, YFMX)

WRITE (48, 117) ITL (5), ITL (E), ITL (7)

117 FORMAT (3A10)

WRI TE $(48,100)$ NEF, XFMN, XFMX, YFMN, YFMX

WRITE (48, 105) (FRQ (LI), LI=1, NEF)

WRI TE $(48,105$ ) (AMF ( $J I), J I=1, N E F$ )

RETURN

END

SUBROUTINE FIT

C

**********************************************************

THIS SUBROUTINE ITERATES ON YIELD WITHIN ITERATIONS ON 


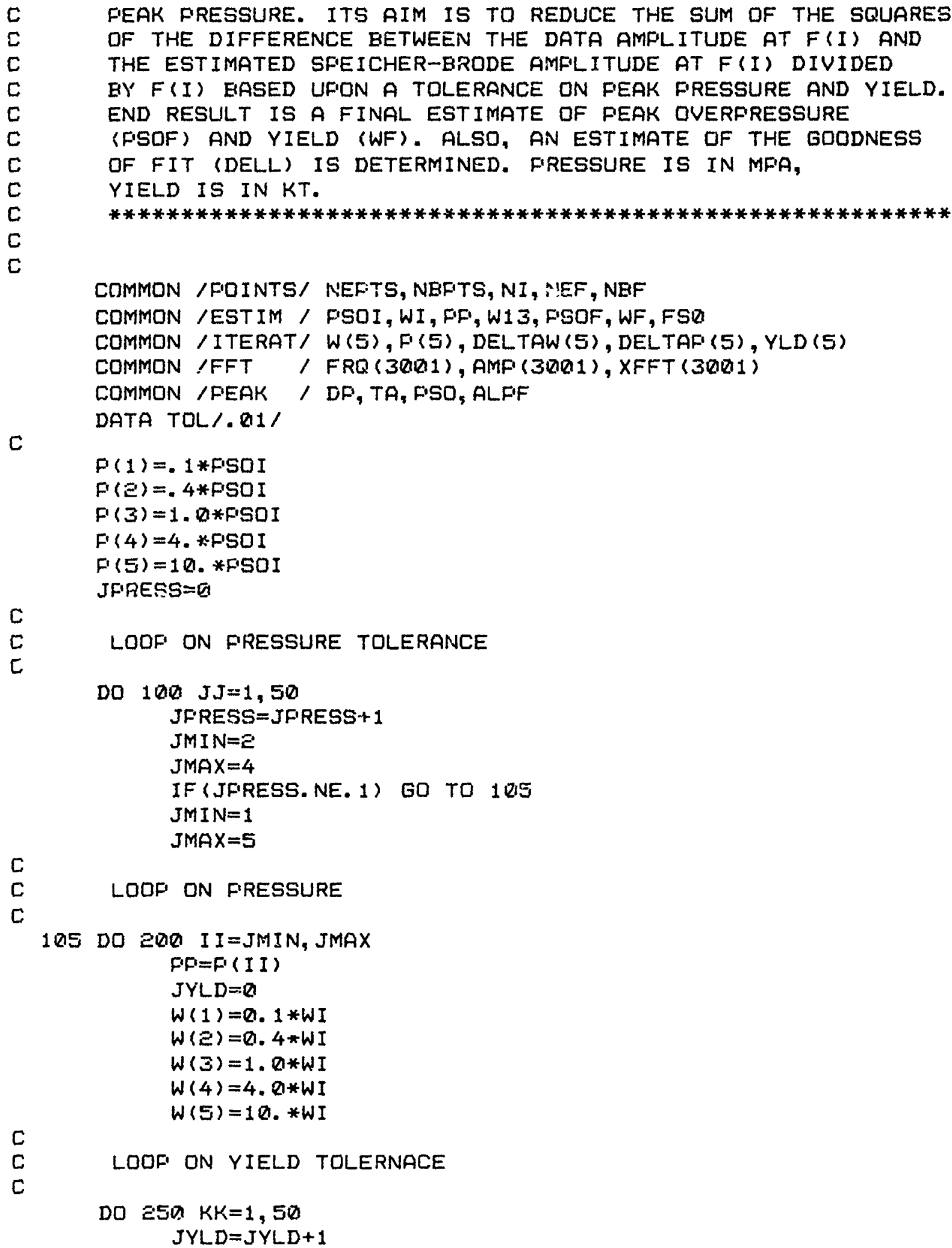




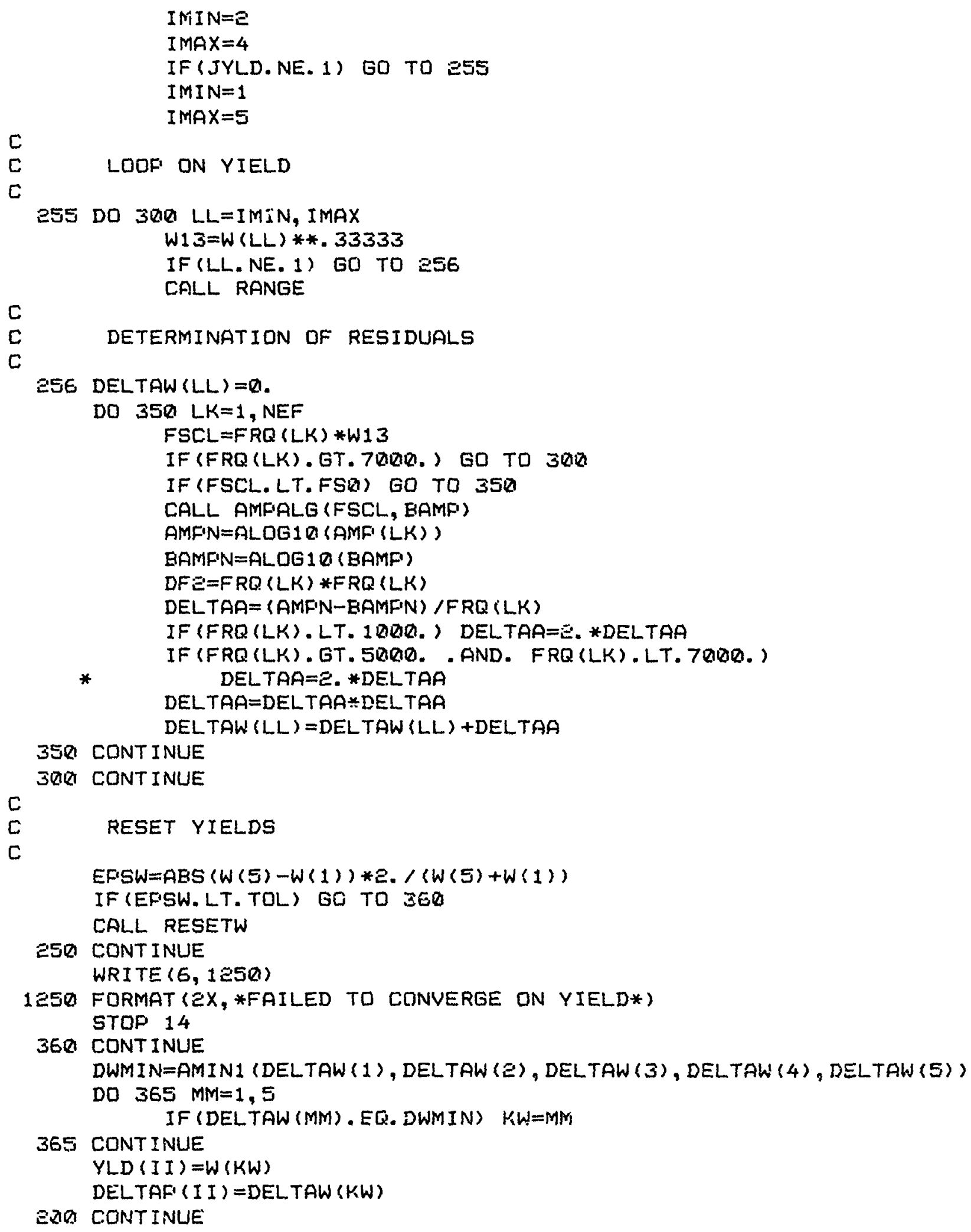




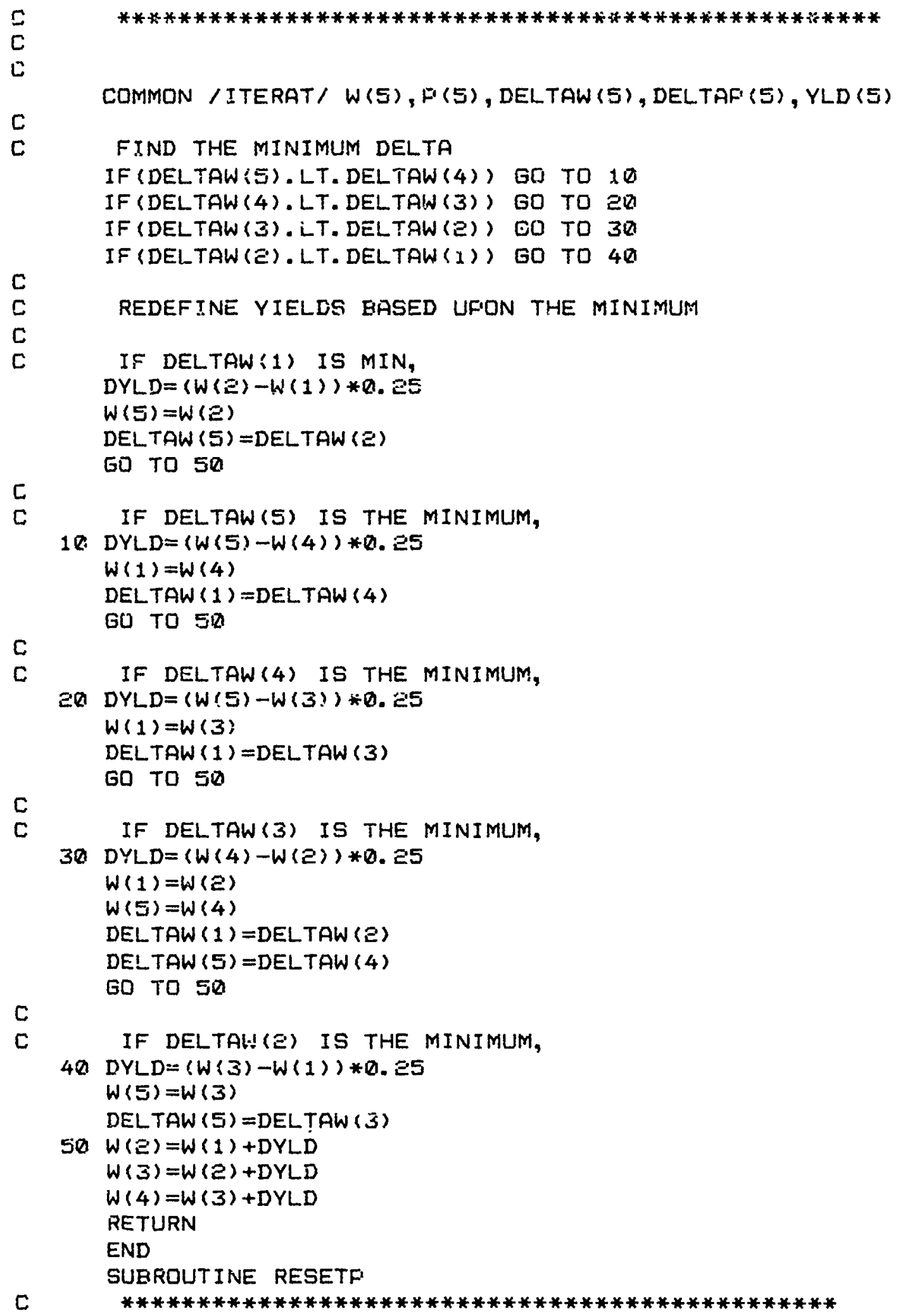




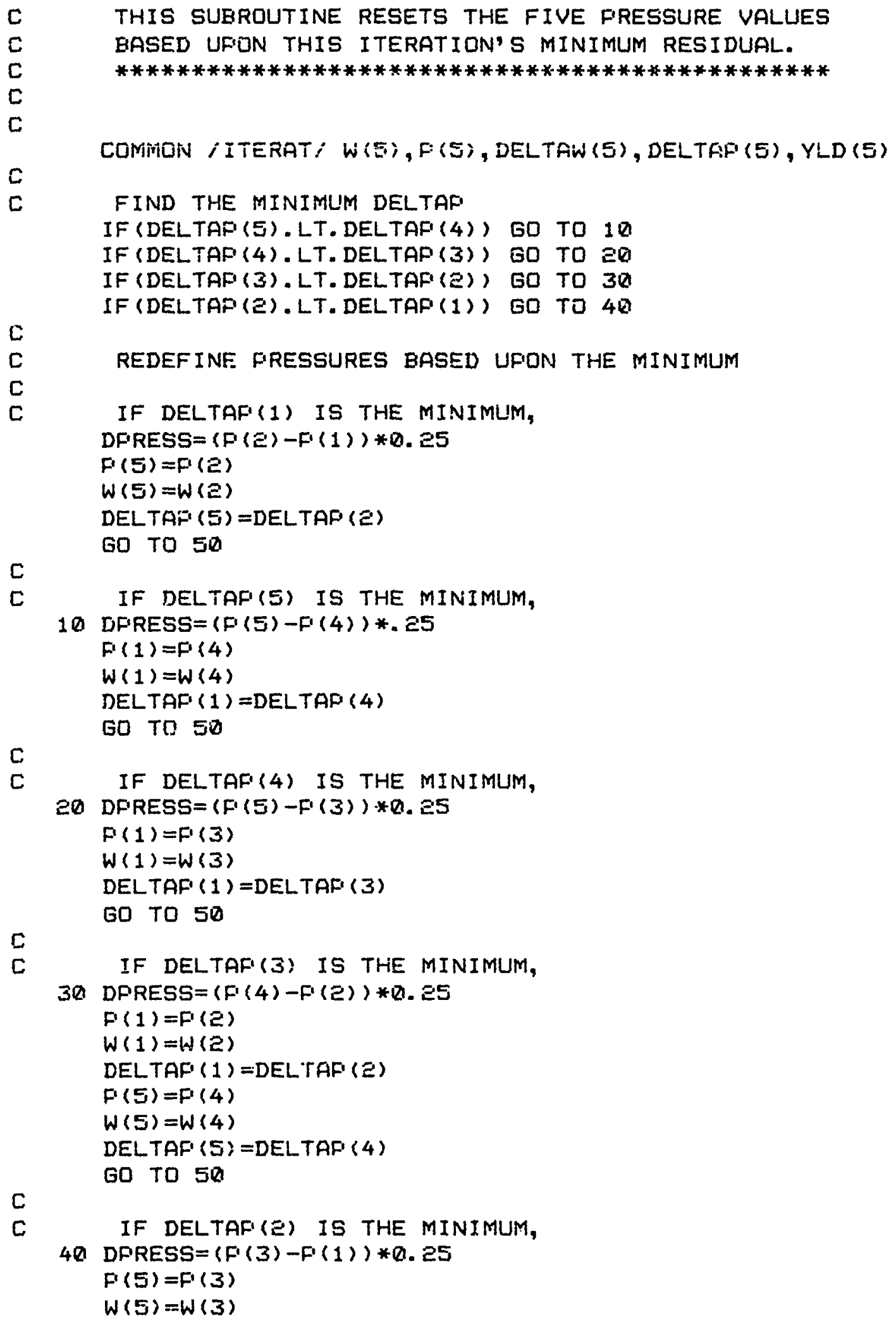




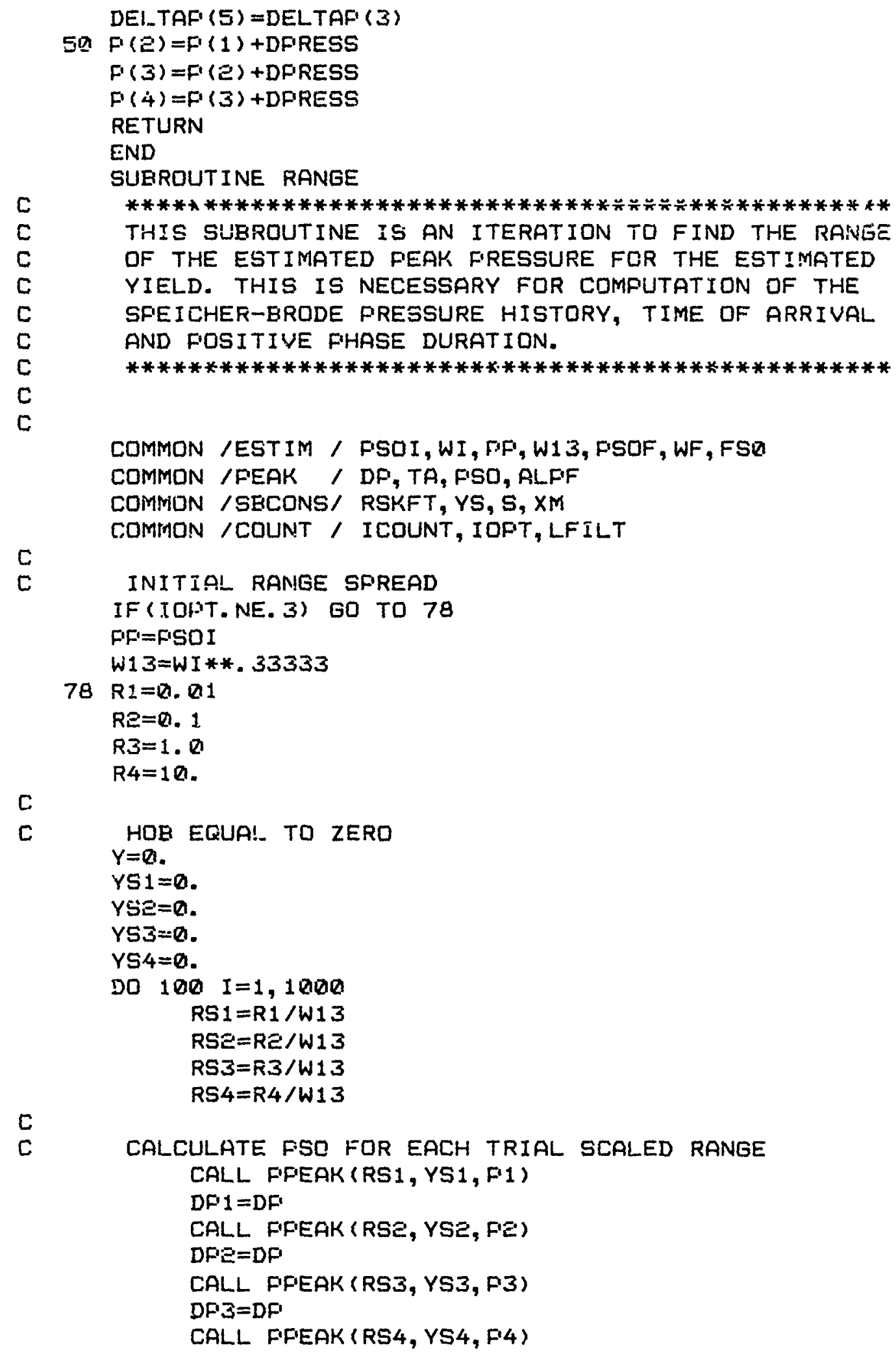


c

C WRITE (6, 114Q)

1140 FORMAT ( $E X$, *PRESSURE OUT OF RANGE*)

C

C EETWEEN R1 AND RE

$110 . \quad D R=(R E-R 1) / 3$.

$\mathrm{R} 4=\mathrm{Re}$

$R Z=R 1+D R$

$R 3=R 2+D R$

EO TO 99

$c$

C BETWEEN RE AND R3

$120 \quad D R=(R 3-R E) / 3$.

$R 1=R 2$

$\mathrm{R} 4=\mathrm{R3}$

$R 2=R 1+D R$

$R 3=R e+D R$

GO TO 99

c

ᄃ

130

BETWEEN R3 AND R4

$D R=(R 4-R 3) / 3$.

$R 1=R 3$

$R Z=R 1+D R$

$R 3=R E+D R$

99 IF ( $(R 4-R 1)$. LE.. D QDQ1) GO TO 101
190 CONTINUE

WRITE (E, 11QQ)

1100 FORMAT (2X, *FAILED TO CONVERGE DN RANGE*)

WRITE (6, 1ZQQ) I

1 2QQ FORMAT (EX, *I=*, IS)

WRITE (6, 12Q1) FP, R1, R4

1201 FORMAT ( $X X, * F F=*, E 12.5, /, \Xi X, * R 1=*, E 12.5, /, 2 X, * R 4=*, E 12.5)$ STCP1E

101 RAKFT $=(R 1+R 2+R 3+R 4) * R .25$

RSKFT $=$ RAKFT $/ W 13$

$\mathrm{DP}=\left(\mathrm{DF}^{\prime} 1+\mathrm{DP} 2+\mathrm{DF} 3+\mathrm{DF} 4\right) * 0.25$

$F S Q=1 . /(D F / 1 Q 0 Q$. $)$

IF (ICOUNT. NE. 1$)$ GO TO 103

TASEC $=($ TA/ 1000.$) * W 13$

DFOS $=(D F / 1000) * W$.

RANKM $=$ RAKFT*. 3048

FSOF $=\mathrm{PP}$

$W F=W 13 * W 13 * W 13$

c 
c

WRITE FINAL RESULTS TO DUTFUT FILE WRITE (6, 1102$)$ FSOF, WF, RANKM, TASEC, DFOS

1102 FORMAT $\left(/ /, 1 X_{3} *++++++++++++++++++++++++++++++++++++++++++*, /\right.$, * EX, *FEAK QVERFRESSURE, MPA=*, 6X, E12. $5,1 /$,

* EX, *NUCLEAR YIELD, KT=*, 11X, E12. $5,1 /$,

* EX, *RANGE FROM GZ,KM=*, $11 X$, E1E. 5,11 ,

* $\quad E X, *$ TIME OF ARRIVAL, SEC $=*, 8 X, E 12.5,1 /$,

* EX, *POSITIVE FHASE DURATION, SEC $=*, E 12.5,1,1 \mathrm{X}$,

$*$

c
WRITE $(48,1103)$
PSOF, WF
WRITE $(48,1104)$ DP, TA, RSKFT

1103 FORMAT (EE 15. 8)

1104 FORMAT (3E15.8)

103 RETURN

END

SUEROUTINE FFEAK (X, Y, FEAKF)

C

**********************************************************

C

THIS SUEROUTINE CALCULATES THE PEAK OVERPRESSURE (MPA),

TIME OF ARRIVAL (TA, MS/KT**1/3), AND POSITIVE FHASE

DURATION (DF, MS/KT**1/3) AFTER SPEICHER-BRDDE, JUNE, 1982.

C

C

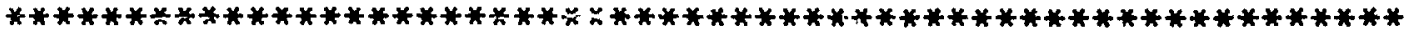

c

C

c

COMMON /FEAK / DF, TA, FSO, ALPF

COMMON /SBCONS/ RSKFT, YS, S, XM

XLEAST $=1 \cdot E-9$

YLEAST $=1 . E-9$

$Z M A X=10 Q$.

IF (X.LT. XLEAST) $X=X L E A S T$

IF (Y.LT. YLEAST) $Y=Y L E A S T$

$R=S Q R T(X * X+Y * Y)$

$\mathrm{R} 2=\mathrm{R} * \mathrm{R}$

$R 3=R * R 2$

$R 4=R 2 * R 2$

$R G=R e * F \cdot 4$

$R 8=R 4 * R 4$

$Z=Y / X$

$\mathrm{ZZ}=\mathrm{Z} * \mathrm{Z}$

$\mathrm{Z3}=\mathrm{Z} * \mathrm{ZZ}$

$25=22 * 23$

$Z 17=Z * * 17$.

$Z 18=Z * 18$.

$Y 7=Y * * 7$.

IF (Z. GT. ZMAX) $Z=Z$ MAX

$X M=170 . * Y /(1 .+337 . * Y * * .25)+.914 * Y * * 2.5$

C

C SCALED TIME OF ARRIVAL

C 
$U 1=(.543-21.8 * R+386 . * R 2+2383 . * R 3) * R 8$

$U 巳=2.99 E-14-1.91 E-10 * R 2+1.03 E E-6 * R 4-4.43 E-6 * R E$

$U 3=(1.028+2.087 * R+2.69 * R E) * R 8$

$U T A=U 1 /(U E+U 3)$

TA=UTA

IF (X.LT.XM) GO TO 101

$W 1=(i . \overline{8} 6-34.605 * R+496.3 * R 2+2383 . * R 3) * R 8$

$W E=3.0137 E-13-1.212 \theta E-9 * R E+4.128 E-6 * R 4-1.116 E-5 * R E$

$W 3=(1.63 e+2.629 * R+2.69 * R 2) * R 8$

$W T A=W 1 /(W 2+W 3)$

TA=UTÁ

C

C

SCALED POSITIVE PHASE DURATION

c

$101 S=1 .-1.1 E 10 * Y 7 /(1 .+1.1 E 1 Q * Y 7)-(2.441 E-8 * Y * Y /$

* (1. +9.E1(2*Y7))*(1./(4.41E-11+X**10.))

$\mathrm{DF}=\{(1640700 .+24629 . * \mathrm{TA}+416.15 * T A * T A)\}$

* (10880.+619.76*TA+TA*TA)\}

* * $(.4+.001204 *(T A * * 1.5) /(1 .+.001559 * T A * 1.5)+$

c

* $(.0426+.5486 *(T A * .25) /(1 .+.00357 * T A * 1.5)) * 5)$

$A A=1.22-(3.908 * Z 2) /(1 .+810.2 * Z 5)$

$\mathrm{BE}=\mathrm{E}=321+(218 /(1 .+1.113 * 218)) * 6.195-(.03831 * 217) /$

* (1.+.02415*217)+.669e/(1. +4164.*Z**8.)

$C C-4.153-(1.149 * Z 18) /(1 .+1.641 * Z 18)-1.1 /(1 .+2.771 * Z * 2.5)$

$\mathrm{DD}=-4.166+(25.76 * \mathrm{Z} * 1.75) /(1 .+1.38 \approx * Z 18)+8.257 * \mathrm{Z} /(1 .+3.219 * \mathrm{Z})$

$E E=1 .-(.004642 * Z 18) /(1 .+.003886 * Z 18)$

$F F=.6(096+(2.879 * Z * 9.25) /(1 .+2.359 * Z * 14.5)-17.15 * Z 2 /$

* $(1 .+71.66 * Z 3)$

$G G=1.83+5.361 * 22 /(1 .+.3139 * Z * 6$.

$H H=-(E 4.67 * Z 5+.2905) /(1 .+441.5 * Z 5)-1.389 * Z /(1 .+49.03 * Z 5)+$

$* \quad(3.808 * Z * 1.5) /(1 .+154.5 * Z * 3.5)+(.0 R 14 * F e /(1 .-.158 * R+$

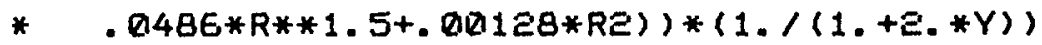

c

C FEAK QVERPRESSURE

$F D=10.47 /(R * * A A)+B B /(R * C C)+D D * E E /(1 .+F F * R * G G)+H H$

FEAKF'=PQ*.

RETURN

END

SUEROUTINE SPBRODE

c

******************************************************

THIS SUBROUTINE CALCULATES THE FRESSURE HISTORY FOR

THE FINAL FRESSURE-YIELD FAIR DETERMINED EY SUEROUTINE

FIT. IT USES THE SFEICHER-ERODE JUNE, 1982 ALGORITHM.

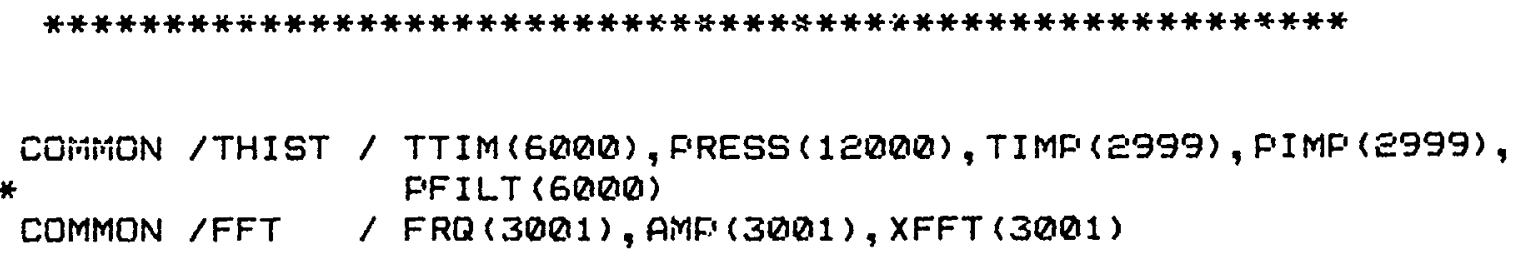




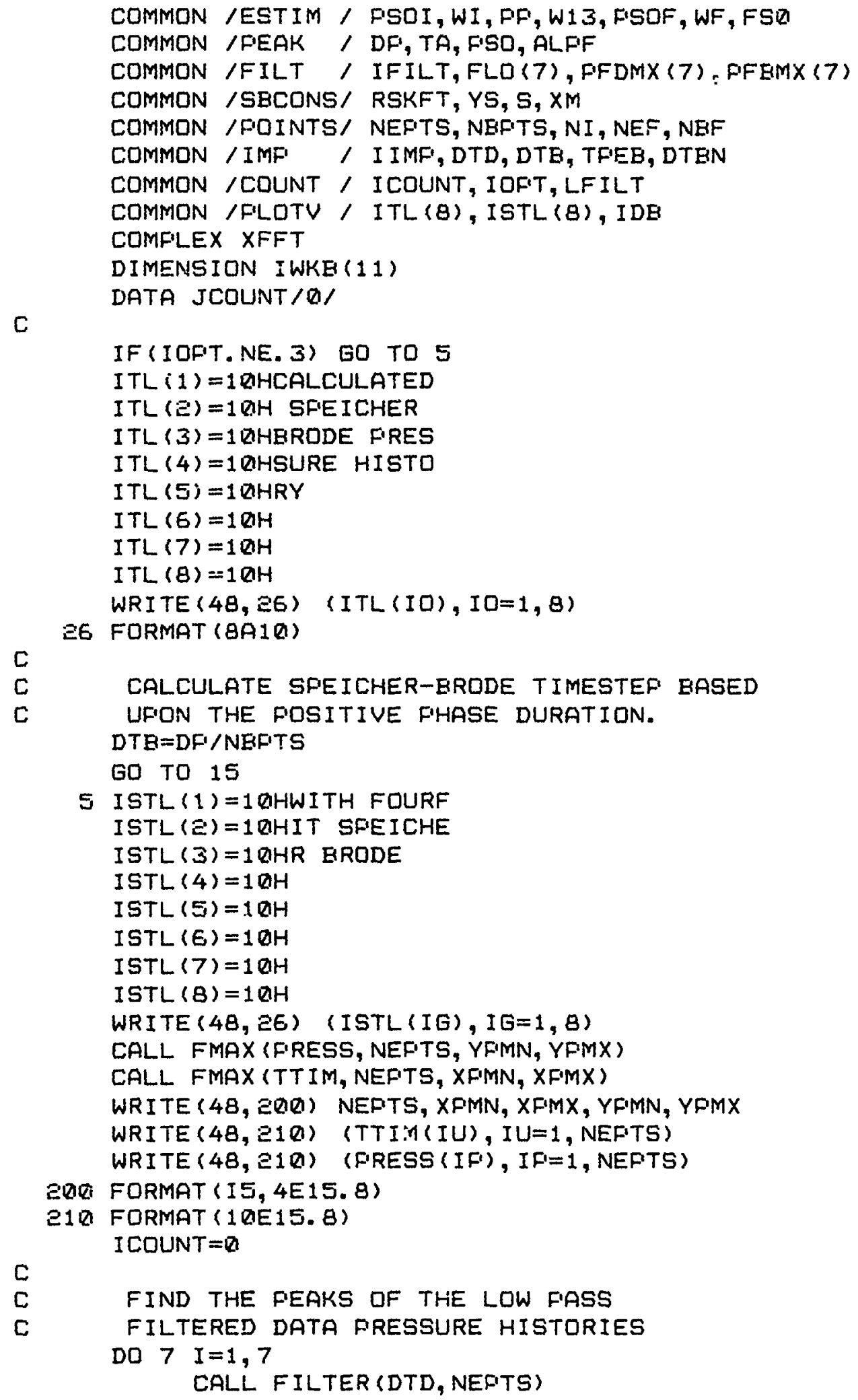




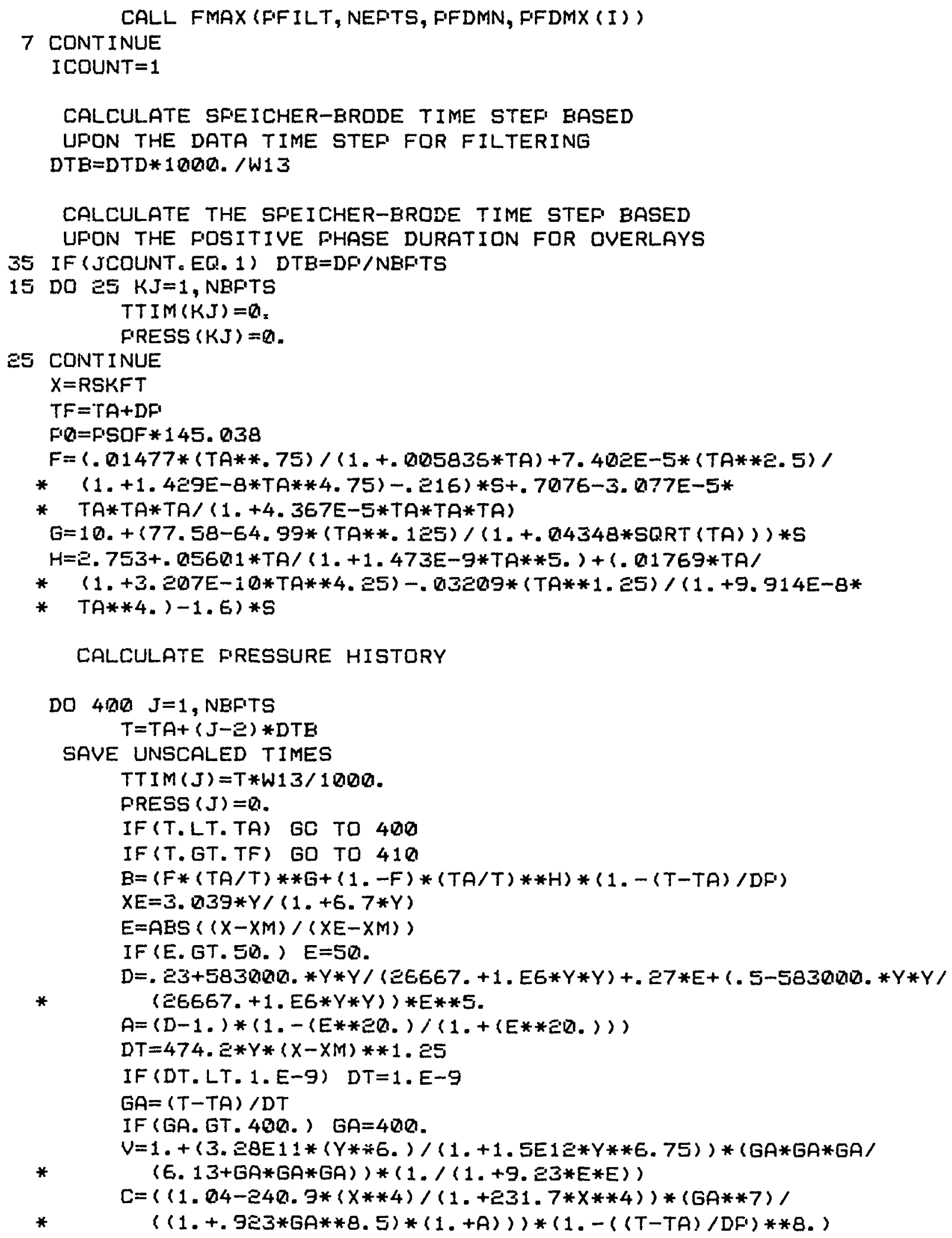




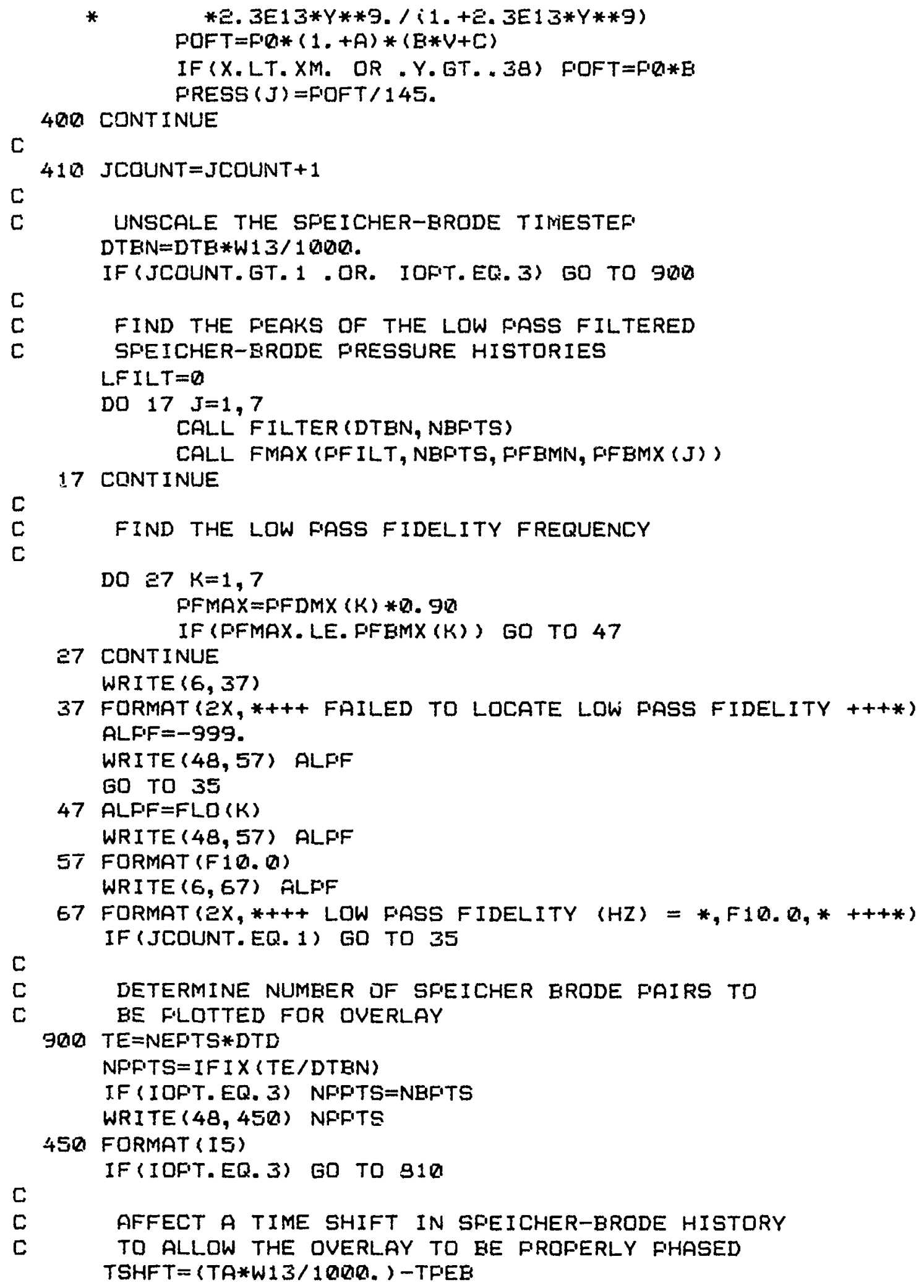




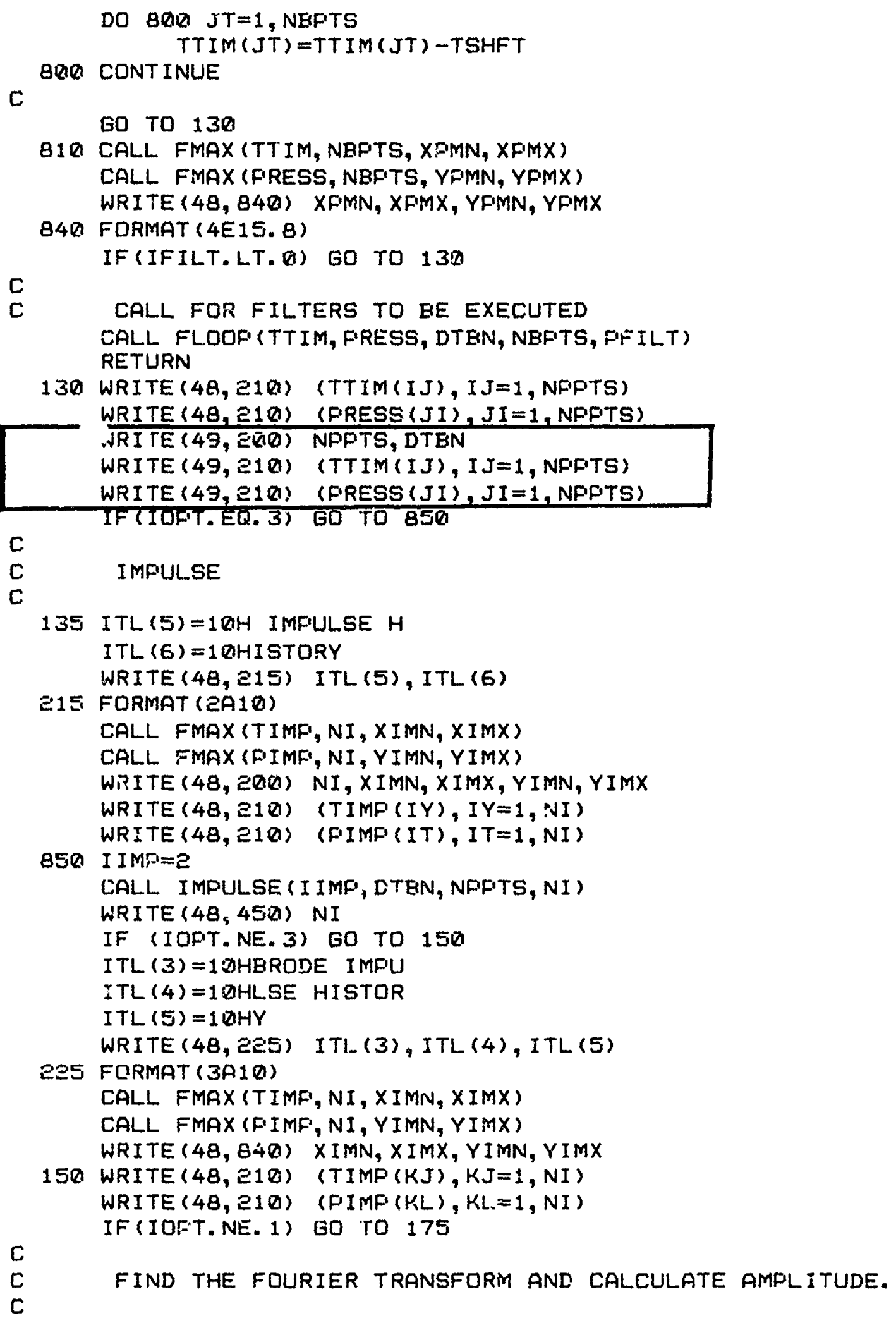


ITL $(5)=10 H$ FOURIER A
ITL $(5)=1$ QHMPLITUDE $S$
ITL $(7)=1$ QHFECTRUM

WRITE (48, 2ES) ITL (5), ITL (6), ITL (7)

CALL FMAX (FRG, NEF, XFMN, XFMX)

CALL FMAX (AMP, NEF, YFMN, YFMX)

WRITE (48, 2QR) NEF, XFMN, XFMX, YFMN, FMX

WRITE ( 48, E1Q) (FRQ (ID), IO=1, NEF)

WRITE ( $48, \geq 10)$ (AMP (IP), IF=1, NEF)

175 TOTT $=$ DTEN*NBFTS

c

FREQUENCY INCREMENT

DFE $=1, / T O T T$

$F Q E=0$.

WKE $=0$.

$N B F=N B F \cdot T S / 2+1$

DO $349 L K=1, N E F$

$F R Q(L K)=0$.

AMF $(L K)=Q$.

$X F F T(L K)=0$.

349 CONT INUE

CALL FFTRC (FRESS, NBPTS, XFFT, IWKB, WKE)

C

AMFLITUDE SFECTRUM

DO $500 \quad K K=1$, NBF

$F Q B=F Q B+D F B$

$F R Q(K K)=F Q B$

$X R B=R E A L(X F F T(K K)) / N B F T S$

$X I B=A I M A G(X F F T(K K))$ /NBFTS

SQQ CONTINUE AMF $(K K)=S Q R T(X R B * X R B+X I B * X I E) * T O T T$

c

WRITE $(4 B, 450) \quad N B F$

IF (IOFT. NE. 3) GO TO 165

ITL $(3)=1$ QHBRODE FOUR

ITL $(4)=1$ QHIER AMPLIT

ITL $(5)=1$ QHUDE SFECTR

ITL $(6)=1$ QHHUM

WRITE (48, 235) ITL (3), ITL (4), ITL (5), ITI. (6)

235 FORMAT ( $4 A 10$ )

C.ALL FMAX (FRQ, NBF, XFMN, XFMX)

CALL FMAX (AMF, NBF, YFMN, YFMX)

WRITE (48, 84Q) XFMN, XFMX, YFMN, YFMX

$165 \operatorname{WRITE}(48,210)$ (FRQ (IU), IU=1, NBF)

WRITE $(4 B, 210)$ (AMP (IE), IE=1, NEF)

RETURN

END

SUEROUTINE FLOOP (TTIM, FRESS, DT, NF, FFILT)

C

$* * * * * * * * * * * * * * * * * * * * * * * * * * * * * * * * * * * * * * * * * * * * * *$

C THIS SLBROUTINE FERFORMS THE LOOFING REQUIRED

C TO FILTER THE DATA OR THE ERODE UF TO SEVEN

$r$ TIMES. FOR LESS THAN SEVEN FI!TER LEVELS, 


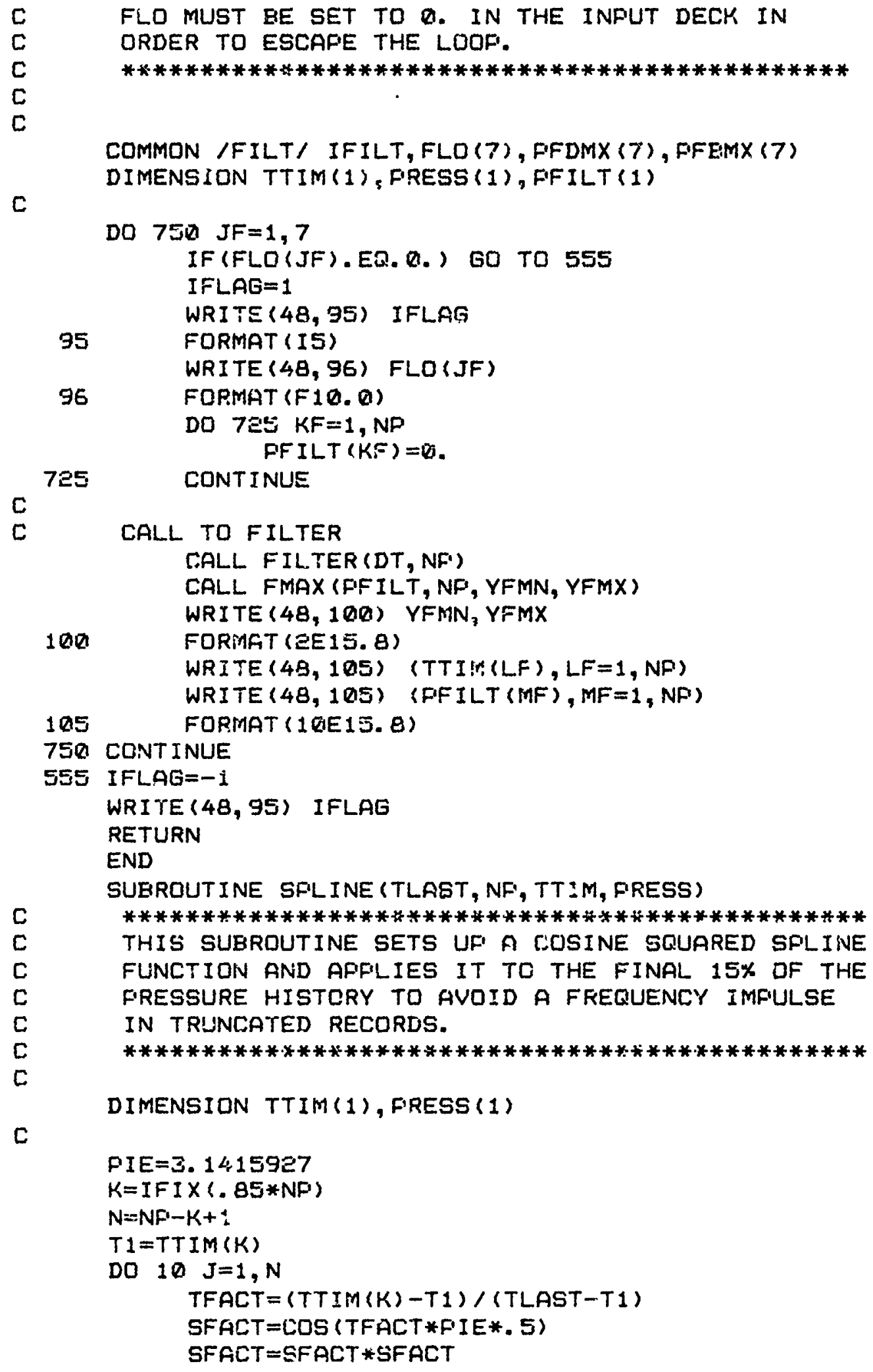


CONTINUE

RETURN

END

SUBROUTINE IMFULSE (IIMF, DT, NP, NI)

$c$
$E$
$E$
$c$
$c$
$c$
$c$ PRESSURE DATA (IIMP=1) OR DF THE CILCULATED SFEICHERBRODE (IIMF=Z) HY SIMFSON'S APPROXIMATION.
COMMON /THIST / TTIM(6000), FRESS ( LEQ00), TIMF (Z999), FIMF (2999), * PFILT (GDQR)

C

$$
\begin{aligned}
& \text { NTMP }=N F-3 \\
& N I=N T M F /= \\
& \text { DO } 90 \quad I=1, N I \\
& \operatorname{TIMP}(I)=0 . \\
& \operatorname{PIMP}(I)=0 .
\end{aligned}
$$

9Q CONTINUE

$$
I J=\emptyset
$$

SUMIMF= $=$.

DO $80 \mathrm{~J}=3, \mathrm{NTMP}, 2$

$I J=I J+1$

$T I M P(I J)=T T I M(J)$

AREA $=\{$ PRESS $(J-1)+4$. *PRESS $(J)+F$ RESS $(J+1)) * D T / 3$. SUMIMP $=$ SUMIMP+AREA

80 CONTINUE PIMP $(I J)=S U M I M F$

RETURN

END

SUBROUTINE FILTER (DT, NP)

$c$
$c$
$C$
$c$
$C$
$c$
$c$
$c$

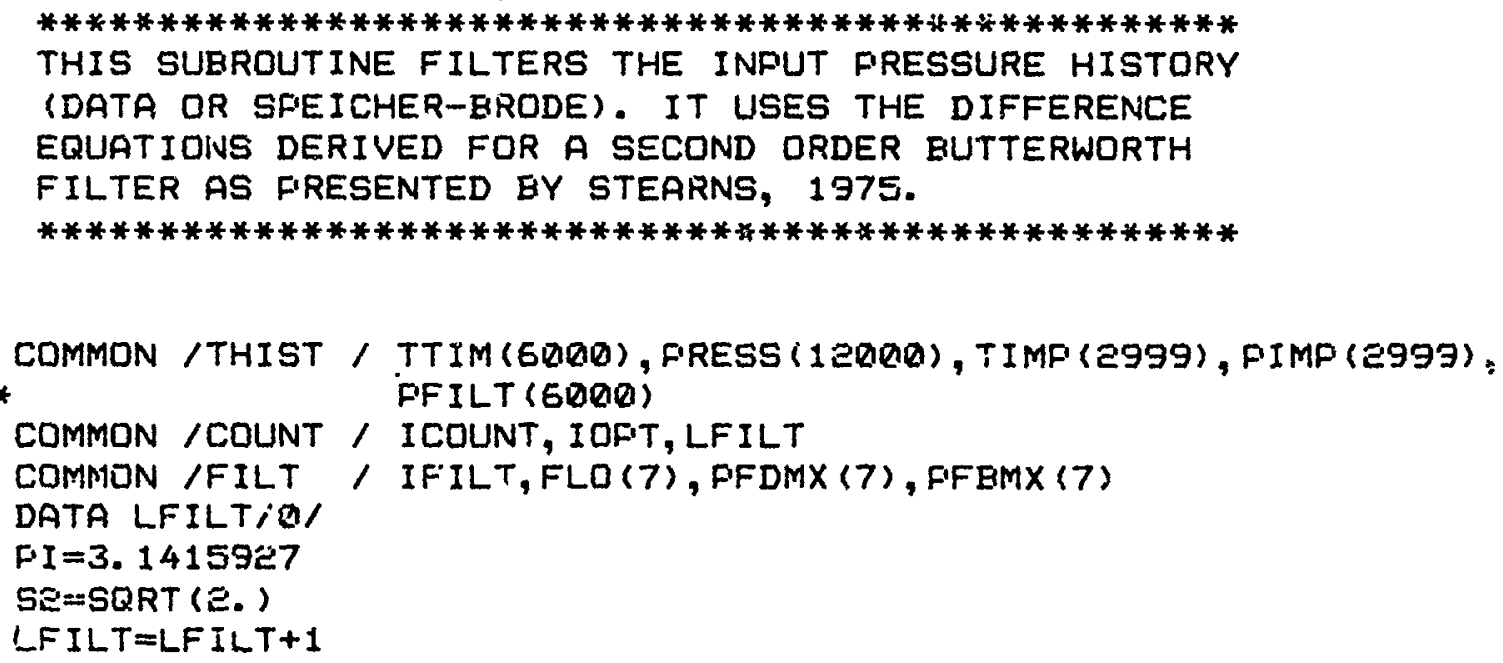




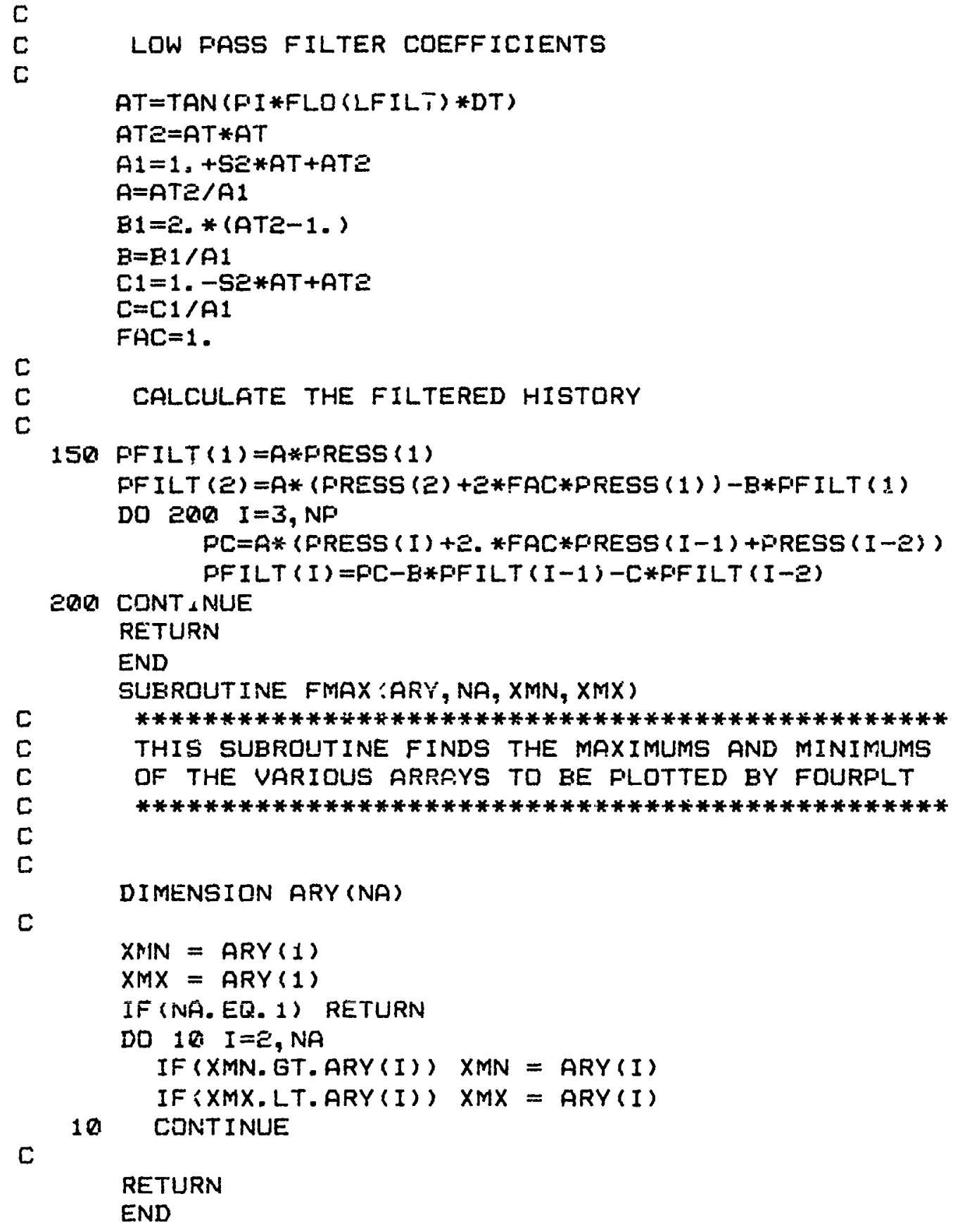


An?ENHDIX B

PROGRAM FREQRES USER'S MANUI:L

\section{B.1 INPUT VARIABLES}

Tab?e 2 lists all variables used in the input file for program FREQRES and the format in which they occur. In order to run FREQRES, first one has to select two digitized time history records with the same time step and record duration. One of the records should be a loading waveform and is considered the input. The other record should be some type of response time history and is considered the output. From Table 2, NEPTS is the number of discrete data points in each of the digitized records. NSKIP is the skip factor if the user wishes to work with less than NEPTS points. The total number of points from the input and output data records now considered for analysis is NPT $=$ NEPTS/NSKIP

The digitized time step is multiplied by NSKIP to get a new resultant time step. The discrete data points are averaged locally, so that all NEPTS points read from tape are considered in the analysis. TFAC, XFAC, and AFAC are the time, input data, and output data conversion factors, if the user does not want to work, units as specified on the data record tapes. Also, a -1.0 for XFAC or AFAC will invert the input or output data records, respectively.

ISPBX is a trigger indicating whether or not the user wants to spline the beginning portion of the input time history with a cosine squared sp?ine, such that the input value at zero time is forced to zero. If one 
elects to apply this spline, then TSPBX is the time before which the spline is applied to the input data. ISPEX is a trigger indicating whether or not the user wants to apply the cosine squared spline to the final portion of the input time history such that the final input value is forced to zero. TSPEX specifies the time at which the final portion spline begins. If a final portion spline is requested and TSPEX is left blank, then the default is the final 15 percent of the input record duration is splined. ISPBA, TSPBA, ISPEA, and TSPEA describe the spline conditions for the output data record.

From card 3 of Table 2, IBLX is the baseline correction trigger for the input data. Either a constant or a linear baseline correction can be applied. DELPX specifies the amount of baseline correction. SBX is the start time for the baseline correction and EBX is the end time. If SBY and EBX are specified as equar, then the full value of DELPX is added to all input values after time SBX. If $E B X$ is greater than $S B X$, then the input $p$ lot is rotated about the point defined at SBX by the amount DELPX at time EBX. The resulting input data trace can then be used as is or integrated according to the integration trigger INTX. IBLA, DELPA, SBA, EBA, and INTA describe the baseline correction and integration conditions for the output data.

Cards 5 through 16 in Table 2 specify labels for the $X$ and $Y$ axis for all of the different types of plots resulting from a FREQRES run. Table 2 describes the uses of each 1abel. All of the labels should be centered within the first 30 columns of each line of the input file so that the labels are centered on the axis of the plots. 


\section{B.2. PROGRAM STRUCTURE}

A listing of program FREQRES is provided in Appendix C. Figure 33 provides a flow chart of the program structure. It is easy to follow the program listing as one preceeds through the flow chart, since the program is well documented with comment cards. The first part of the program has extensive comment cards describirg the program input file. The first exccutable part of the program reads the entire input file and then documents all input file conditions in the printed output file. The progran then writes the input file conditions to the time history plot file. The input data record time history is read from TAPE26 and then can be baseline corrected, integrated, and/or splined according to input file specifications. The resulting input data record time history is then stored on a plot file (TAPE48) for post-process plotting. The output data record time history is read from TAPE27 and it can also be baseline corrected, integrated, and/or splined according to input file specification. The resulting output data record time history is then stored on the plot file. Another input data record of arbitarary specification (such as a "best-fit" Speicher-Brode waveform to a HEST pressure input data record) is read from TAPE3. If the time step from the new input data record is not within a 1 percent tolerance level of the time step for the input and output data records read earlier, then the program will stop. The time steps should be nearly identical for best results in this analysis procedure. As an example, assume that the time step for input and output data records is $5 \times 10^{-6}$ seconds and the time step for the new input data record is $1.337 \times 10^{-4}$ seconds. Then one would have to specify an NSKIP value of $\left(1.337 \times 10^{-4}\right) /\left(5 \times 10^{-6}\right)=27$ 
in order to allow the program to run. The resulting time steps would be $1.35 \times 10^{-4}$ seconds and $1.337 \times 10^{-4}$ seconds, which are within the 1 percent tolerance level. If the 1 percent tolerance leve 1 is too restrictive for some data record combinations, the user may have to relax the tolerance level to 2 percent, or at the most 3 percent, by updating the program.

The program FFT's the input and output data record time histories (see Section 2.2) and stores the FFT amplitude spectrums in the plot file. The FRF is calculated by dividing the output record FFT by the input record FFT (see Section 2.4). The FRF phase angle information is of little interest in this analysis, but FRF amplitude ratios are. Therefore, the FRF amplitucie ratios are saved in the plot file.

As was discussed in Section 2.3, the inverse FFT of an FFT does not give back the same exact discrete time series. An inverse FFT is applied directly to the output record FFT, in order to get an output record time history which includes these alterations.

The program then FFT's the new input data record read earlier from TAPE3. This FFT is then multiplied by the FRF through complex math to obtain a new modified output response FFT. The program then inverse FFT's this new FFT to obtain a modified output response time history.

\section{B-3 SAMPLE OUTPUT}

Table 3 presents a sample output listing (TAPE6) from a FREQRES calculation. Record number 4 (Figure 6 ) was the input data record and record number 5 (Figure 7) was the output data record. The output echoes the inpur file variable specification. This output listing shows that the input and output data records consisted of 9970 points each, but a skip 
factor of 27 was used. The large skip factor was used in order to force the time step of the test data records to be equal to the time step of the Speicher-Brode waveform created from a FOURFIT calculation. The Speicher-Brode waveform time step (stated three forins of the way through the output listing) is $1.337 \times 10^{-4}$ seconds and the original test data record time step is $5 \times 10^{-6}$ seconds. The skip factor of 27 now gives the test data records a time step of $(27)\left(5 \times 10^{-6}\right.$ seconds $)=$ $1.35 \times 10^{-4}$ seconds, which is within the 1 percent tolerance level used in the program. Next the listing states that the time, input data, and output data conversion factors were all set to 1.0 . The beginning portions of the inpui and uncput data prior to $2.67 \mathrm{msec}$ and $3.0 \mathrm{msec}$, respectively, were splined to zero. The final 15 percent of the input and output data were also splined to zero. The "very important notice" in the output listing compares the total number of points and time steps between the Speicher-Brode waveform and the test data. If the total number of points is not identical, then the program truncates the time history with the greatest number of points (the Speicher-Brode waveform in this example) so that they are equal. The program then prints out the time steps for user inspection. If the time steps do not meet the tolerance level specified in FREQRES, the program stops and the final three lines shown in the output listing will not be printed. If the tolerance level is met, then the program should run successfully to completion. The last three lines provide the value of the full integration of the output data record, the value of the output FFT amplitude spectrum at zero frequency, and the value of the offset of the inverse FFT output time history (see Section 2.3). Notice that the first and second values are nearly 
identical, and the value of the third is twenty times the value of the second.

Table 4 presents the input file variable specifications for each of the test data records as used in this analysis. Only two of the data records were ever used as input data records in the cause-effect analysis, record numbers 2 and 4 . Al1 of the data records with an NSKIP of 35 were used as output data records when record number 2 was used as tiis input data record. All of the data recor'ss with an NSKIP of 27 were associated with record number 4 . The time scale was always kept at seconds with TFAC $=1.0$. Test data records 8 through 11 were converted from units of $g^{\prime} \mathrm{s}$ to $\mathrm{ft} / \mathrm{sec}^{2}$ with an $A F A C=32.2$ and then integrated so that the output data record could be velocity rather than acceleration versus time. All of the strain plots were inverted with a $A F A C=-1.0$ to be consistent with the pressure plots in which compression is positive. Test data record numbers 8 and 11 were the only records which appeared to need basel ine correcting as noted in Table 4 .

Table 5 presents the total impulse, first FFT value, and inverse FFT offset for test data records 4 through 20 .

\section{B.4 PROGRAM FREPLT}

Program FREPLT is the post process plotting program for the program FREQRES. A complete listing of FREPLT is presented in Appendix D. FREPLT simply reads the plot file created from a FREQRES run (TAPEQ8) and creates eight hard copy plots on the DNA Cyber computer at Los Alamos, New Mexico. The eight plots are as follows:

1. Input data record time history

2. Cutput data record time history

3. Input data record FFT amplitude spectrum up to $3000 \mathrm{~Hz}$ 
4. Output cata record FFT amplitude spectrum up to $3000 \mathrm{~Hz}$

5. FRF amplitude ratios up to $3000 \mathrm{~Hz}$

6. Inverse FFT output record time history

7. Output record FFT wi th new input data record influence

8. Modified output response time history

\section{B. 5 PROGRAMMING NOTES}

This subsection mainly discusses file manipulation among the three programs FOURFIT, FREQRES, and FREPLT. First, a FOURFIT calculation is run with the updates discussed in Section 2.5 and shown in Appendix $A$. These updates create TAPE49 which must be saved.

The input files necessary for a FREQRES calculation are shown in Table 6. The output files created from a successful FREQRES calculation are shown in Table 7. FREPLT only requires one input file, TAPE9, which is the plot file from the FREQRES calculation, TAPE48. FREPLT creates two output files, TAPE6 and PLOT. TAPEG is printed output. PLOT contains the eight plots described in Secton B 4 which can be disposed to hard copies with a job control instruction:

PESP.ORIENT=ROTATE MAJOR="any message"

From Tab7e 6 , TAPE26 and TAPE27 contain digitized test data records as they are stored on EU tapes under a format used by the Waterways Experiment Station in Vicksburg, Mississippi. The format is readily apparent in the listing of FREQRES in Appendix $C$ with the READ statements for TAPE26 and TAPE27.

For a $71 \mathrm{FFT}^{\prime} \mathrm{s}$ and $\mathrm{FRF}^{\prime} \mathrm{s}$, the maximum frequency of concern for plotting is assumed to be $3000 \mathrm{~Hz}$. There is very little significance at frequencies greater than $3000 \mathrm{~Hz}$ in most structural and soil response characteristics. Also, the power in most FFT amplitude spectrums of test data is negligible at $3000 \mathrm{~Hz}$ and beyond. This maximum frequency of 
concern (for plotting purposes only) can be altered in the portion of

FREQRES as stated below:

C Assumming record duration is $.05 \mathrm{sec}$ and maximum frequency

C of concern is $3000 \mathrm{~Hz}$ then the maximum number of points of concern

C for plotting in the frequency domain is $(3000)(.05)=150$. NPFF $=$ NPF

IF (NPF.GT.150) NPFF $=150$

If the input and output data record durations are different from

.05 seronds or if the maximum frequency of concern for plotting is

different from $3000 \mathrm{~Hz}$, then the 150 in the last statement above must be al tered accordingly. 


\title{
APPENDIX C
}

LISTING OF PROGRAM FREQRES

\begin{abstract}
PROGRAM FREQRES ( INPUT, OUTPUT, TAPES=INPUT, TAPEE=OUTFUT, * TAPEE, TAFE3, TAPEE6, TAPEE7, TAPE48)
\end{abstract}

$c$

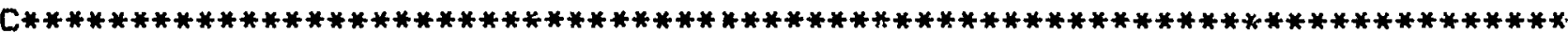

C

C PROGRAM FREQRES DETERMINES THE FREQUENCY RLSPONSE FUNTION

C BETWEEN TWO SETS OF DATA ("INFUT" DATA TRACE. X (NT)

C FROM TAPEZ6 AND "OUTPUT" DATA TRACE A(NT) FROM

C TAPEZ7). THE "INPUT"/"OUTPUT" LABELS ARE ONLY

C RELEVGNT IN "CAUSE-EFFECT" ANALYSIS BETWEFN TWD SETS

C OF DATA.

C RESULTS ARE WRITTEN TO A

C FILE (TAFE4E) TO BE READ AND PLOTTED EY FROGRAM

C FREFLT.

C

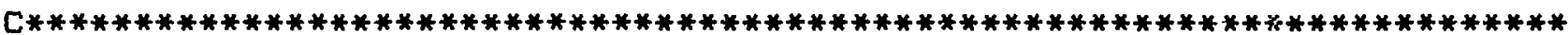

C

DIMENSION FRQ (3000), XFFT (3000), AFFT (3000), AMP (3000),

*TIMX (6000), XTD (6000), ATD (6000), DDT (1 2000), FRESS (6000)

DIMENSION IX $(8), \operatorname{IA}(8), \operatorname{ITX}(6,4), \operatorname{ITY}(6,4)$

DIMENSION DUM (3), IWKE (5SD0), WKE (5S00)

EQUIVALENCE (IWKE (1), WKE (1))

DIMENSION COPS (3000), CIPS (3000)

C

COMPLEX XFFT, AFFT

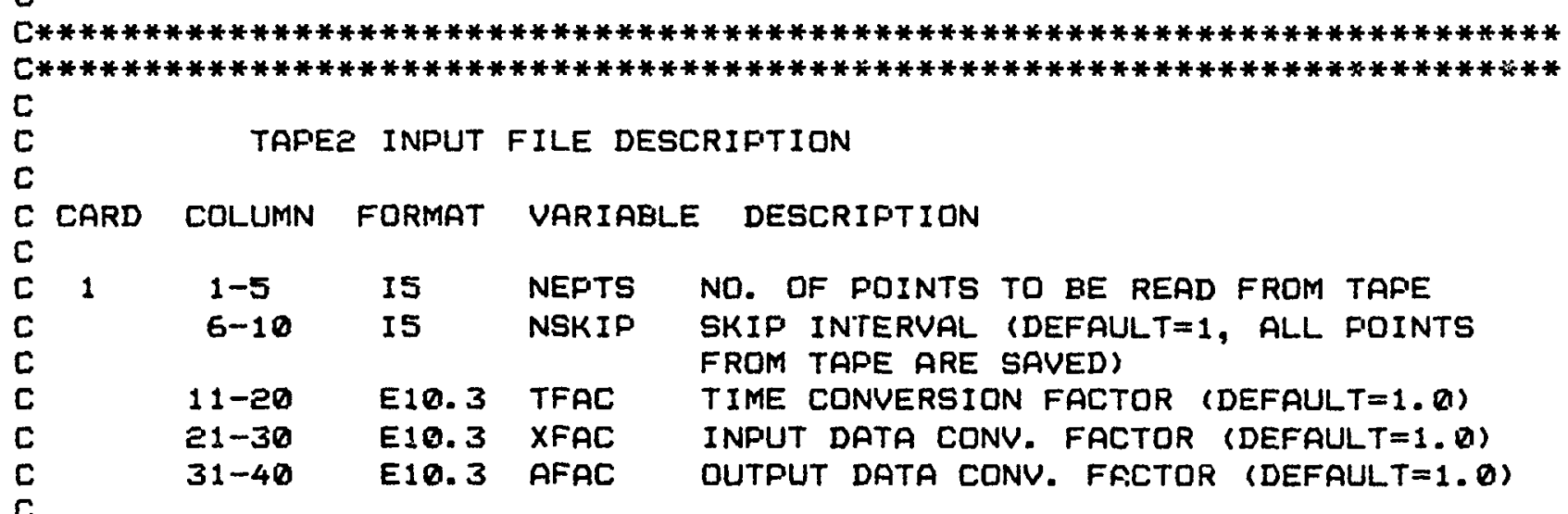




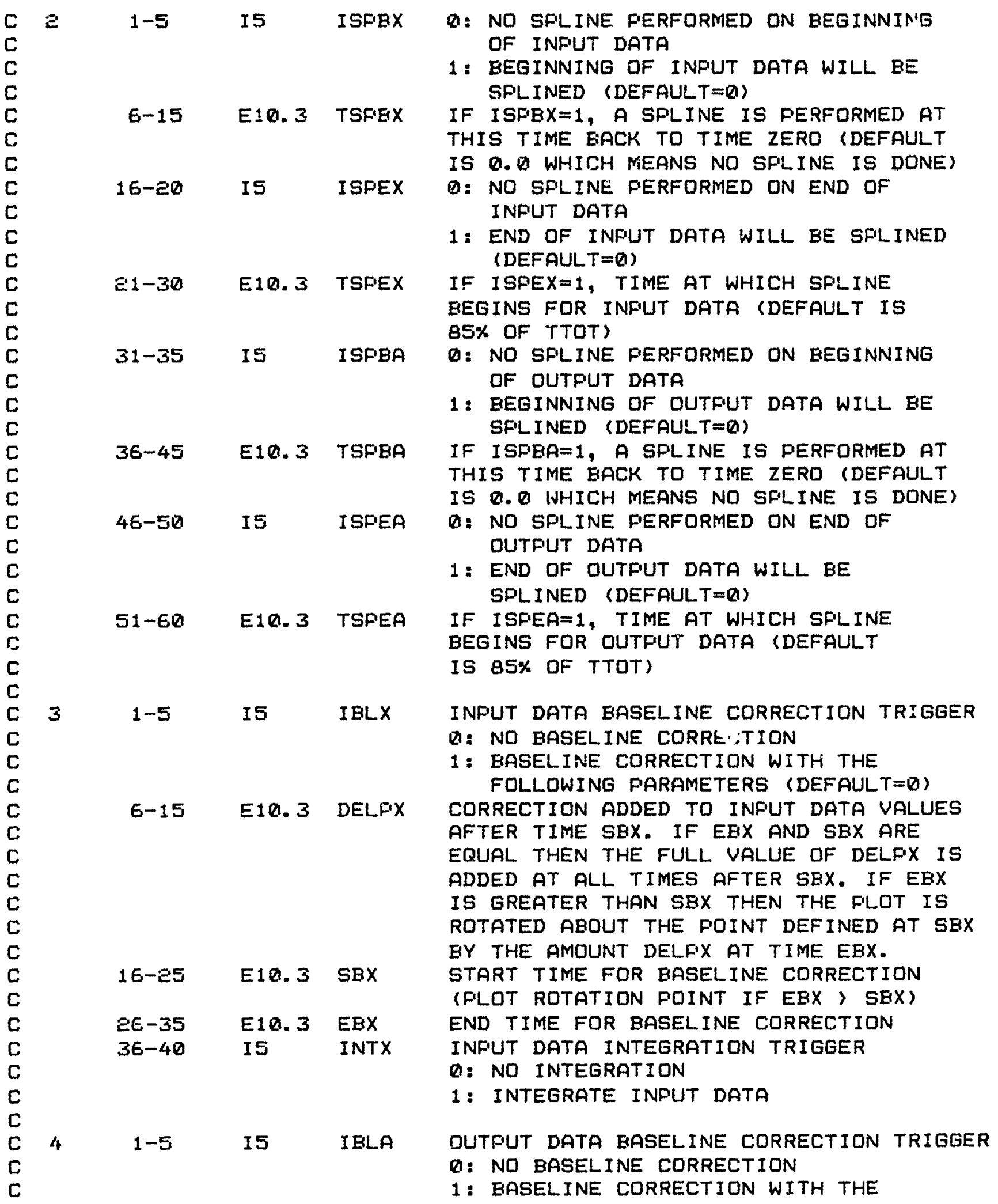


c

c

C

C

C.

C

C.

C

C

C

C

C

C

C

C

C

C

C

c

C

C

C

C

C

C

c

C

C.

c

C

C

C

C

C

C

C

C 11 1-4Q 4A1Q ITX

C

C

c

C 12 1-4Q 4A1Q IT

C

$\mathrm{C}$

C

C $13 \quad 1-40$ 4A1Q ITX
$5 \quad 1-40 \quad 4 A 10$ ITX

$6 \quad 1-40 \quad 4 A 10$ ITY

$1-40 \quad 4 A 10$ ITX

1-40 4A1Q ITY

$1-4 Q \quad 4 A 10$ ITX

$1-40 \quad 4 A 10 \quad$ ITY

$1-40$

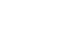

$1-40$
FOLLOWING PARAMETERS (DEFAULT $=(n)$

CORRECTION ADDED TO OUTFUT DATA VALUES

AFTER TIME SBA. IF EBA AND SBA ARE

EQUAL THEN THE FULL VALUE OF DELFO IS

ADDED AT ALL TIMES AFTER SEA. IF EEA

IS GREATER THAN SEA THEN THE PLDT IS

ROTATED ABOUT THE POINT DEFINED AT SEA

BY THE AMOUNT DELFA AT TIME EBA.

START TIME FOR BASELINE CORRECTION

(FLOT ROTATION FOINT IF E.BA , SEA)

END TIME FOR BASELINE CORFECTION

OUTPUT DATA INTEGRATION TRIGGER

Q: NO INTEGRATION

1: INTEGRATE OUTFUT DATA

NOTE: ALL OF THE FOLLOWING LABELS SHOULD BE CENTERED WITHIN THE FIRST 30 COLUMNS OF EACH LINE OF THE INFUT FILE.

INFUT DATA X-AXIS LABEL; EXAMPLE: TIME (SEC)

INPUT DATA Y-AXIS LABEL; EX: FRESSURE (FSI)

QUTPUT DATA X-AXIS LABEL; EX: TIME (SEC)

QUTFUT DATA Y-AXIS LAEEL; EX: STRAIN (IN/IN)

INFUT DATA FOURIER AMP. SPEC. $X$-PXIS LABEL; EX: FREQUENCY $\langle H Z\rangle$

INFUT DATA FOURIER AMF. SFEC. $Y$-AXIS LABEL; EX: AMFLITUDE (FSI-SEC)

QUTFUT DATA FOURIER AMF. SFEC. $X$-AXIS LABEL; EX:

FREQUENCY ( $\mathrm{HZ}$ )

OUTFUT DATA FOURIER AMF. SPEC. $Y$-AXIS LABEL; EX: AMFLITUDE (SEC)

FREQUENCY RESFONSE FUNCTION

$X$-AXIS LABEL; EX: FREQUENCY (HZ) 


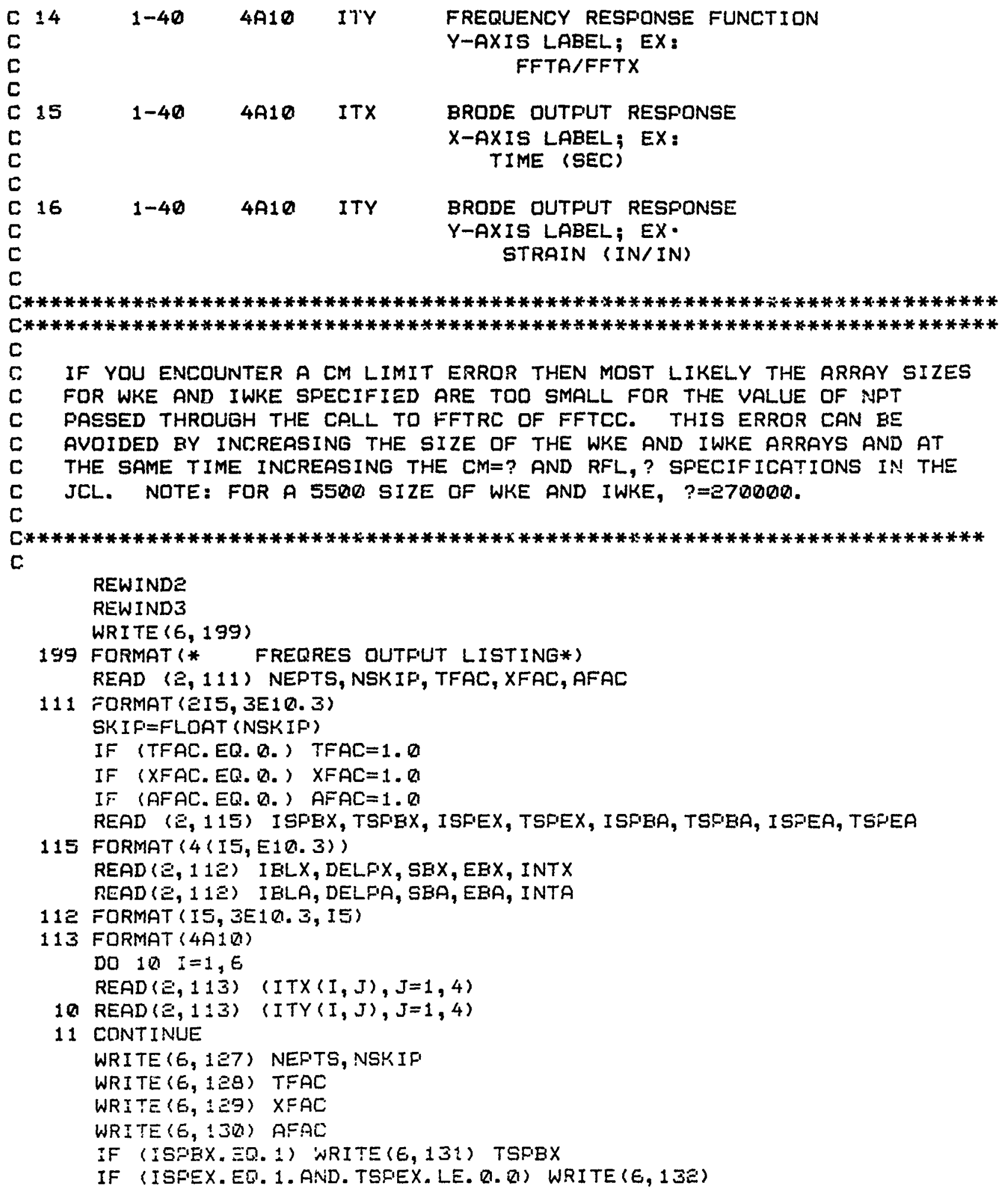


IF (ISFEX. EQ. 1. AND. TSFEX. GT. Q. Q) WRITE (6, 1.T3) TSFEX

IF (ISFBA. EQ. 1) WRITE (E, 134) TSFEA

IF (ISFEA.EG. 1. AND. TSEEA. LE. (1. (1) WRITE (6, 135)

IF (ISPEA.EQ. 1. AND. TSNEA. GT. Q. Q) WRITE!E, 13S) TSPEA

IF (IBLX.EQ=1) WRITE(G,1E3) DELFX, SBX, EBX

IF (IBLA.EE. 1) WRITE $(6,1 Z 4)$ DE:FA, SBA, $\subseteq E A$

123 FORMAT $(/, *$ BASELINE CORRECTICN REQUESTED FOR INRUT DATA RECORD*

,+ WITH:*, $/, *$ DELFX $=*, E \pm Z .3, * ; \quad S B X=*, \equiv 1 Z .3, * ; \quad$ EEX $=*$

$+, E 10.3)$

124 FORMAT(/, * EASELINE CORRECTION REQLESTED FOR OLTPLT DATA RECORD*

,$+ *$ WITH:*, $1, *$ DELFA $=*, E 10.3, * ; \quad$ SSA $=*, \Xi 10.3, * ; \quad$ ESA $=*$

$+, E 10.3)$

127 FORMAT( $/$ * THE NUMEER OF FOINTS READ FROM THE DATA RECORD TG:-ES*

,$+ *$ IS *, IS, * WITH A SKIP OF *, IZ, * CONSIDERED FOR ANALYSIS*)

128 FORMAT $(1, *$ TIME CONVERSIDN FACTOR $=*, E 1 Q .3)$

129 FORMAT (* INPUT DATA CONV. FACTOR $=*$, E10.3)

130 FURMAT (* DUTFLIT DATA CONV. FACTQR $=*$,E10.3)

131 FORMAT $/$, * BEGINNING PORTION OF INFUT DATA SFLINED FROM TIME*

,+ * EQUAL 0. TO TIME EQUUAL *, E10.3)

132 FORMAT $(1$, * FINAL $15 \%$ OF INPUT DATA SPLINED TO ZERO*)

133 FORMAT $(/, *$ INFUT DATA FROM TIME $=*$, E10.3,* ON SFLINED TO ZERQ*)

134 FORMAT $(/, *$ BEGINNING FDRTIDN OF OUTFUT DATA SPLINED FROM TIME*

+ * EQUAL Q. TO TIME EQUAL *, E1Q.3)

135 FORMAT $(/, *$ FINAL $15 \%$ OF OUTFUT DATA SPLINED TO ZERD*)

136 FORMAT $(1, *$ QUTFUT DATA FROM TIME = *,E10.3, * QN SFLINED TO ZERC*) WRITE $(48,111)$ NEPTS, NSKIF, TFAC, XFAC, AFAC

WRITE (48, 115) ISPBX, TSFBX, ISFEX, TSFEX, ISPBA, TSFBA, ISPEA, TSFEA

WRITE $(48,112)$ IBLX, DELFX, SBX, EBX

WRITE $(48,112)$ IELA, DELFA, SBA, EBA

REWINDEE

REWINDE7

c

C READ INFUT DATA RECORD TAFE HEADER INFDRMATION

C

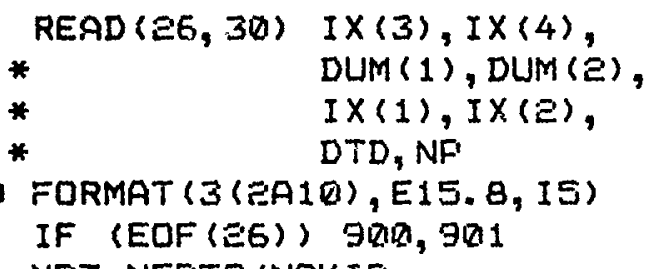

901 NPT =NEPTS/NSKIF

$D T D=T F A C * S K I F * D T D$

$\operatorname{TIMX}(1)=D$.

DO $1 \geq I=E, N F T$

12 $\operatorname{TIMX}(I)=\operatorname{TIMX}(I-1)+D T D$

TTOT $=T I M X(N F T)$

IF (TSFBX LT. D. QD1*TTOT. OR. TSFBX. GT. TTOT) ISFBX $=\varnothing$

IF (TSPBA. LT. D. QQ1*TTOT. DR. TSFBA. GT. TTOT) ISFEA $=\square$

C.

c READ INPUT DATA RECORD VALUES 
C

READ (E6, 5Q) (DDT (I), I=1, NEFTS)

50 FORMAT (SE1E. 8)

IF (EOF (EE)) $9 Q 0,9 Q E$

90อ. $I M=\varnothing$

DO 13 I=NSKIF, NEPTS, NSKIF

$I M=I M+1$

$X T D(I M)=D$.

DO $14 J=1$, NSK IF

$14 X T D(I M)=X T D(I M)+D D T(I+1-J)$

i $3 \times(D \leq I M)=(X T D(I, Y) / S K I P) * X F A C$

IF (IM.LT.NET) NET=IM

C

C BASELINF CORPECTIUN FOR INPLT DATA

c

IF (IELX.EQ. (A) GO TO Z:

DO $15 I=1, N F$

15 IF (SEX.LT.TIMX(I)) GC TO $1 E$

16 ISBX $=I$

IF ((EEX-SBX). GT. (D. DQD*TTOT)) GO TO 101

IF (ISEX. GE. NPT) GO TC $\exists S \mathrm{~B}$

GO TO 1 DQ

101 CONTINUE

DO $17 \mathrm{I}=\mathrm{J} . \mathrm{SBX}, \mathrm{NOT}$

17 IF (EEX.LT.TIMX(I)) GO TO IB

18 IEBX $=I$

IF (IEEX. LE. ISEX. OR. IEEX. GE. VRT) GO TO 998

DO 19 I $=$ ISEX, NFT

$19 X T D(I)=X T D(I)+D E L F X *((I-I S E X) /(I \equiv E X-I S E X))$

GO TO $E 1$

10e DO ED I=ISEX, VFI?

ED $X T D(I)=X T D(I)+D E L F X$

21 IF (INTX. EQ. 1) CALL INTGRT (DTD, NFT, TIMX, XTD, DDT)

IF (ISFEX.EG. 1) CALL SF'INE (TSEEX, TTOT, NFT, TIMX, XTD)

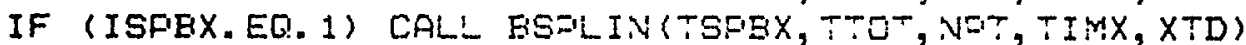

I $X(5)=10 \mathrm{H}$ INFUT DAT

IX $(6)=1 Q H A$ RECQRD:

$I X(7)=1 Q H X(N T)$

$I X(3)=18 \mathrm{H}$

CALL FLTSAV (1, IX, ITX, ITY, NFT, TIMX, .TD)

C

C READ OUTPUT DATA RECORD TAFE HEADER INEORYATICN

C

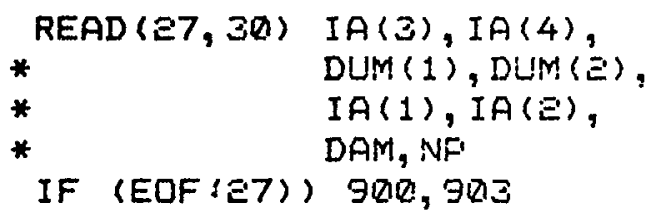

c

903 CONT INUE 


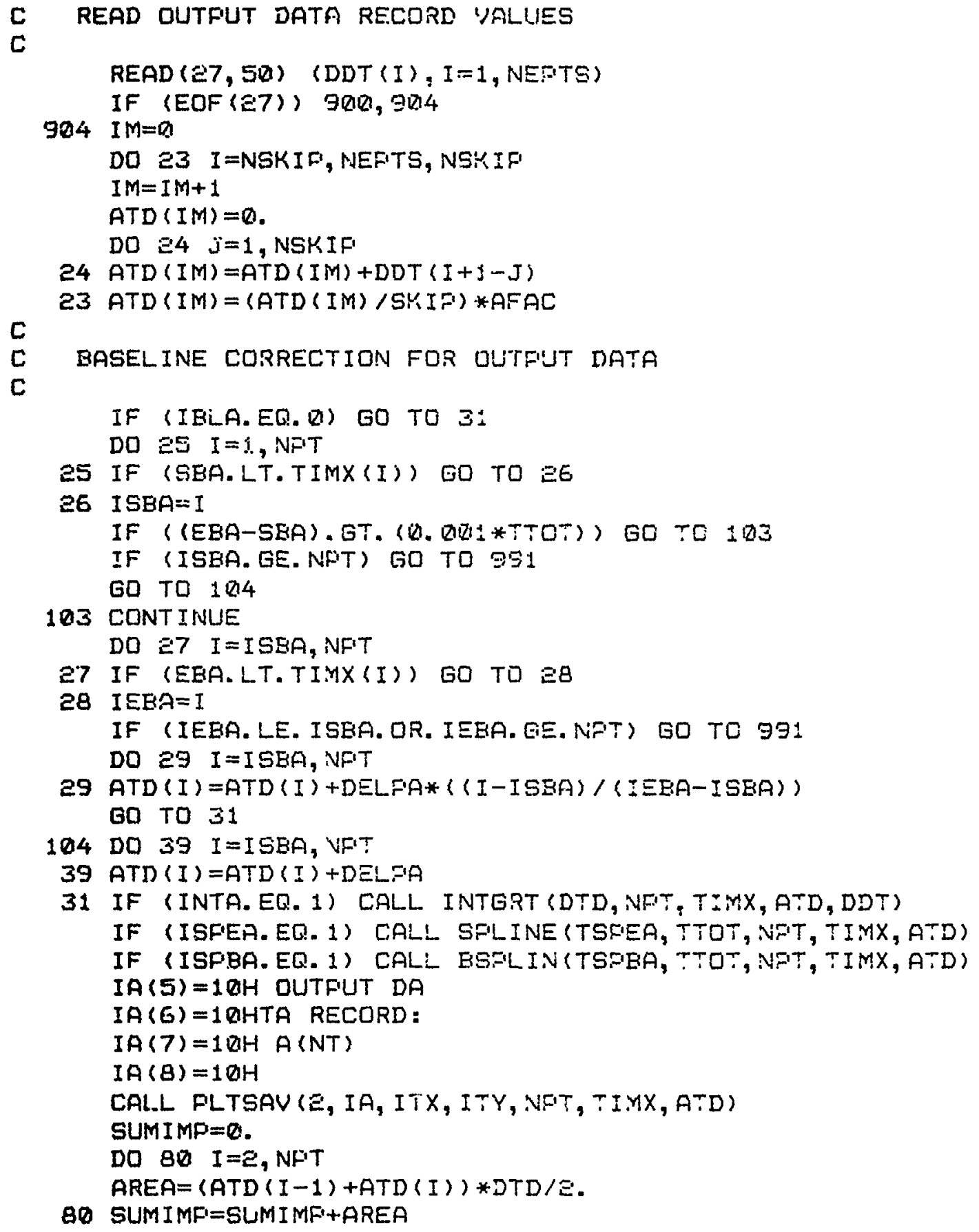




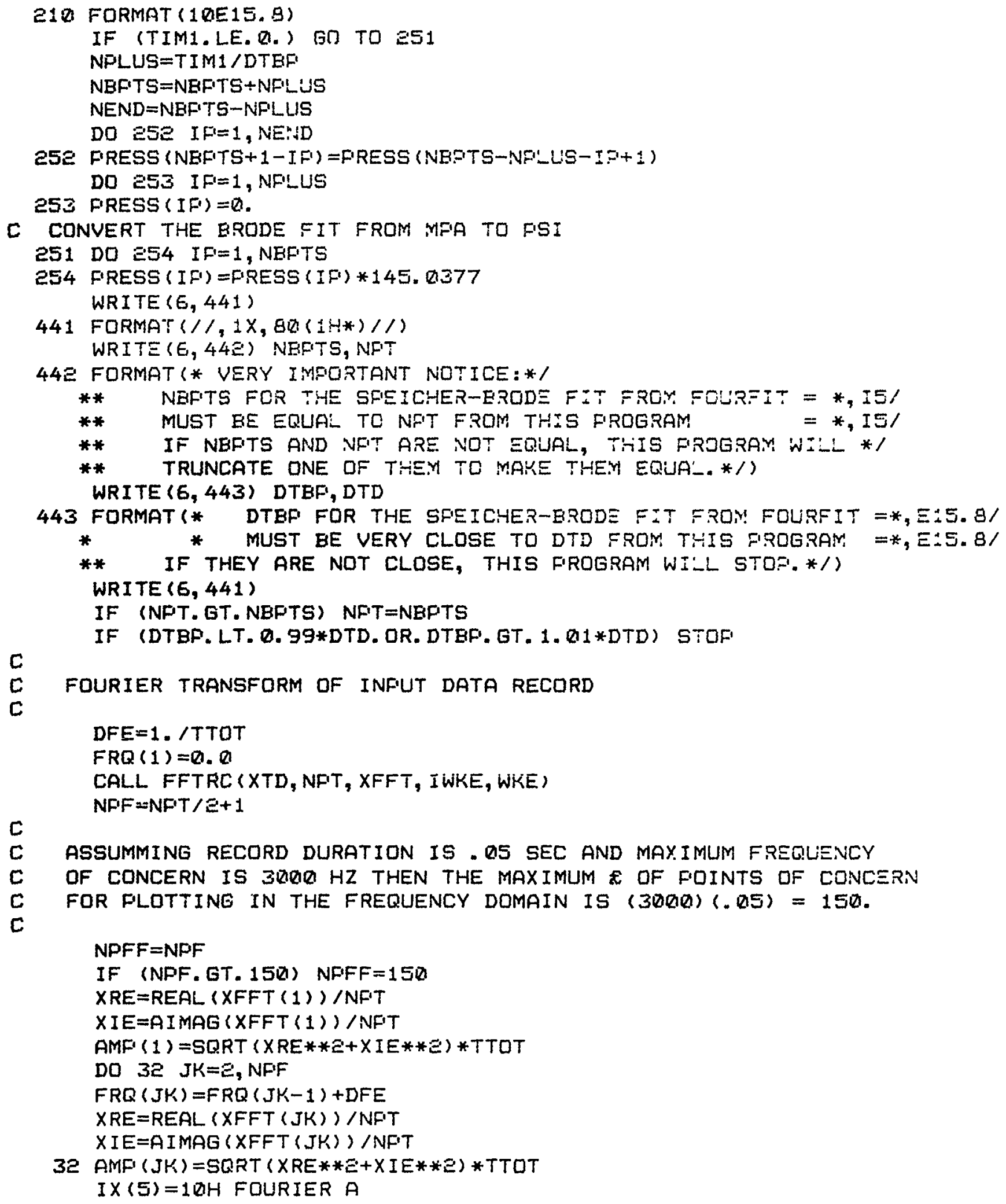




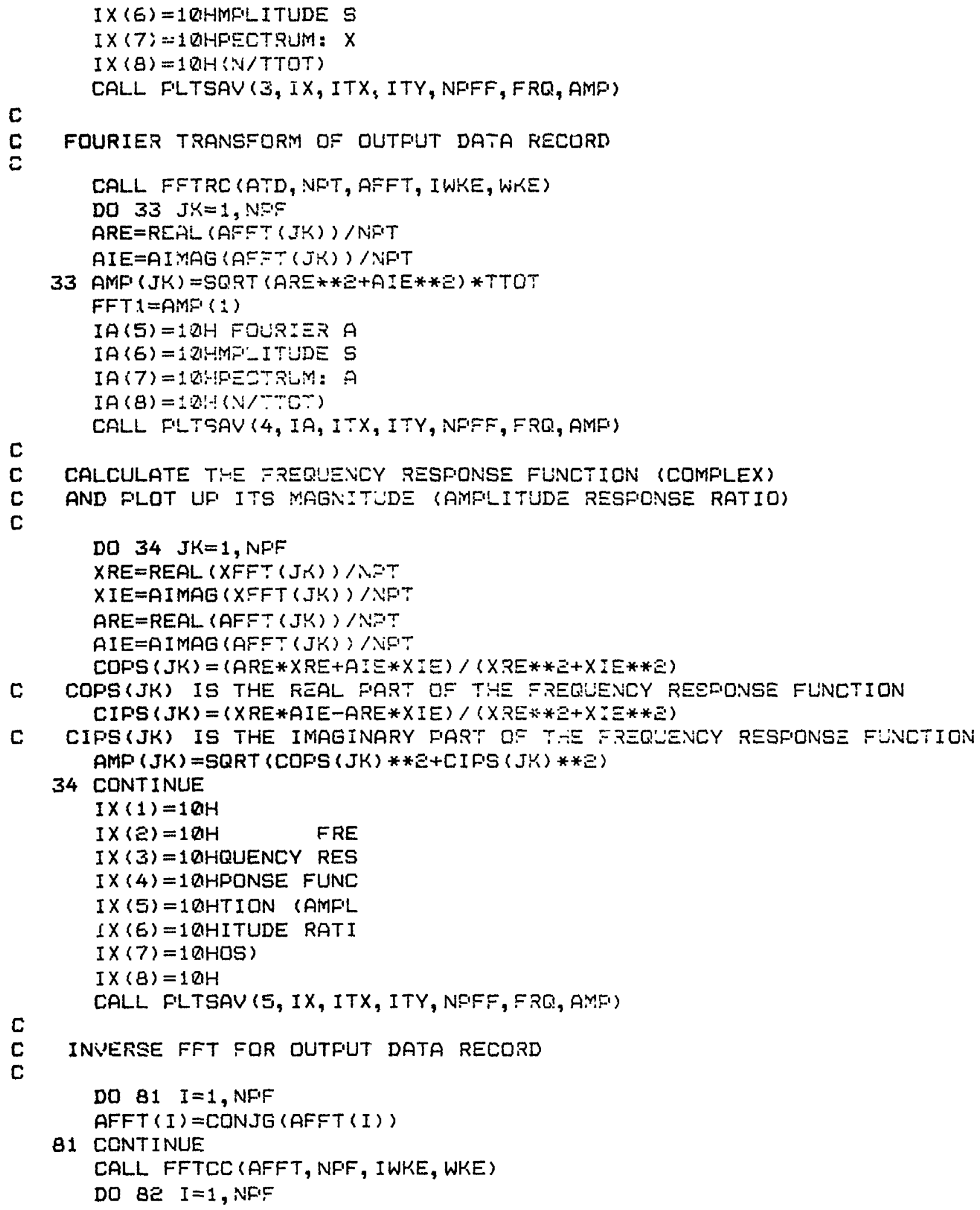

C

C INIERSE FFT FQR OUTFUT DATA RECORD

C

DO $81 I=1$, NF.F

$\operatorname{AFFT}(I)=$ CONJG $(A F F T(I))$

81 CCNTINUE

CALL FFTCC (AFFT, NFF, IWKE, WKE)

DO 8 E $I=1$, NFF 


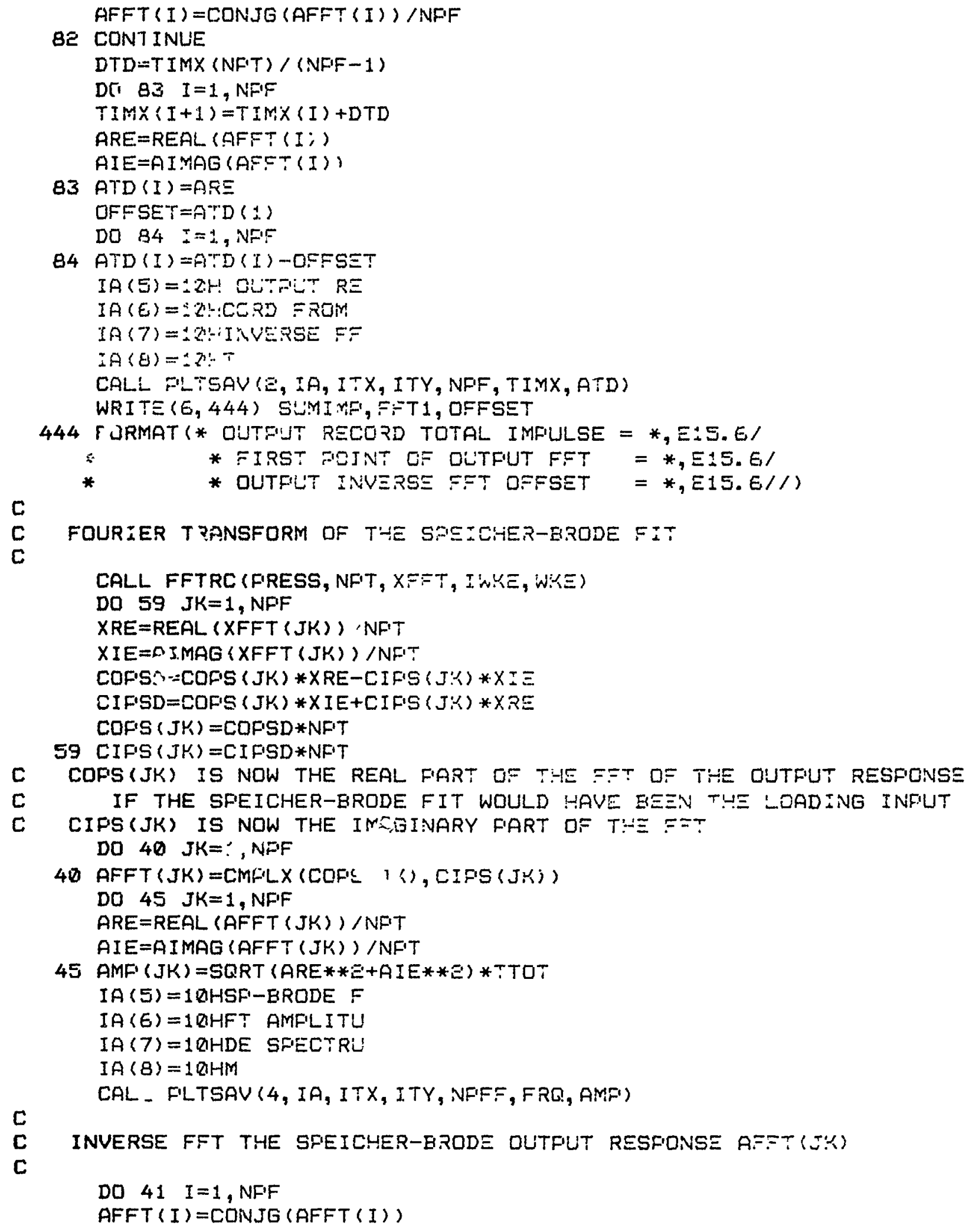


41 CONTINUE

CALL FFTCC (AFFT, NFF, IWKE, W:ES)

DO $42 I=1$, NFF

AFFT (I) $=$ CONJG (AFFT (I ) ) /NFE

42 CONTINUE

ARE =REAL (AFFT (I))

AIE $=A I M A G(A F F T(I))$

43 ATD $(I)=A R E$

UFFSET $=A T D(1)$

DO $44 I= \pm, N F F$

44 ATD (I) $=A$ TD (I) -OFFSET

IA $(5)=184$ DUTFUT RE

IA $(E)= \pm B H C O K D$ IF LO

IA $(7)=1$ DHAD ING WVRE

$I A(8)= \pm 2 H$ SF-ERODE

CALL FLTSAV LE, IA, ITX, ITY, NFF, TIMX, ATD;

GO TO 999

900 WRITE $(E, 7 R)$

70 FORMAT (1H, $\triangle$ END-RG-FILE REACHED EARLY*, $/ 1$ ) GO TO 999

990 WRITE (E, 71)

71 FOFMAT (1H, *ERROR IN EASEINE CORRECTION INSTRLCTIONS FOR *, $+*$ INPUT DATA*, $/ / / 1)$

GO TO 999

991 WRITE $(6,72)$

72 FORMAT $(1 H$, *ERROR IN EASELINE CCRRECTION INSTRLCTIONS FOR *, +*OUTPUT DATA*, ///)

999 END

SUBRDUTINE FLTSAV (N, ITLT, IXL, IY', NN, XF, YF')

DIMENSION ITLT (1), IXL $\{E, 1), I Y L(E, 1), X F(1), Y F(1)$

WRITE (48, 35) (ITLT(L), $L=1,8$ )

35 FORMAT (BA1Q1)

WRITE $(48,36) \quad(I X L(N, L), L=1,4)$

36 FORMAT (4A1D)

WRITE $\{48,3 \in)$ (IYL $(N, L), L=1,4)$

CALL FMAX (XF, NN. XFMN, XFMX)

CALL FMAX (YF, NN, YFMN, YFMX)

WRITE $\{48,37\} \quad N N, X F M N, X$ IMX, YFMN, YFMX

37 FORMAT (IE, 4E15. B)

NRITE $(48,38) \quad(X P(K), K=1, N N)$

WRITE $(48,38)$ (YF $(K), K=1, N N)$

38 FORMAT (1QE15. B)

RETURN

END

SUEROUTINE FMAX (ARY, NA, XMN, XMX)

$-2$

*****************************************************

THIS SUBROUTINE FINDE THE MAXIMUMS AND MINIMLMS

DF THE VARIOUS ARRAYS TO BE FILOTTED EY FREF'L

$* * * * * * * * * * * * * * * * * * * * * * * * * * * * * * * * * * * * * * * * * * * * * * * * * * * * *$

DIMENSIDN ARY (1) 
C

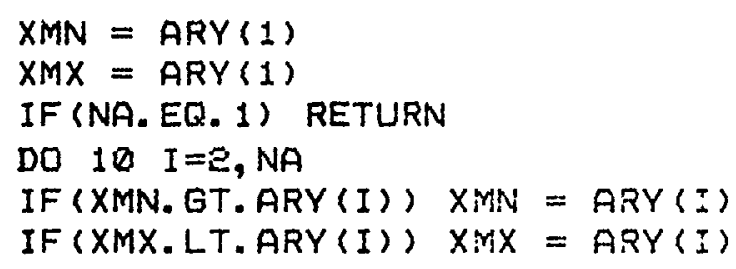




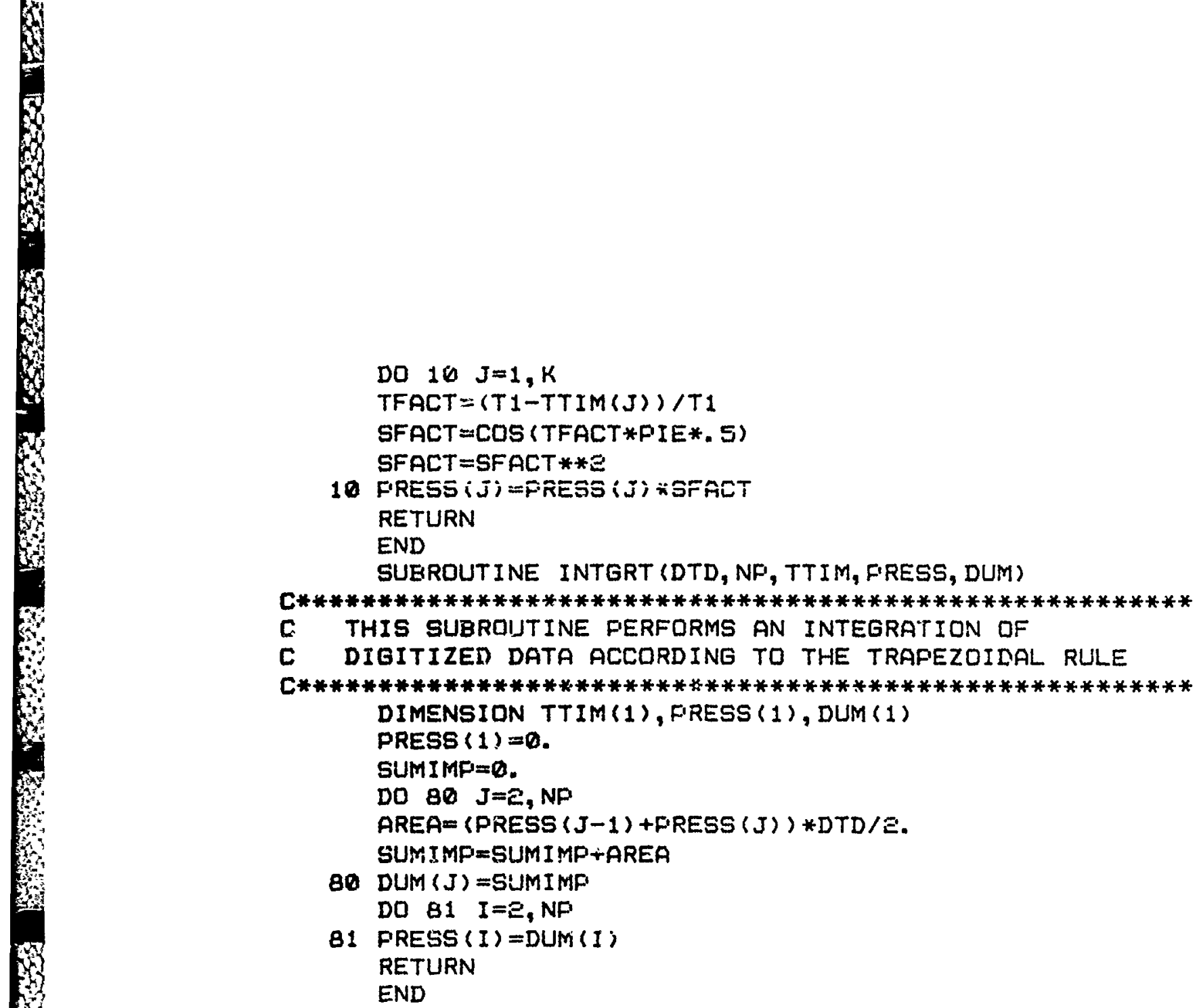


APPENDIX D

LISTING OF PROGRAM FREPLT

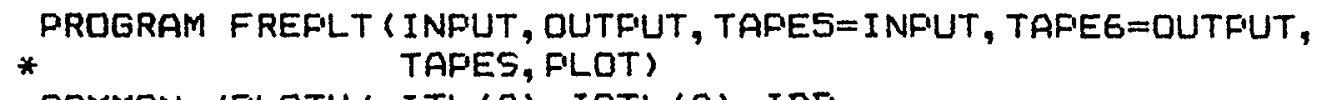

COMMON /FLOTV/ ITL (B), ISTL (B), IDE

COMMON /FID/ NFTS, NSKIF, TFAC, XFAC, AFAC,

* ISPEX, TSFBX, ISPEX, TSPEX, ISPBA, TSPBA, ISFEA, TSPEA,

* IBLX, DELFX, SBX, EEX, IELA, DELFA, SBA, EEA

DIMENSION XARY (GQRQG), YARY (SRRQR), LABX (4;, LAEY (4)

CALL GPLOT ( $1 \mathrm{HU}, 7$ THRABING, 7)

CALL RENAFL (-1)

READ $(9,111)$ NFTS, NSKIF, TFAC, XFAC, AFAC

READ ( 9,115 ) ISPEX, TSFEX, ISPEX, TSFEX, ISPBA, TSFEA, ISFEA, TSFEA

READ $(9,112)$ IBLX, DELPX, SBX, EEX

READ ( 9,112$)$ IELA, DELFA, SBA, EBA

111 FORMAT (EIS, 3E1Q.3)

$11 \Xi$ FORMAT (IS, 3E10.3)

115 FORMAT (4(IS, E10.3))

$N F L T=8$

DO 10 ID $=1$, NFLT

$\operatorname{READ}(9,1 \geq 0)$ (ITL (I), $I=1,8)$

120 FORMAT (BA10)

121 FORMAT (4A1Q)

$\operatorname{READ}(9,1 \geq 1)$ (LABX (I), I=1,4)

$\operatorname{READ}(3,1 \geq 1)$ (LAEY $(I), I=1,4)$

READ ( 9,130$)$ NEFTS, XFMN, XPMX, YFMN, YFMX

130 FORMAT (I5, 4E15.8)

READ $(9,140)$ (XARY (K), $K=1$, NEPTS)

READ ( 9,140 ) (YARY (L). L $=1$, NEFTS)

140 FORMAT (1QE15.8)

$I K=1$

IF (ID.LT.6) GO TO 10

IF (ID.LE. E. OR. ID.EQ.6. OR. ID.EQ. B) GO TO 151

C NEFTS $=150$

C XFMX $=2390$.

151 CONTINUE

CALL FLDTTER (XAFY, YARY, NEFTS, XFMN, XFMX, YFMN, YFMX, IK, LABX, LAEY)

CALL ENDFL $(-1)$

10 CONTINUE

CALL GDONE

END 


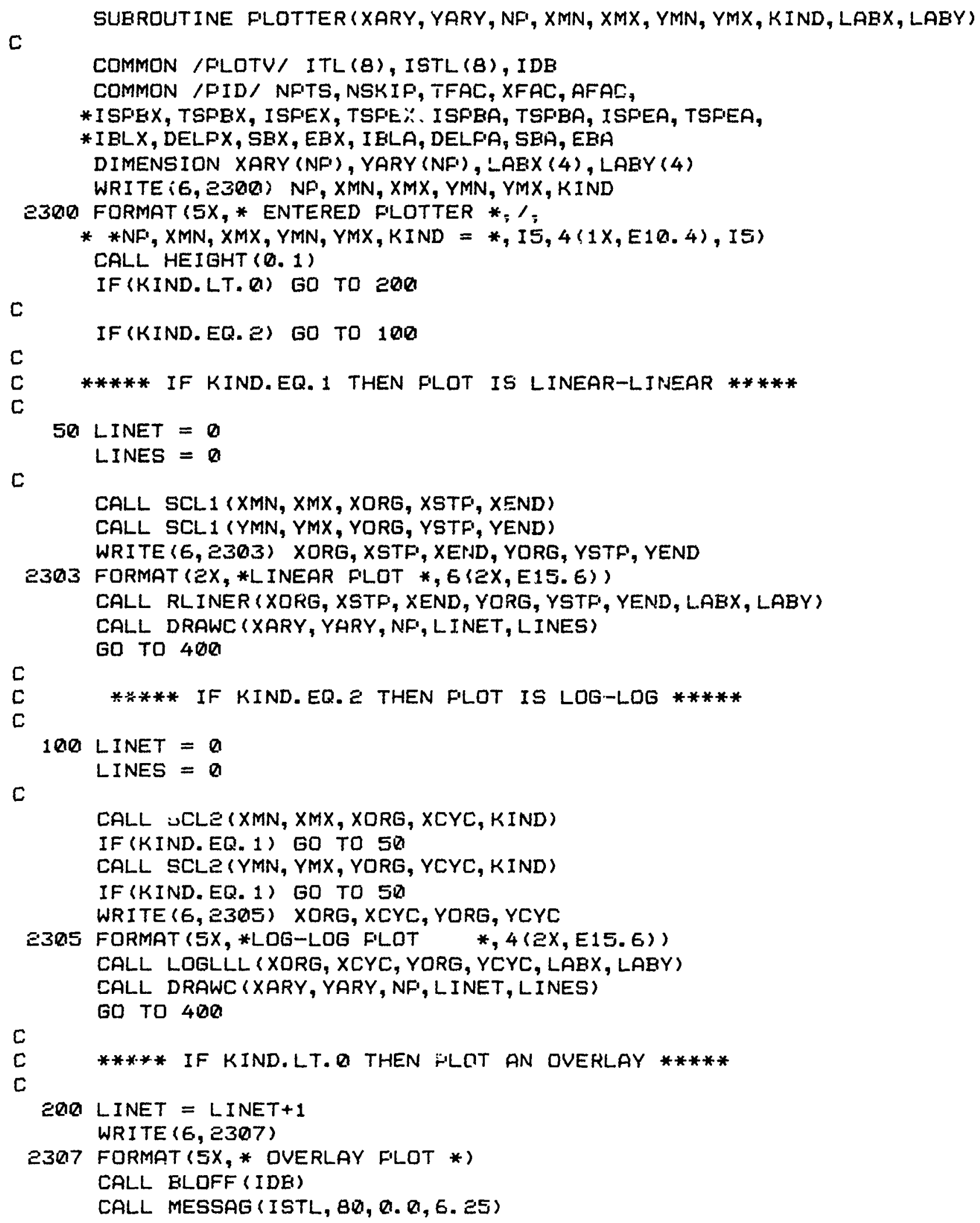




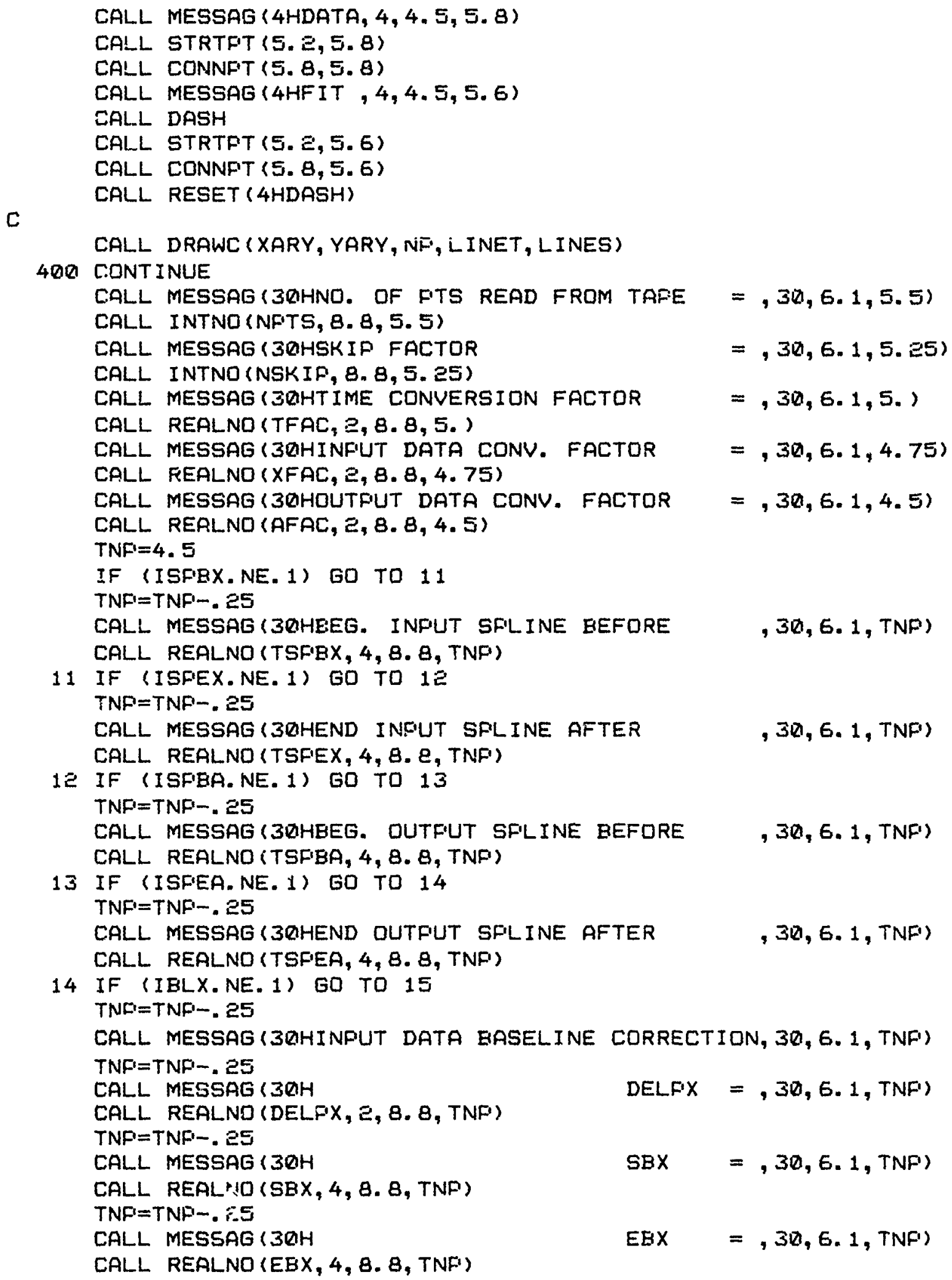




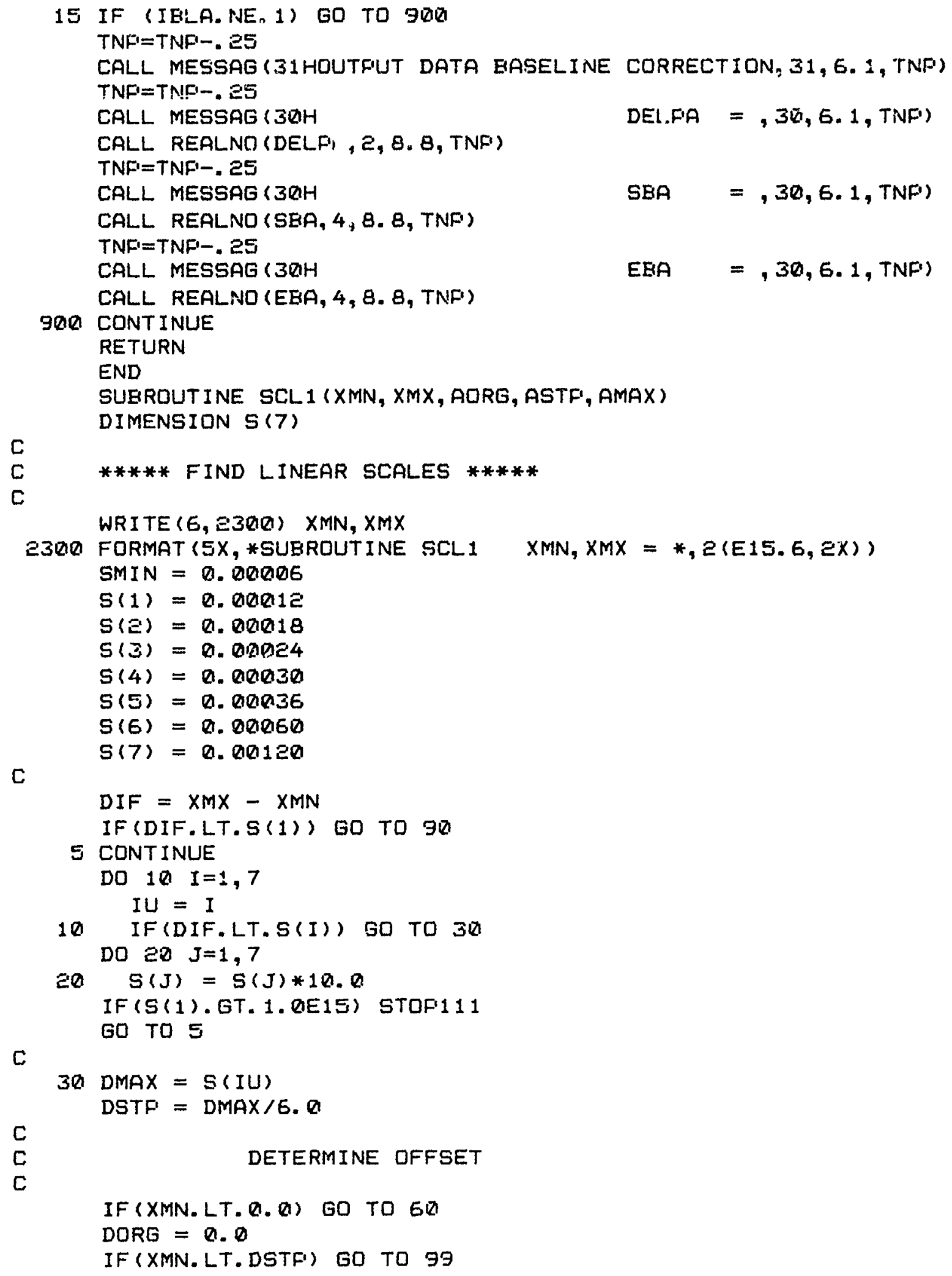

IF \&XMN.LT.Q. (a) GO TO EQ DORG $=0.0$ IF (XMN. LT.DSTF') GO TO 99 


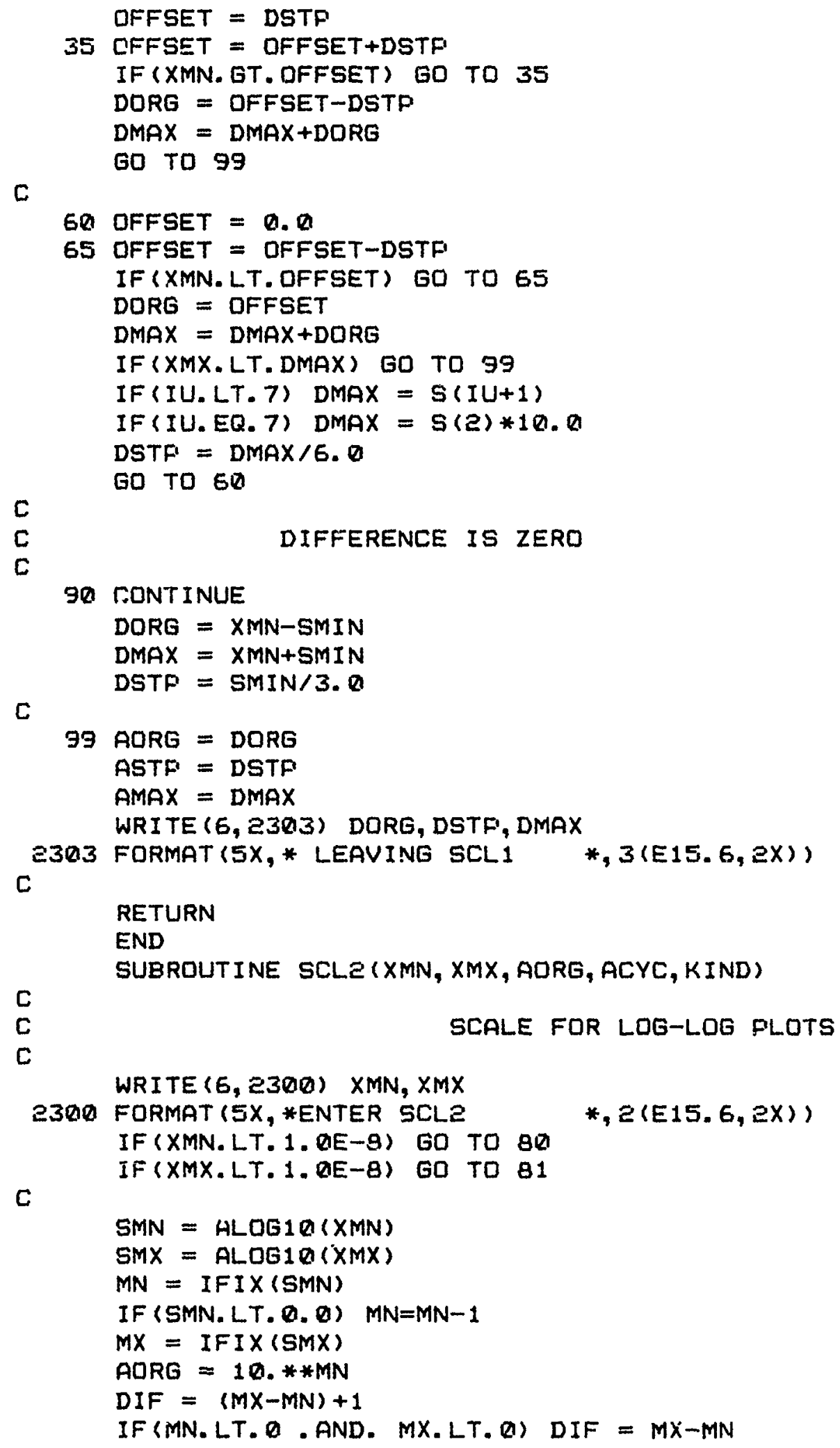




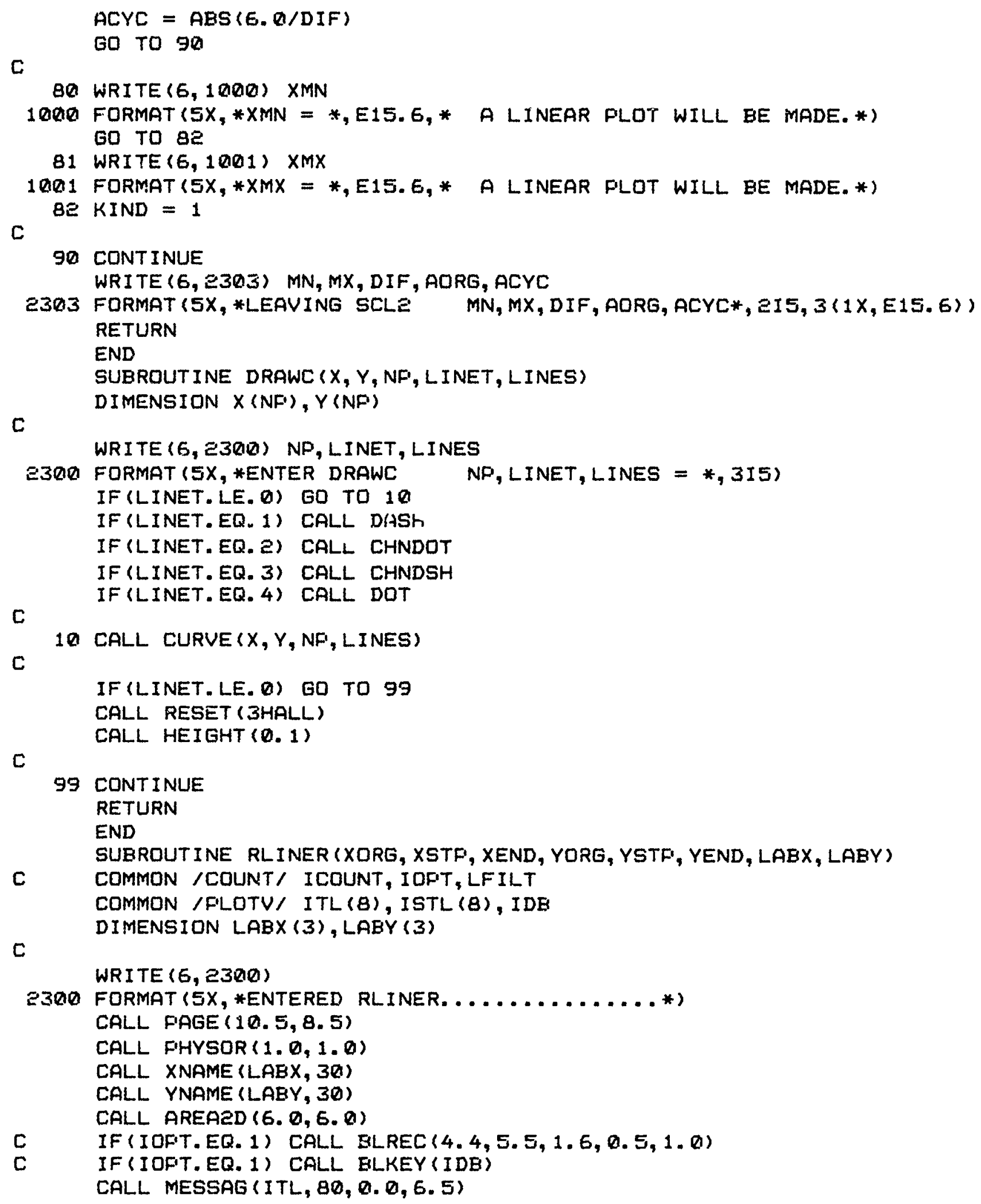




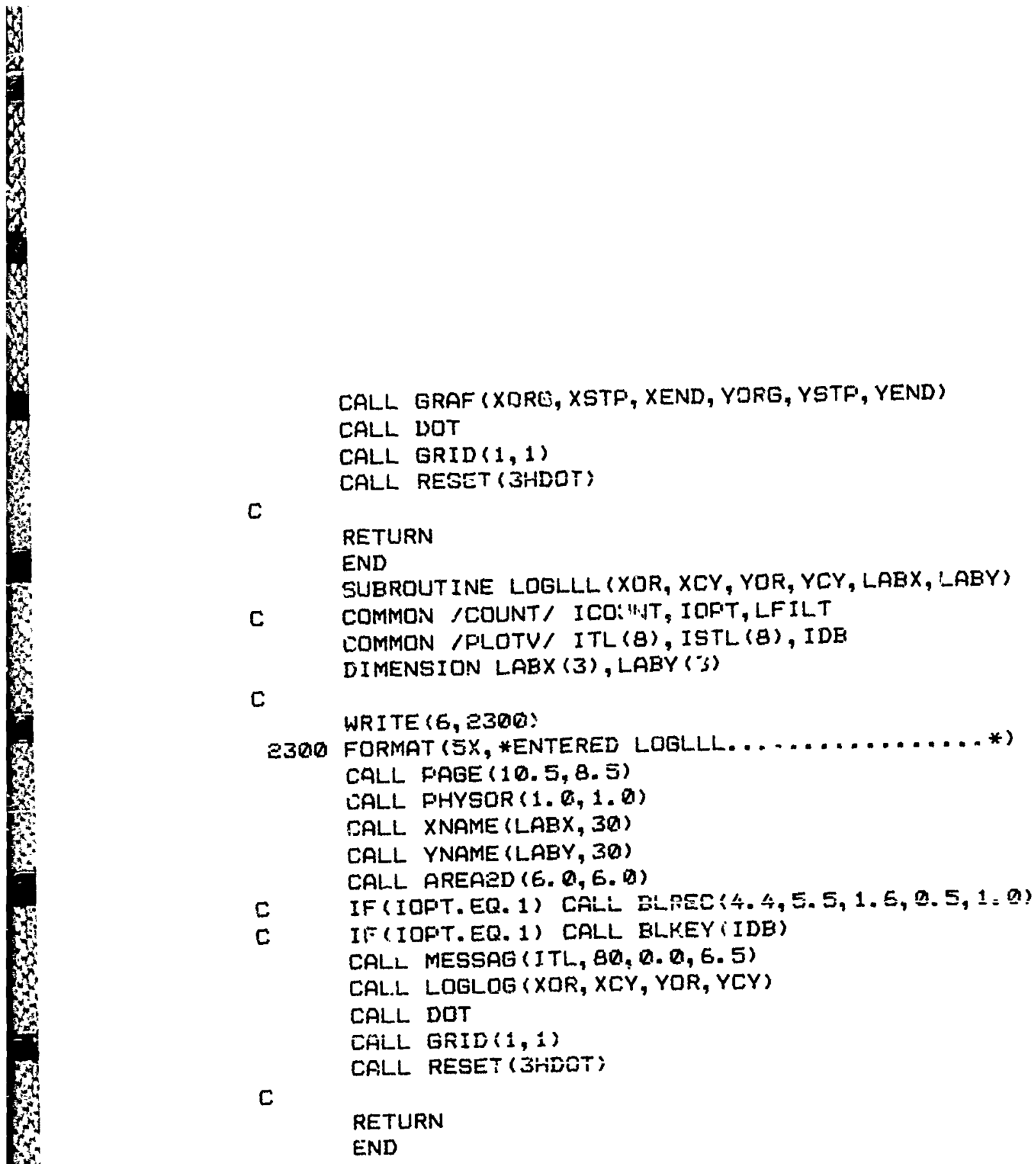


Input $x(t)$

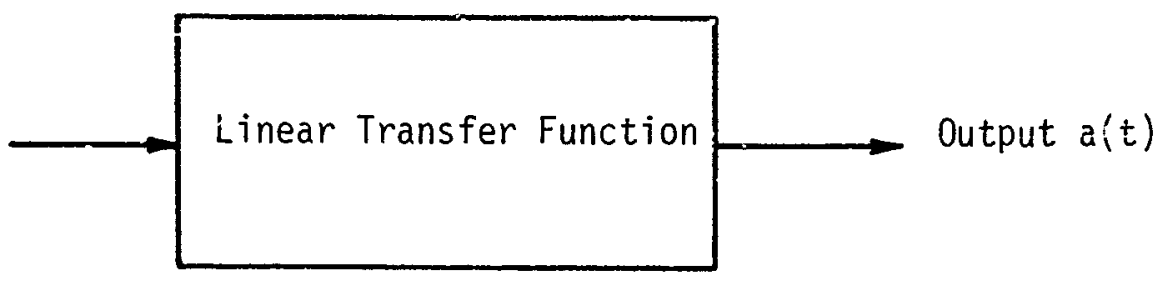

Figure 1. Linear cause-effect relationship between two data records. 


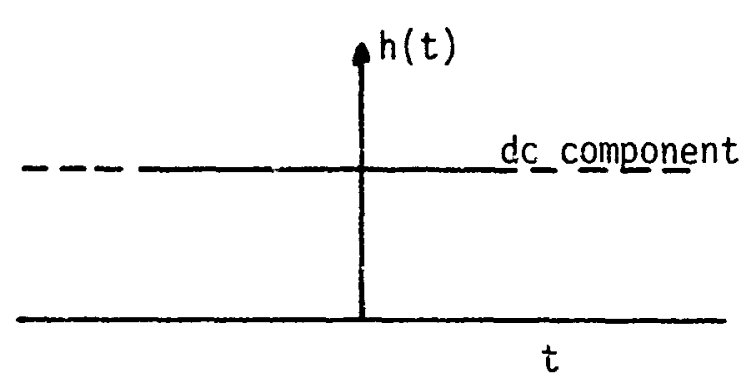

Constant time history

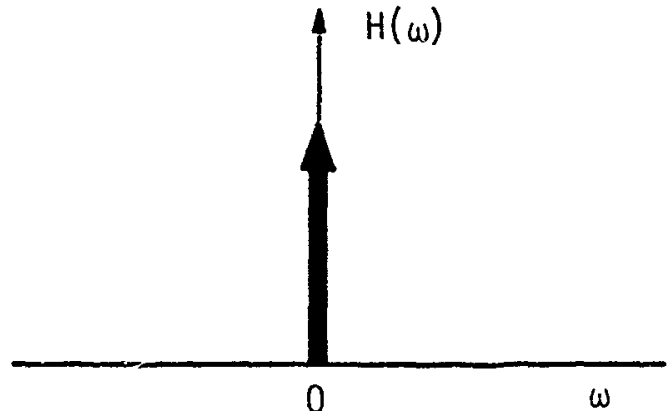

Fourier transform

Figure 2. Constant time history and its Fourier transform. 


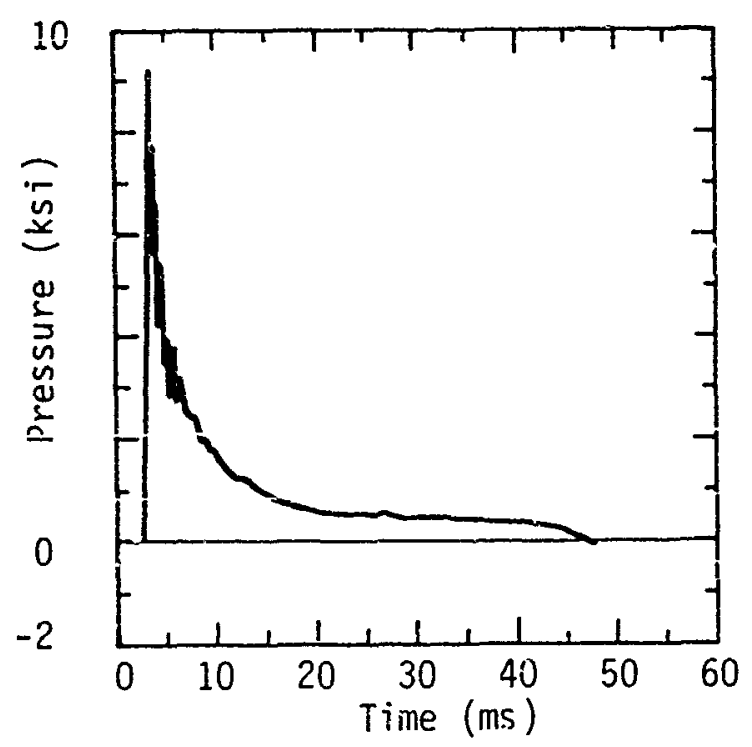

(a) Record \#6 iime history

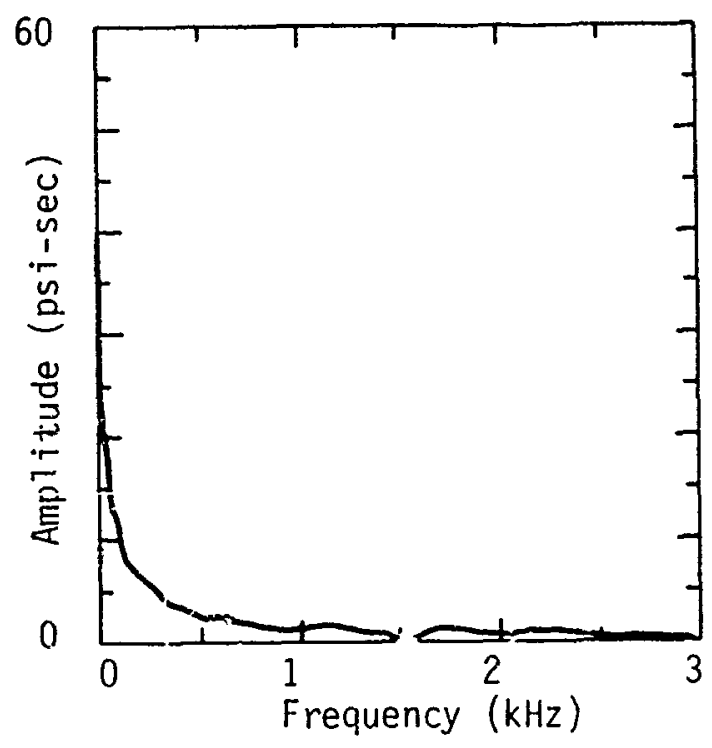

(b) Record \#6 FFT

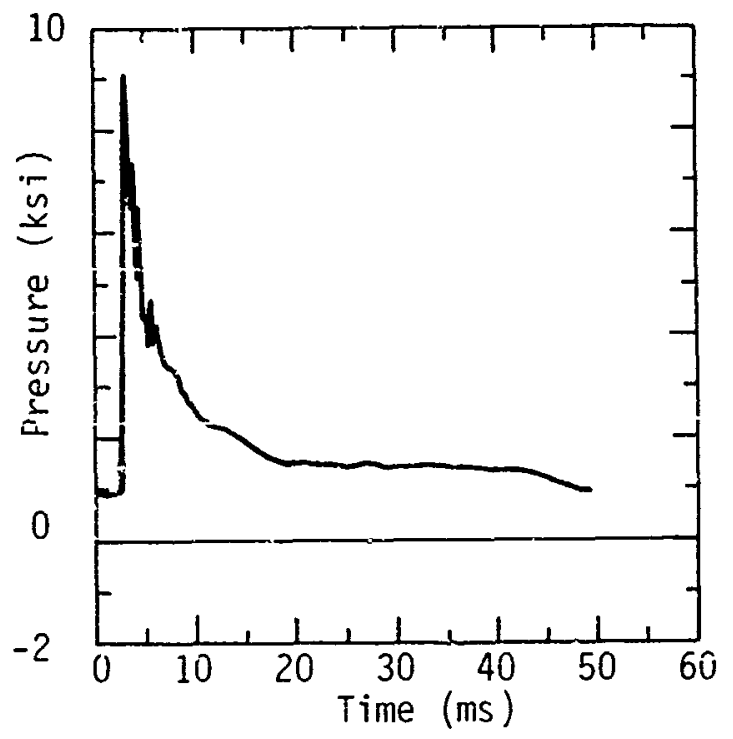

(c) Record \#6 after direct Inverse FFT

Figure 3. Illustration of an original time history, an FFT, and an Inverse FFT. 


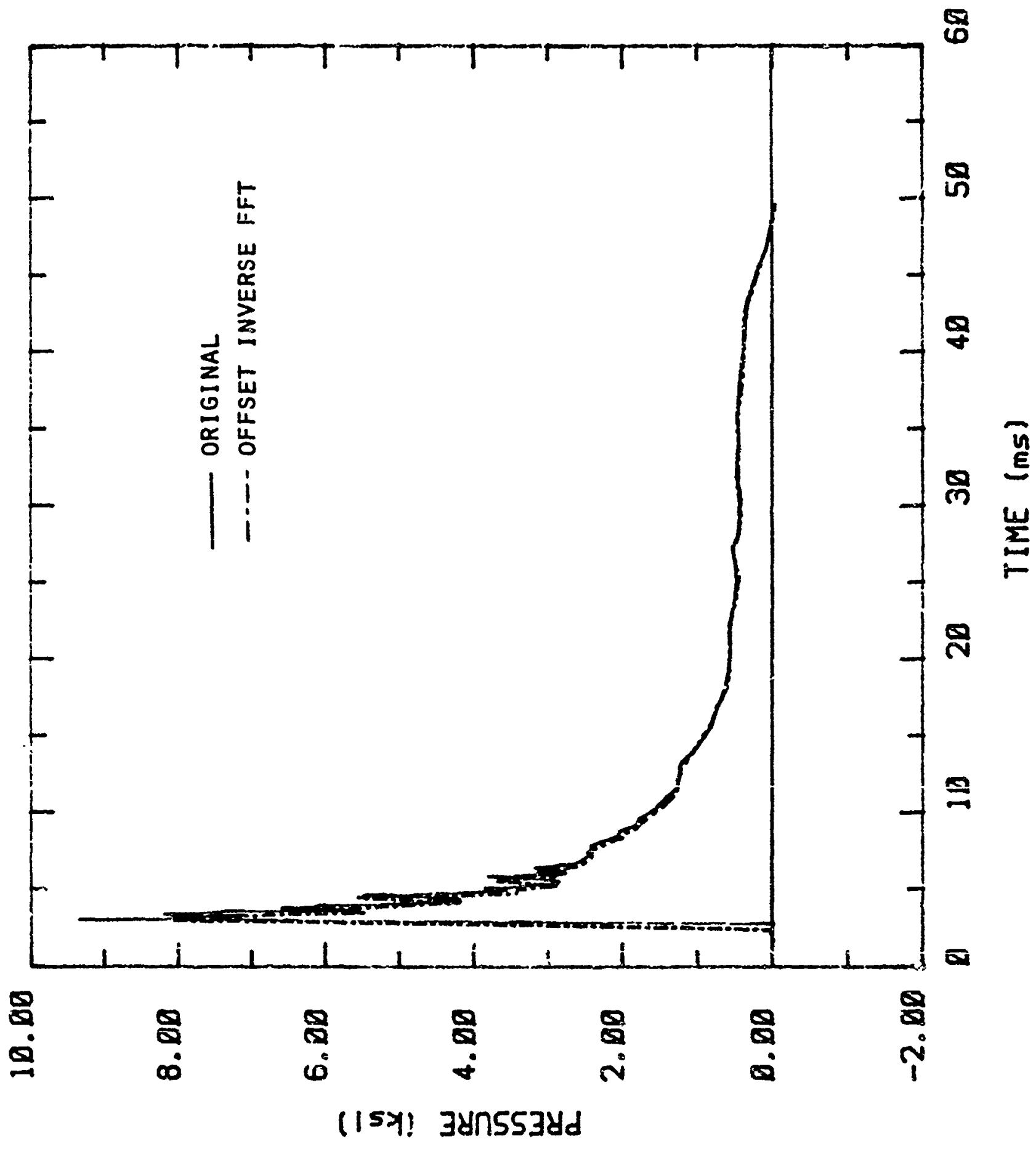

Figure 4. Comparison of the originai record \#6 and an offset Inverse FFT. 


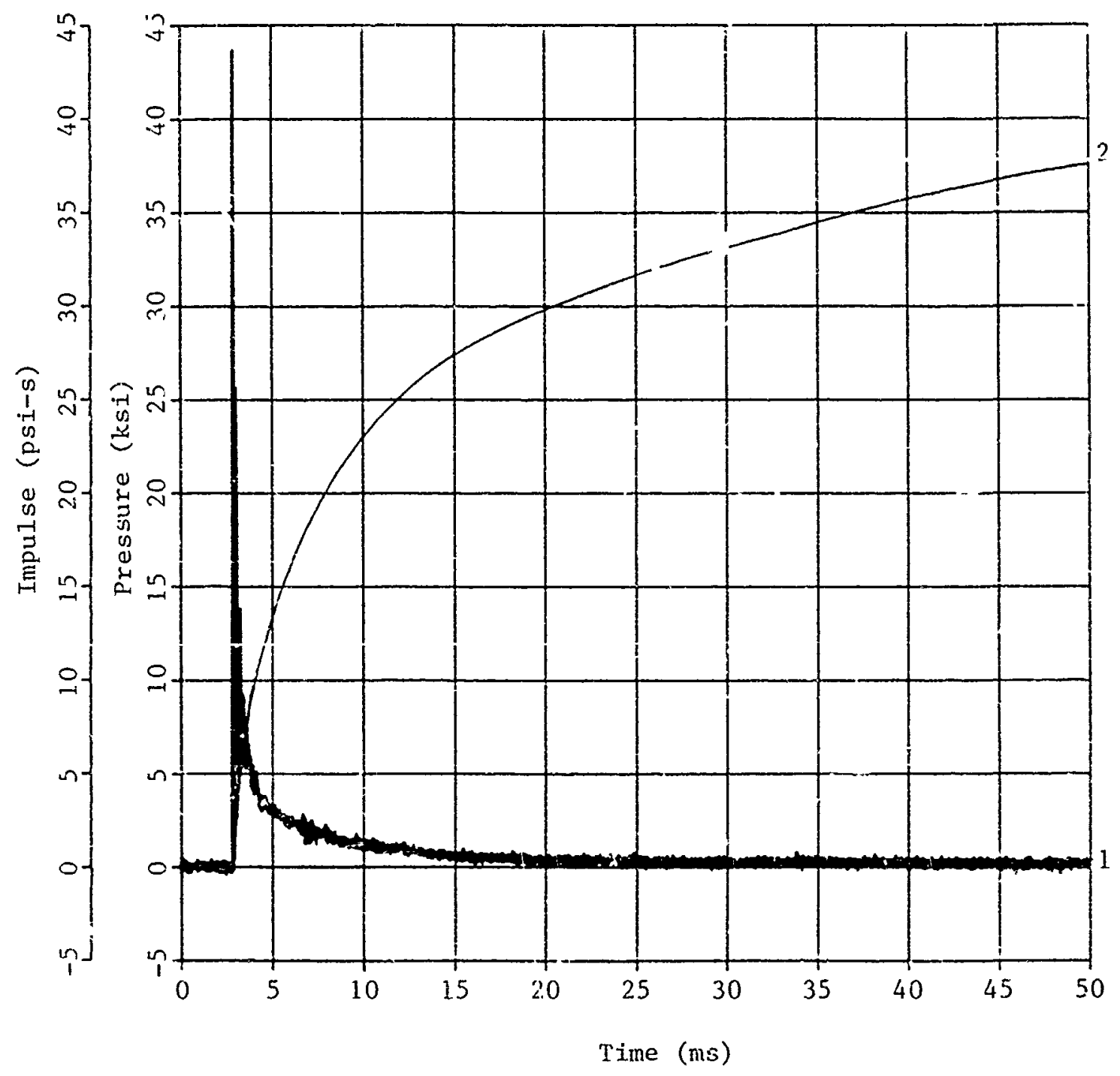

Figure 5. Record \#2, HEST pressure on the structure. 


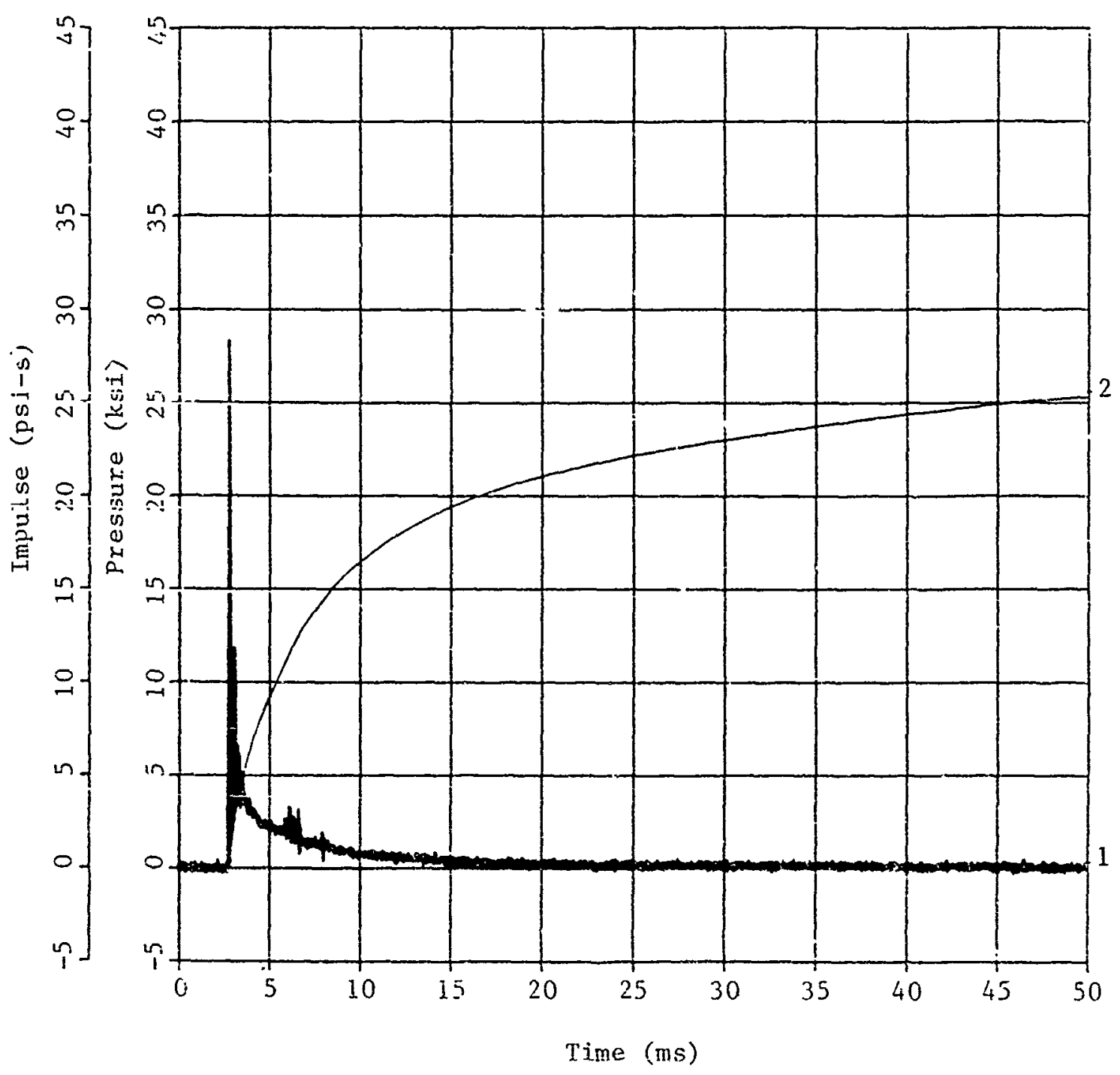

Figure 6. Record \#4, HEST pressure on the soil. 


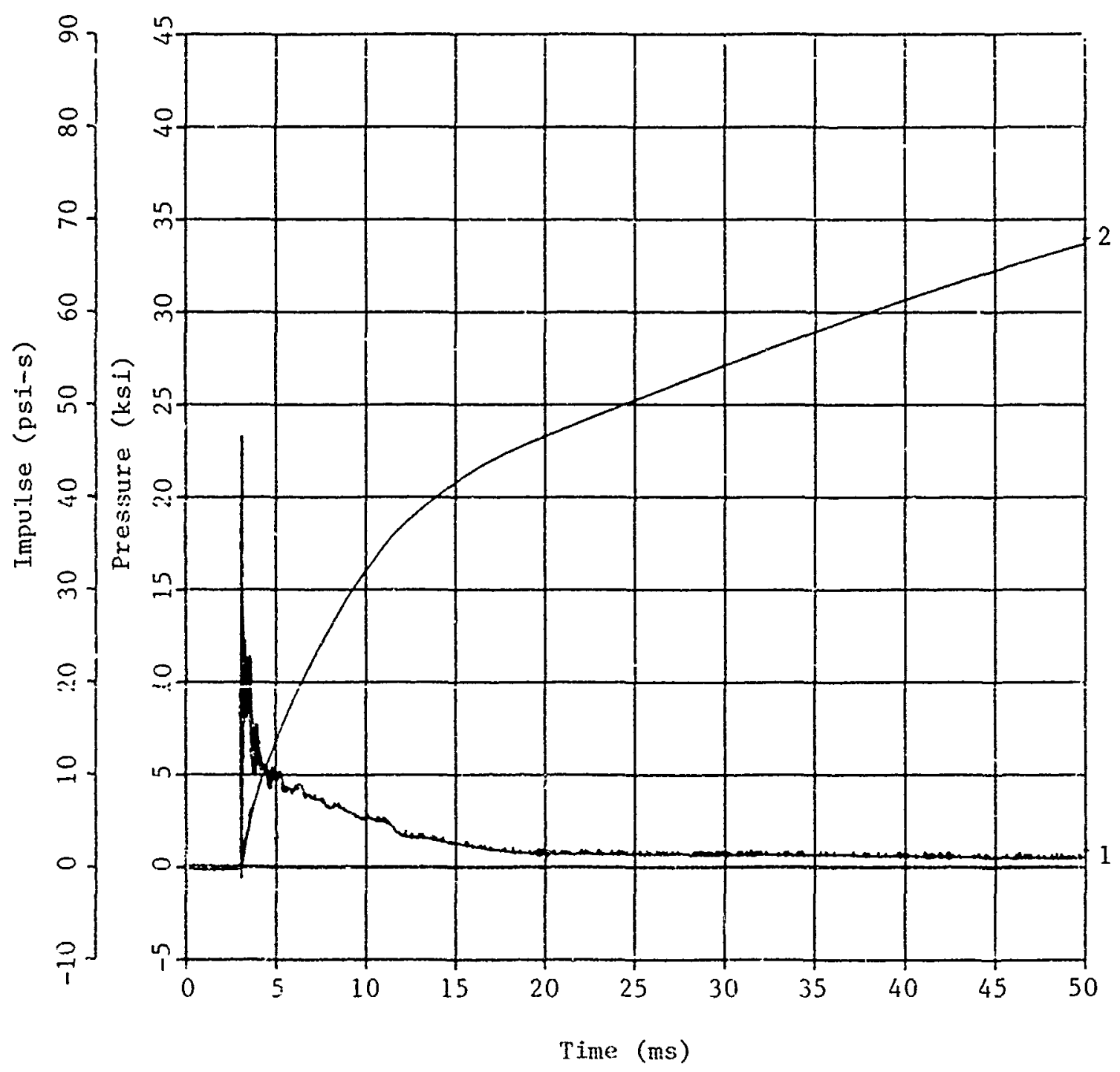

Figure?. Record 35 , soil pressure at $0.5^{\prime}$ depth. 


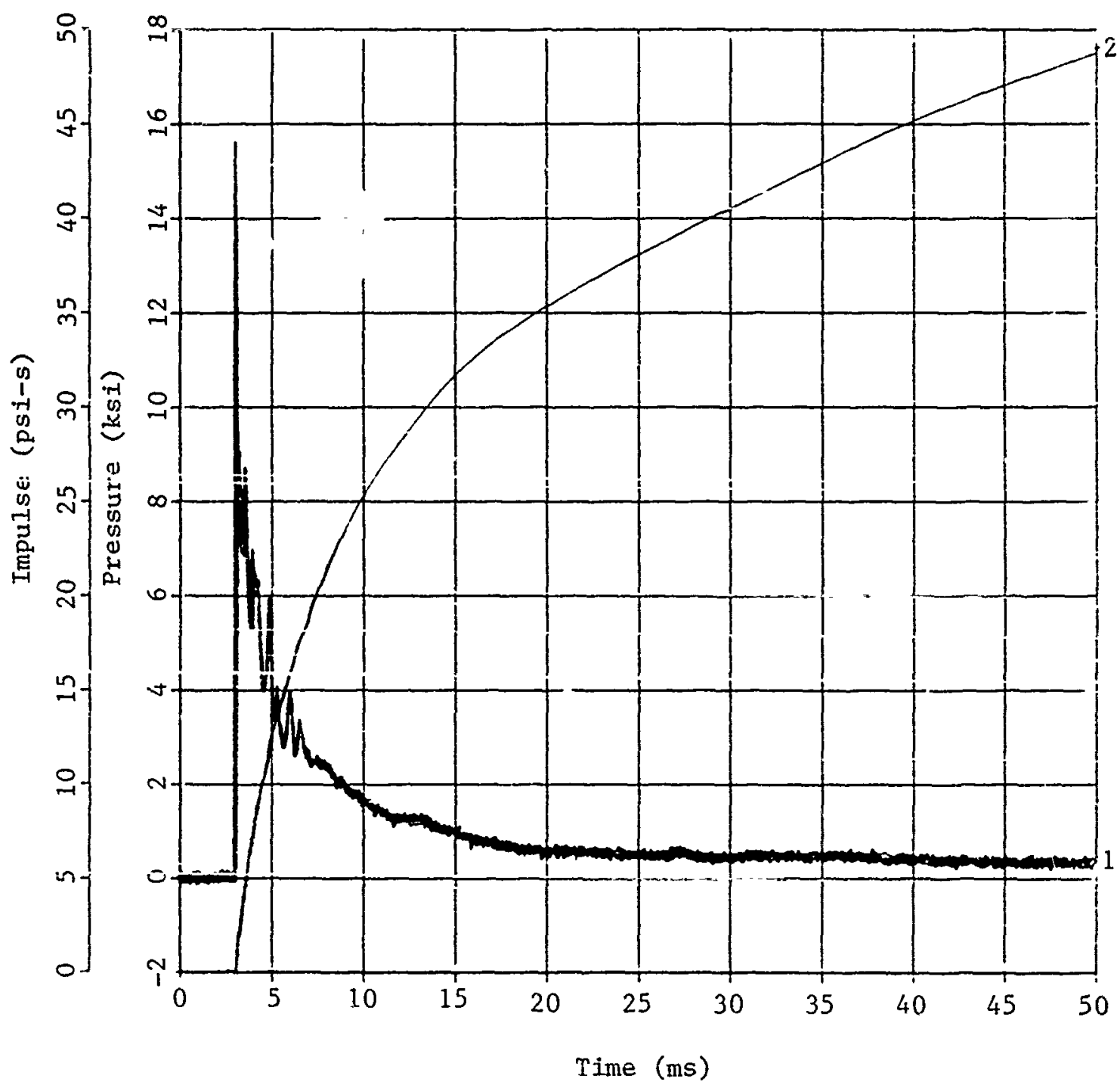

Figure 8. Record \#6, soil pressure at $0.5^{\prime}$ depth. 


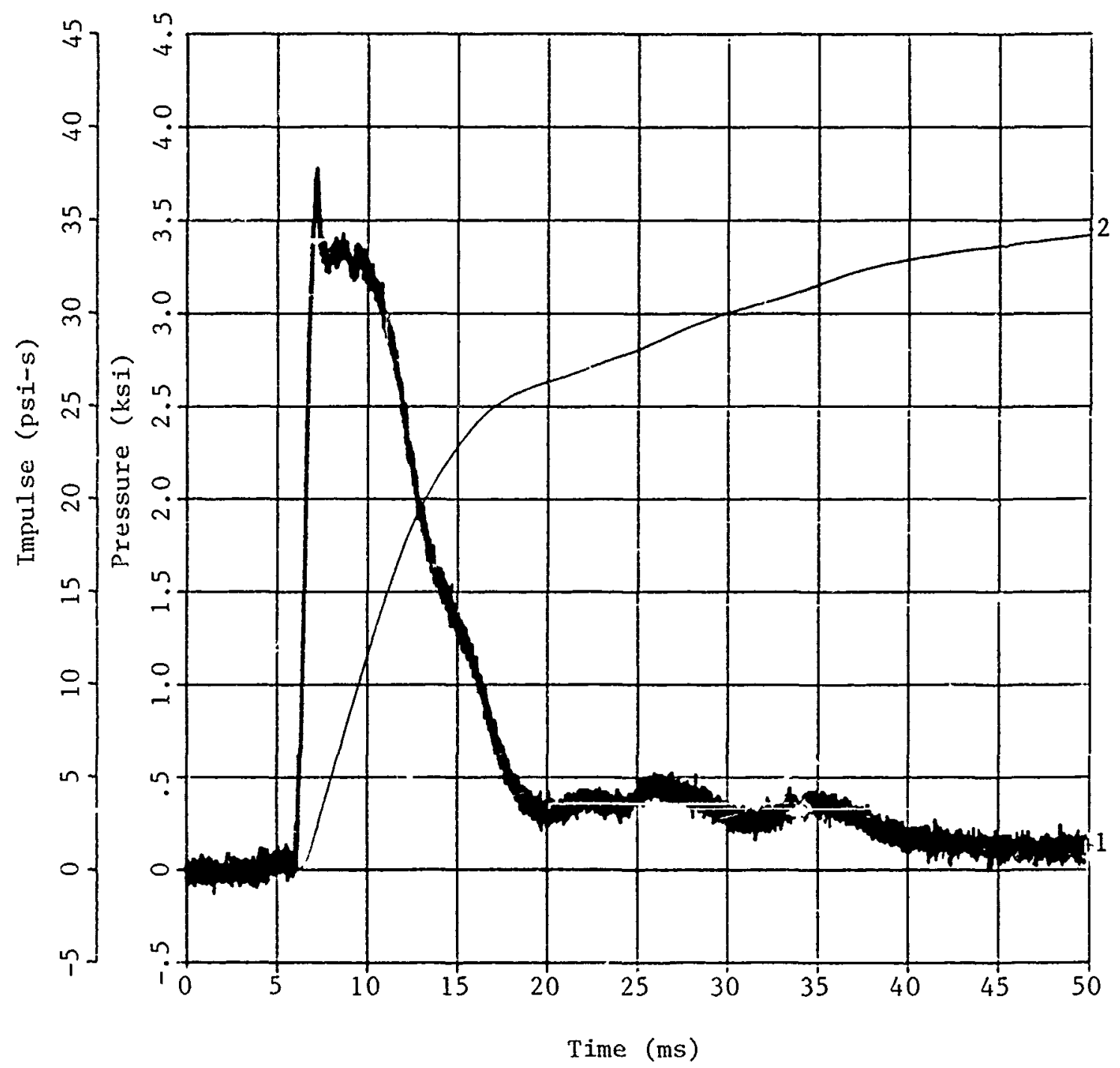

Figure 9. Record $\$ 7$, soil pressure at $5.21^{\prime}$ depth. 


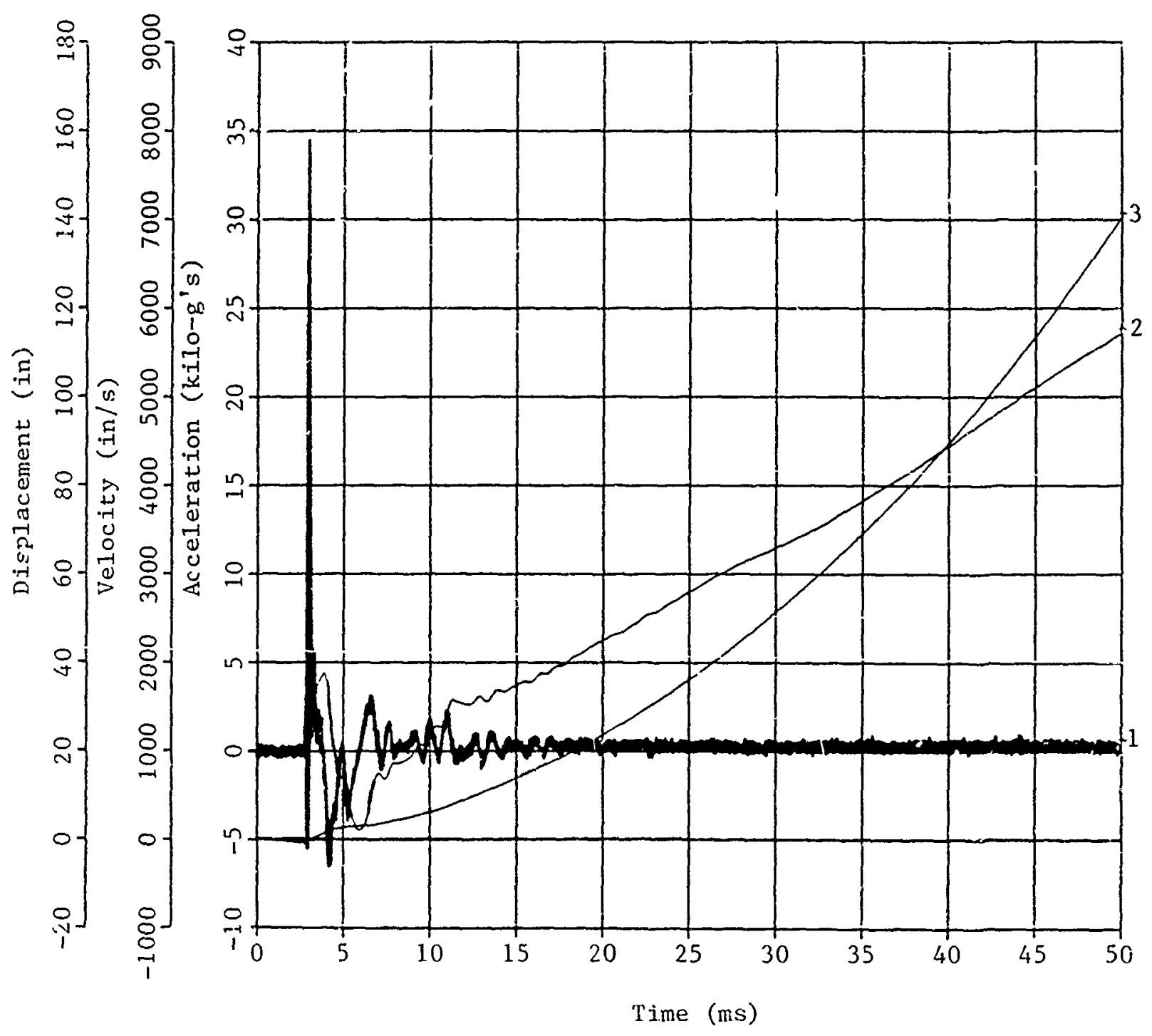

Figure 10. Record \#8, vertical structure acceleration at $0.83^{\prime}$ depth. 


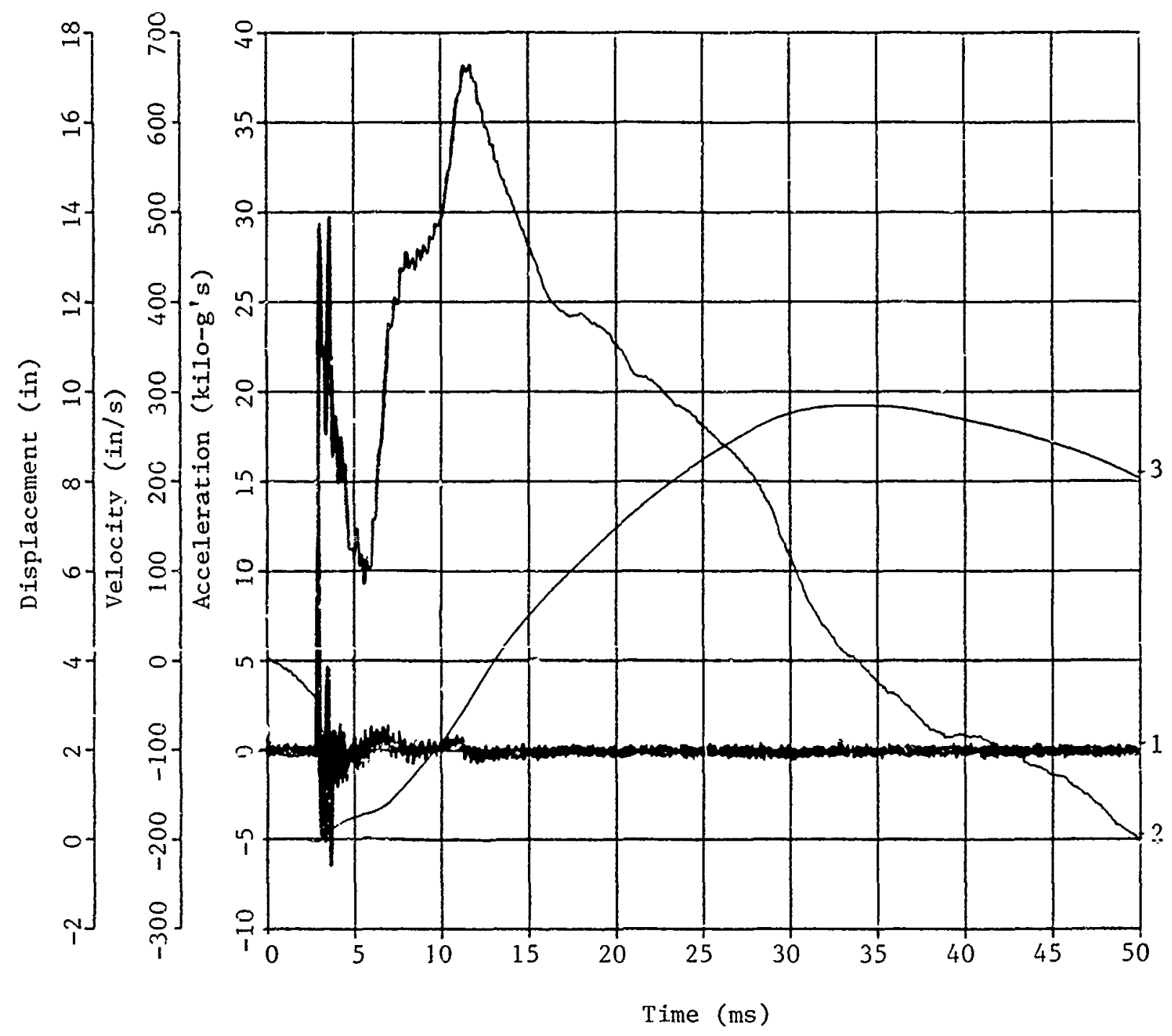

Figure 11. Record \#9, vertical structure acceleration at $3.28^{\prime}$ depth. 


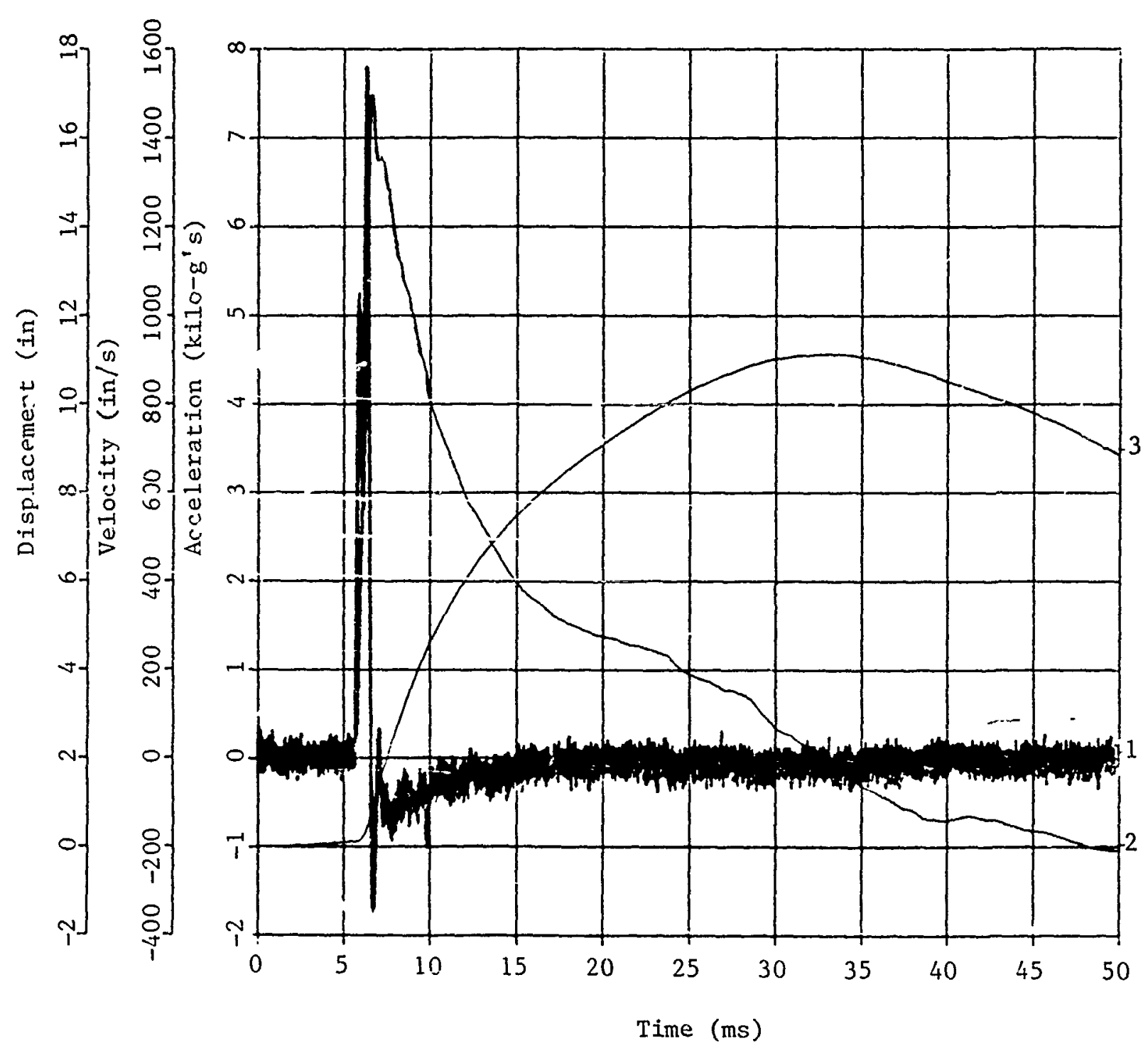

Figure 12. Record \#10, vertical soil acceleration at 5.21' depth. 


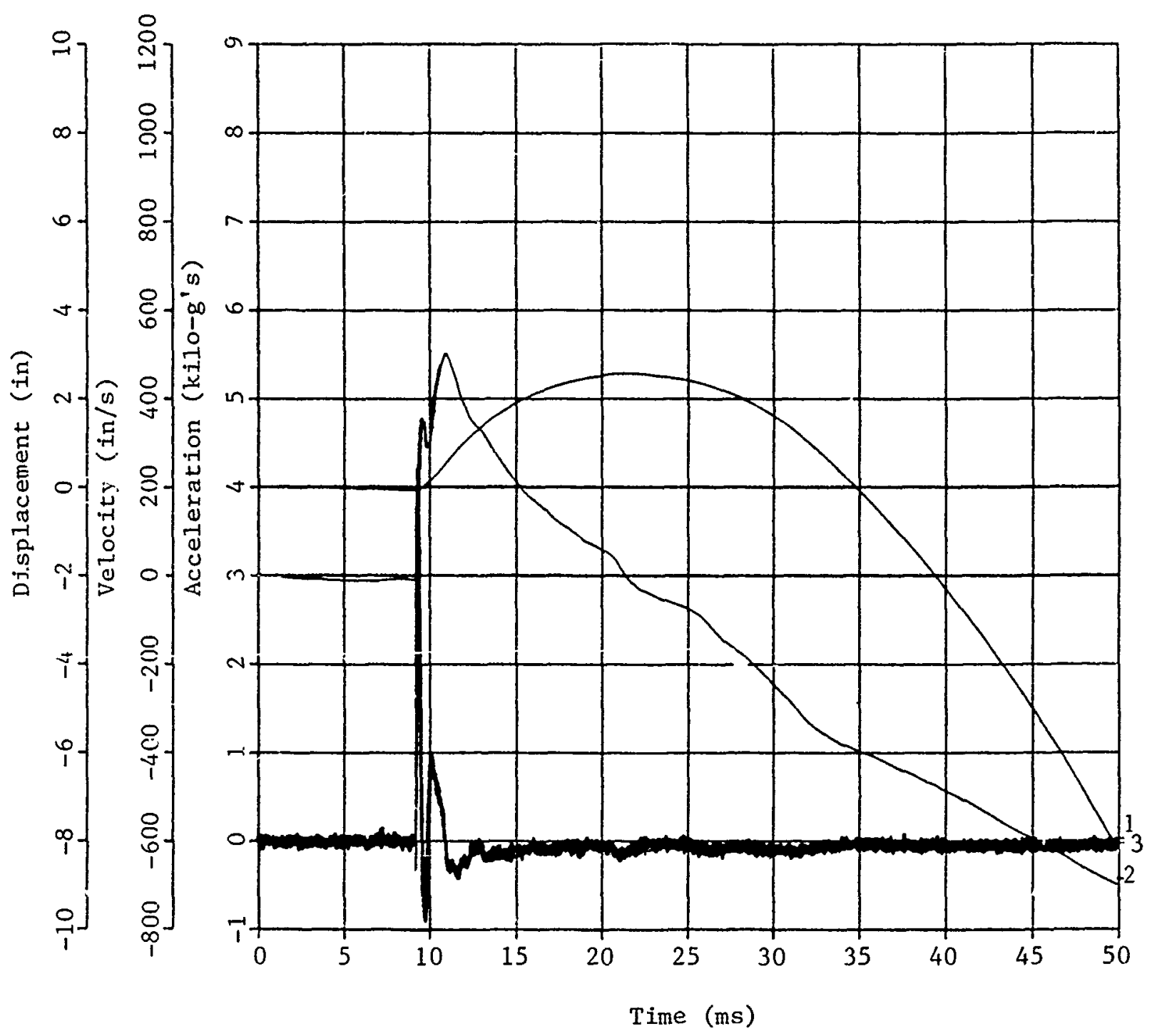

Figure 13. Record \#11, vertical soil acceleration at 12.21' depth. 


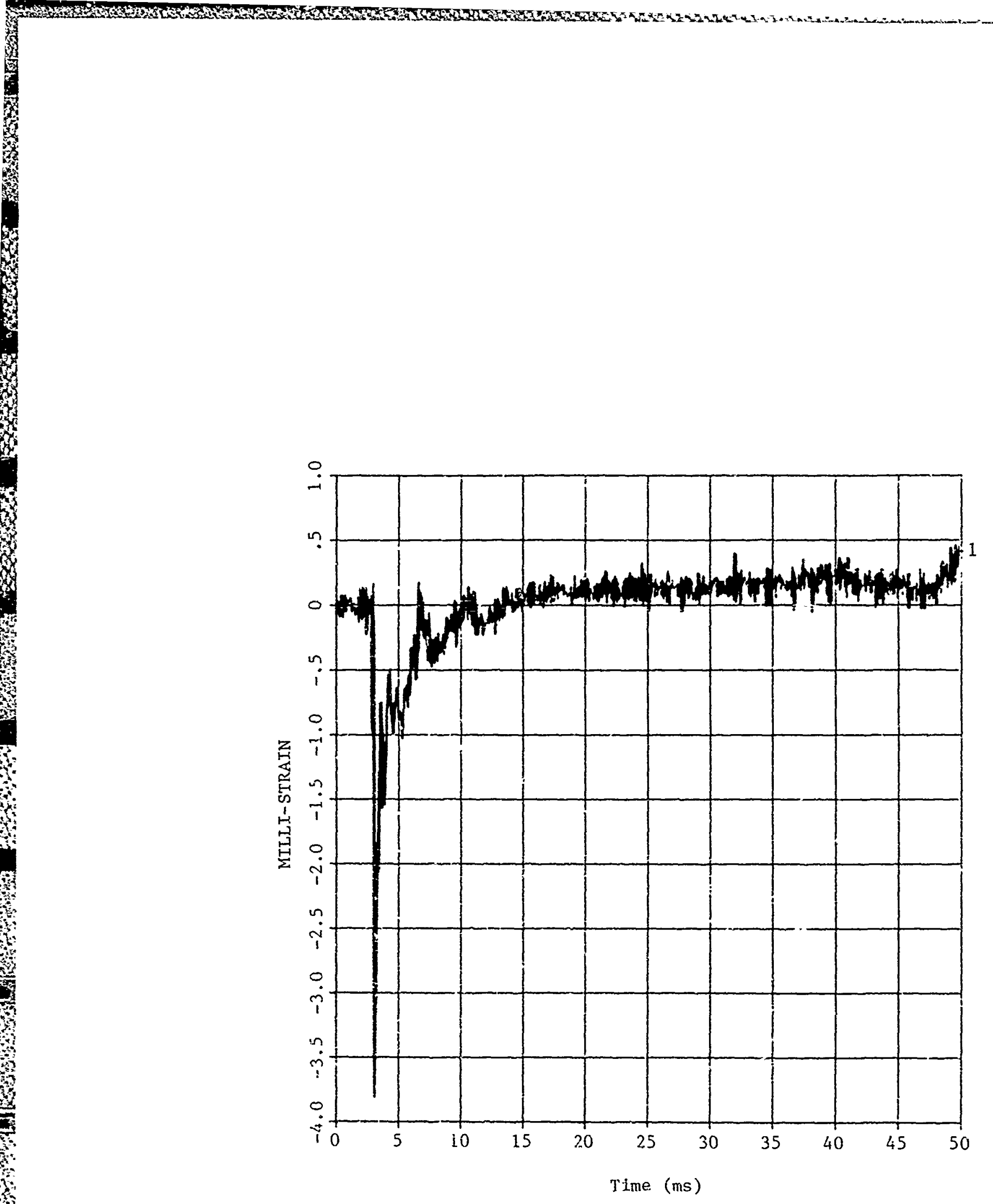

Figure 14. Record \#12, vertical structural strain at $1.29^{\prime}$ depth. 


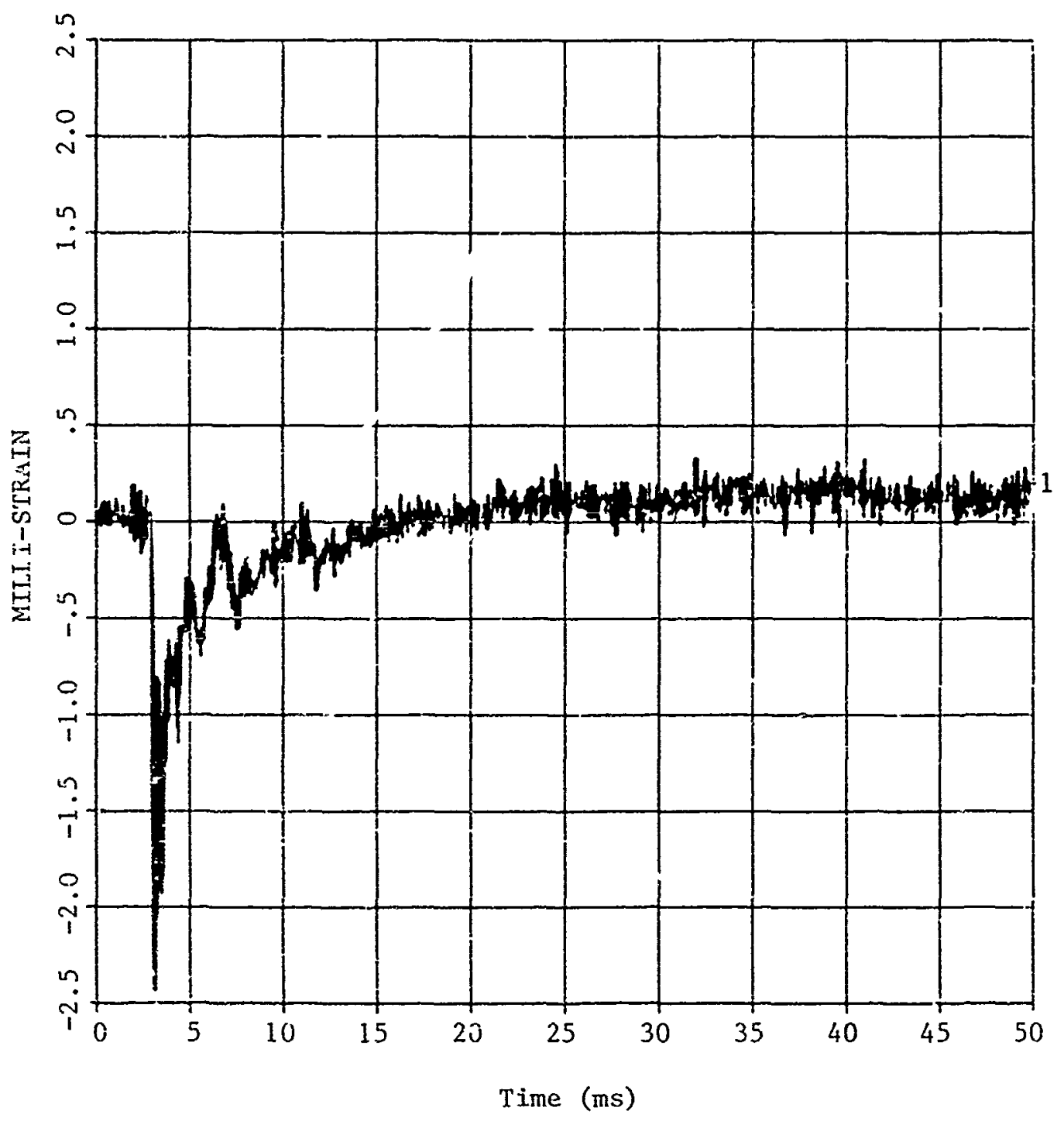

Figure 15. Record \#13, vertical structural strain at $1.29^{\prime}$ depth. 


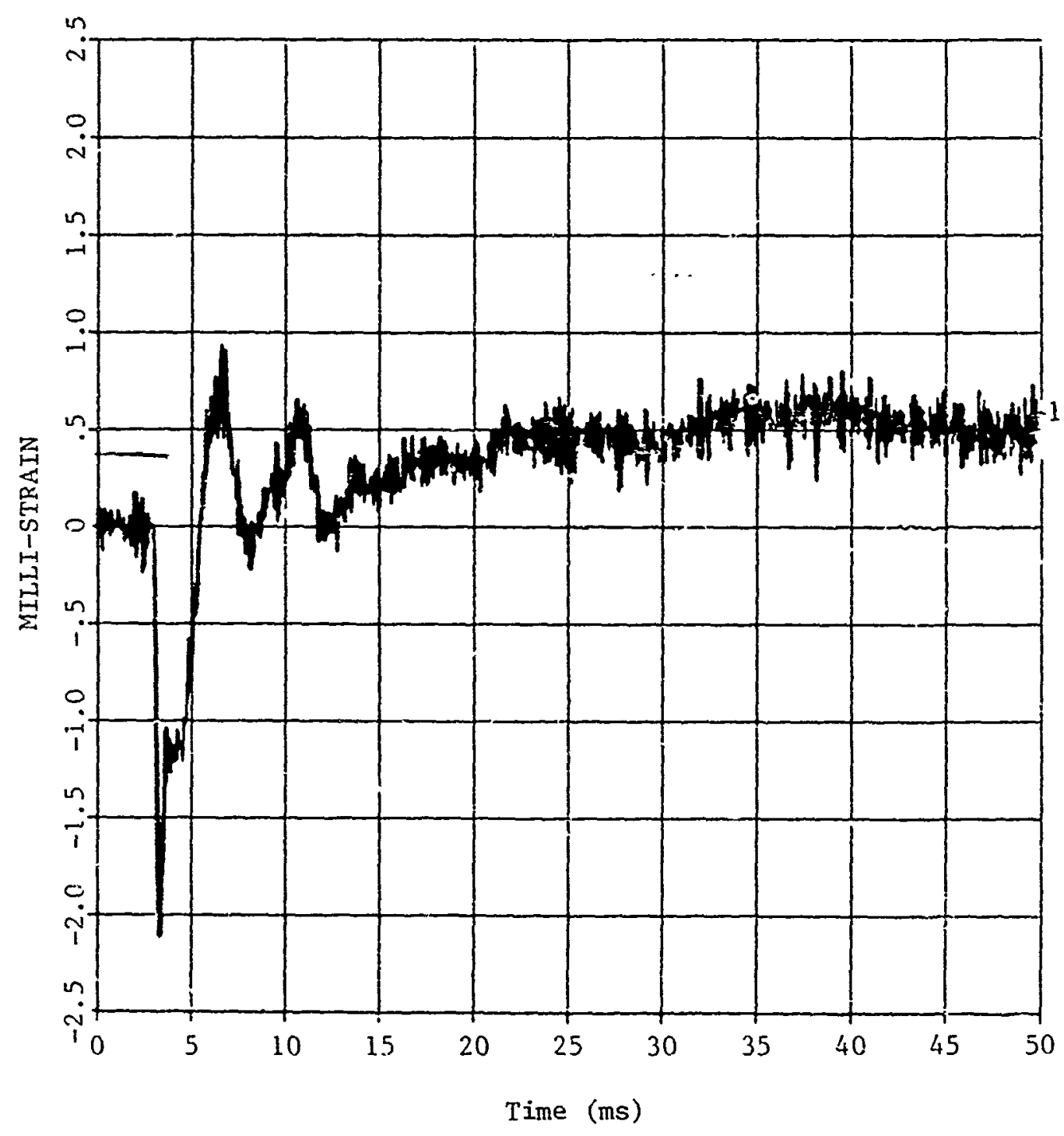

Figure 10. Record $\# 14$, vertical structural strain at $3.33^{\prime}$ depth. 


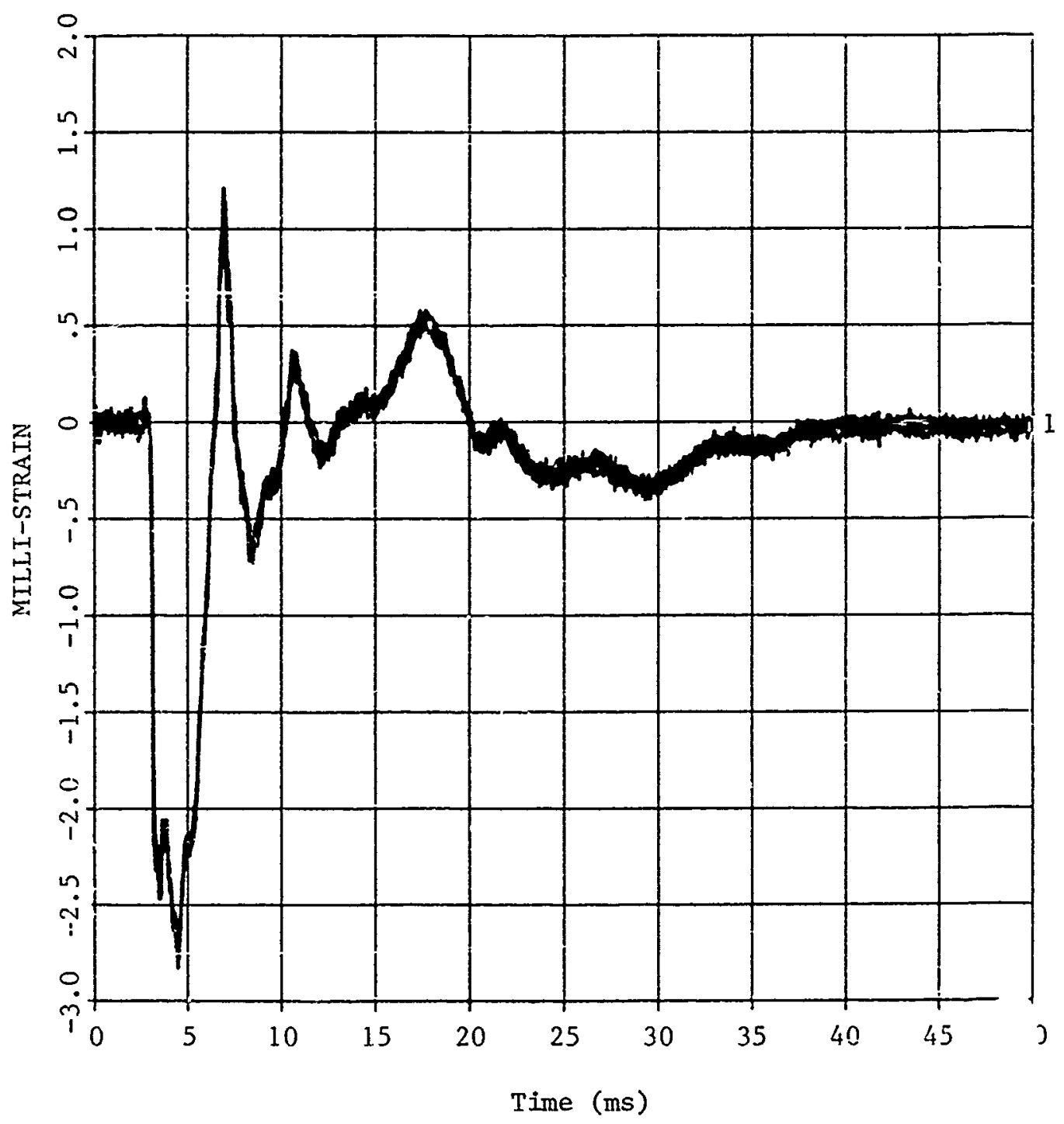

Figure 17. Record \#15, vertical structural strain at $5.21^{\prime}$ dep $\mathrm{h}$. 


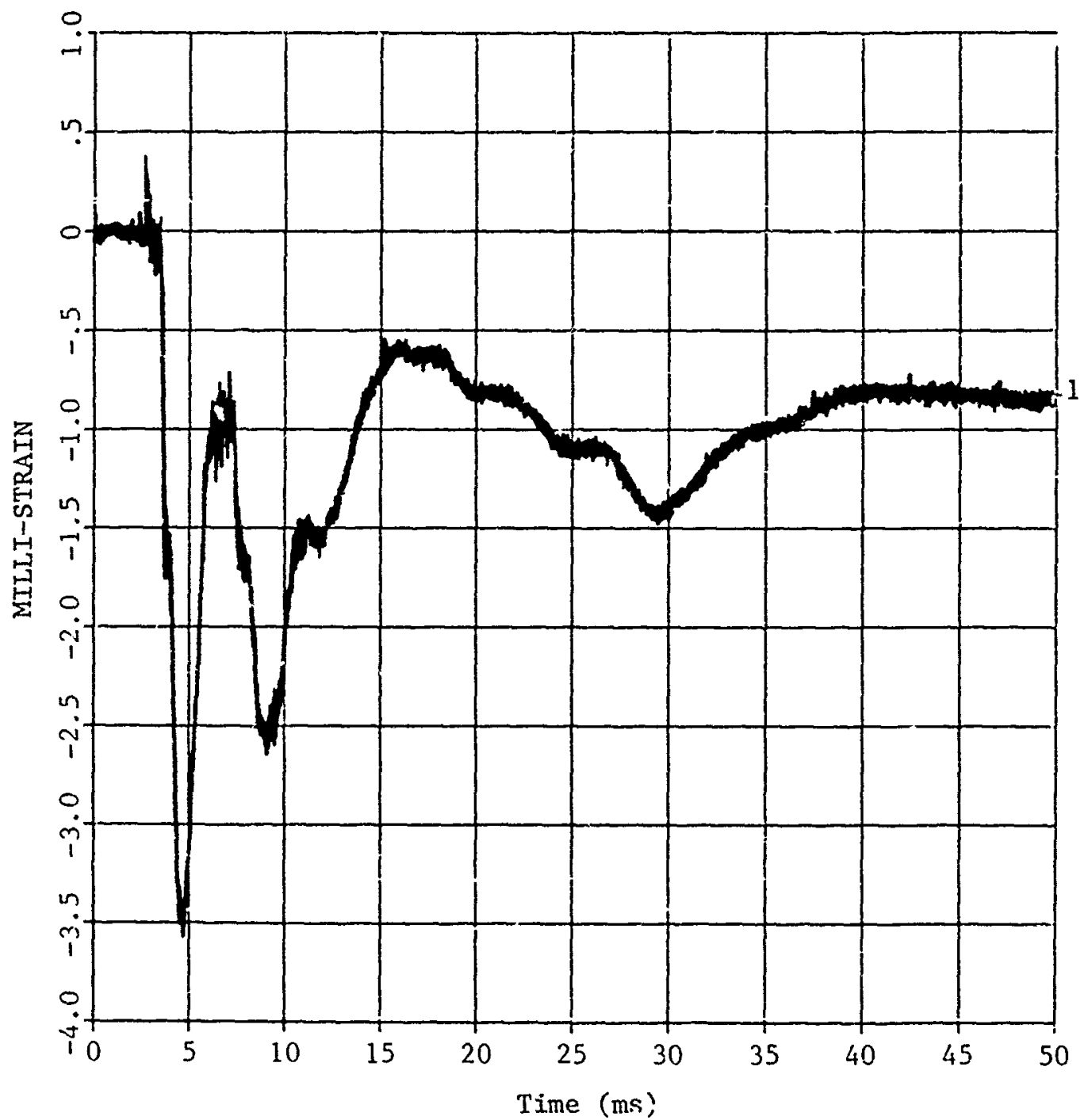

Figure 18. Record \#16, vertical structural strain at 12.21' depth. 


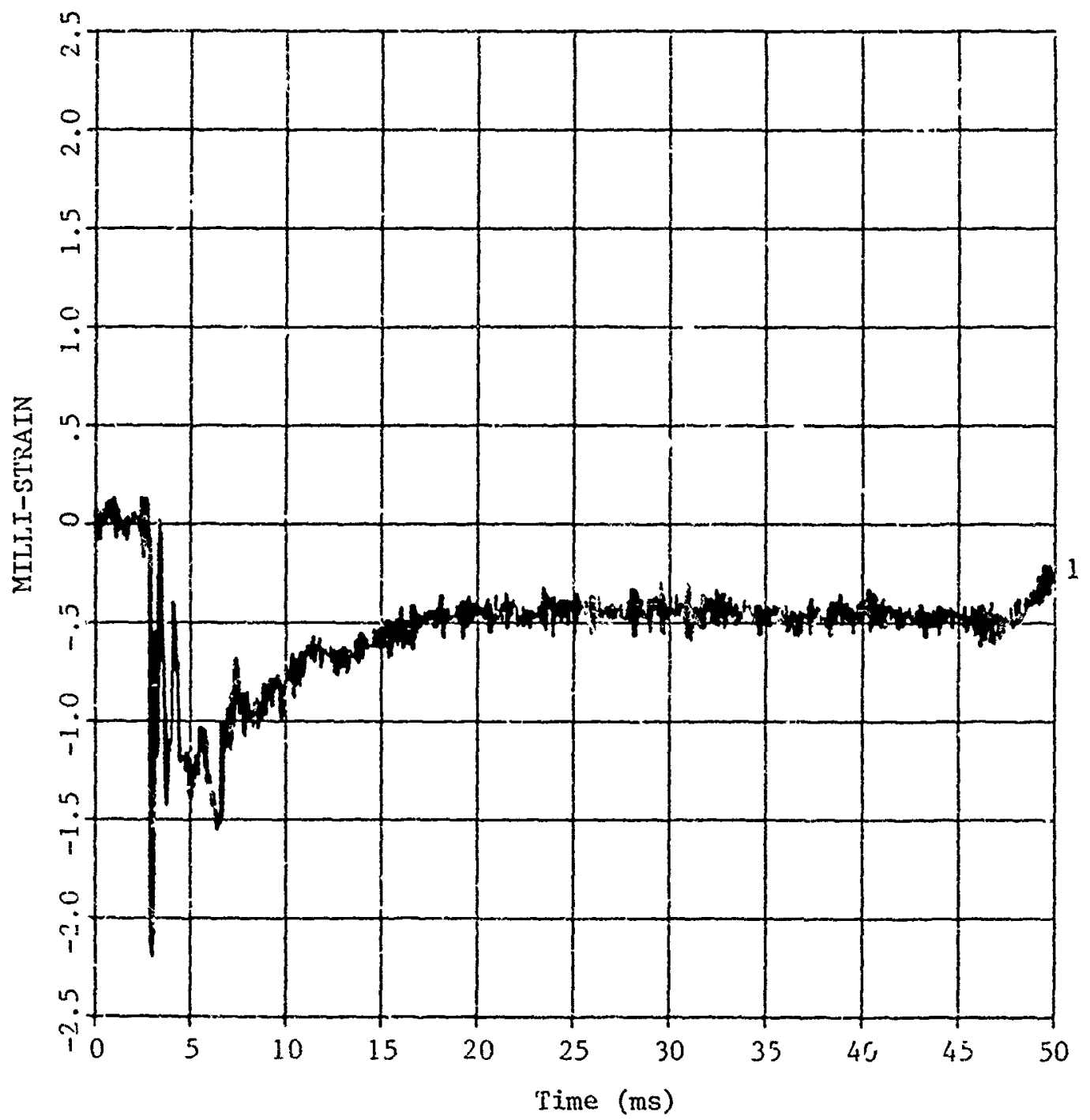

Figure 20. Record \#18, structural hüop strain at $1.29^{\prime}$ depth. 


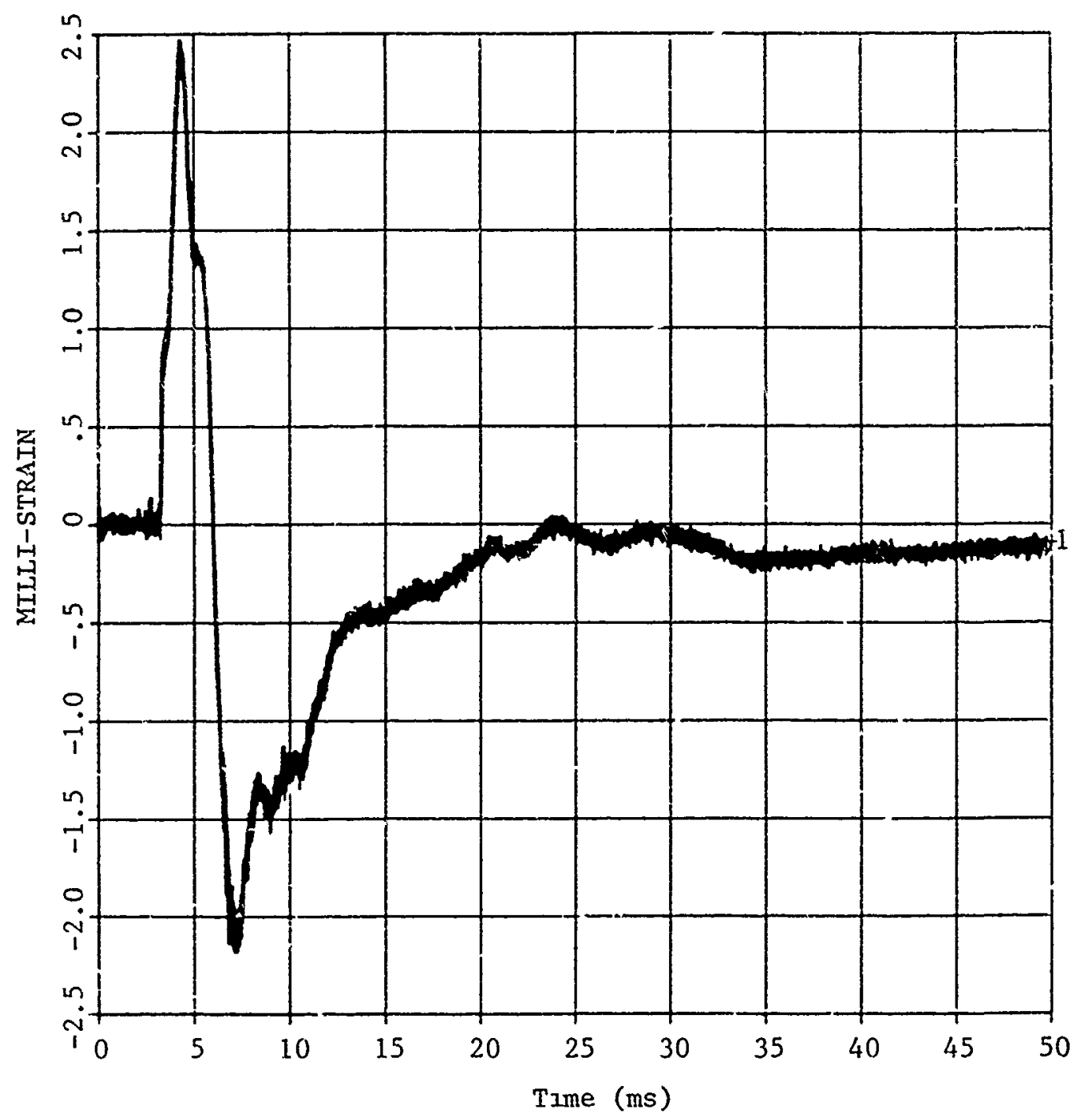

Figure 21. Record \#19, structural hoop strain at $5.29^{\circ}$ depth. 


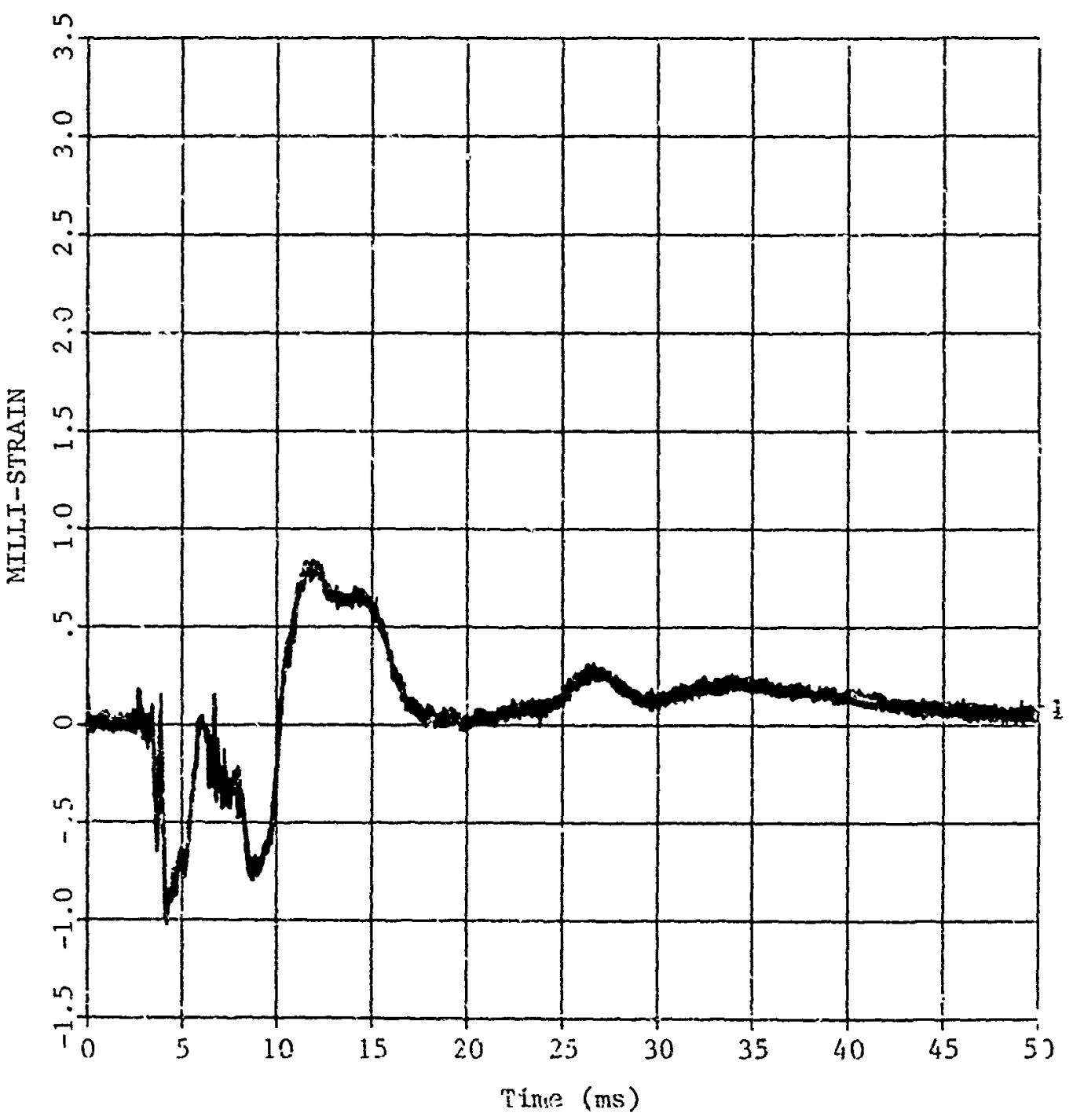

Figure 22. Record $\# 20$, structural hoop strain at $12.21^{\prime}$ depth. 


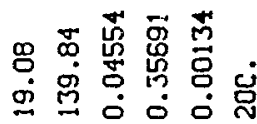

。

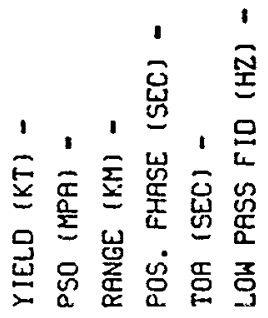

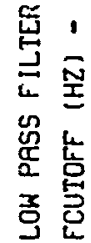

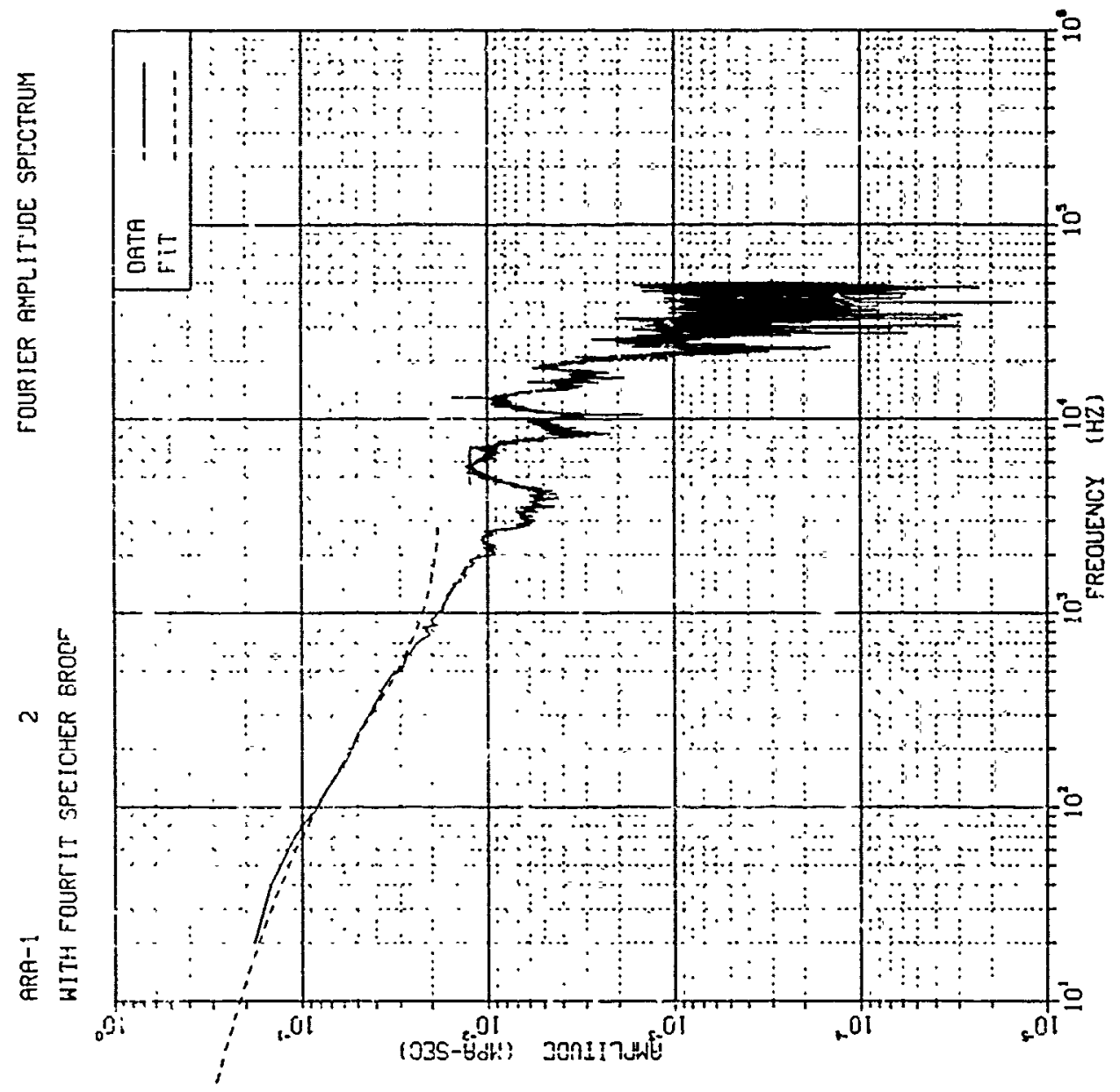

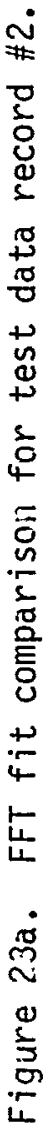

0.5 truscio $504-110-3$ xim 


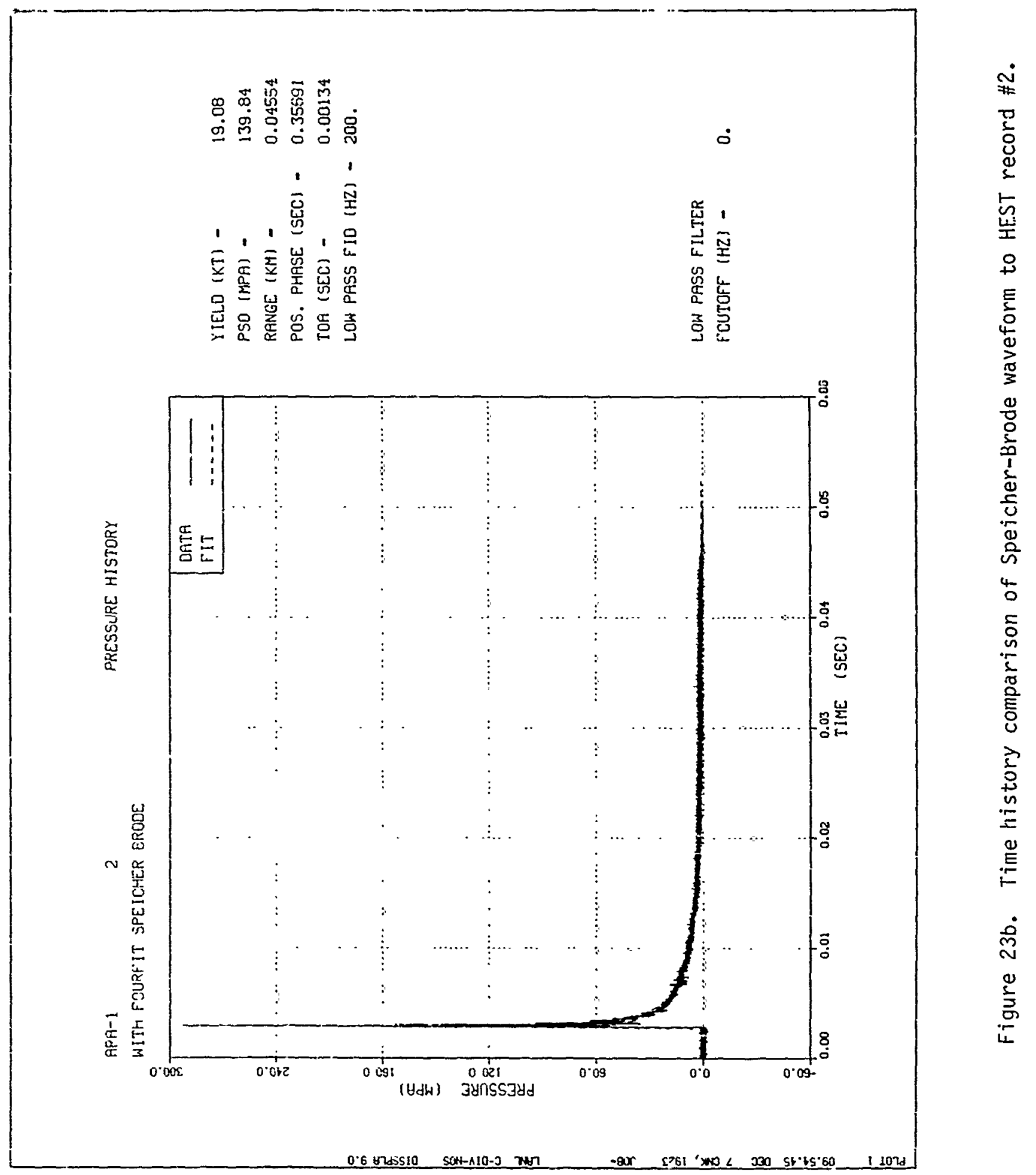




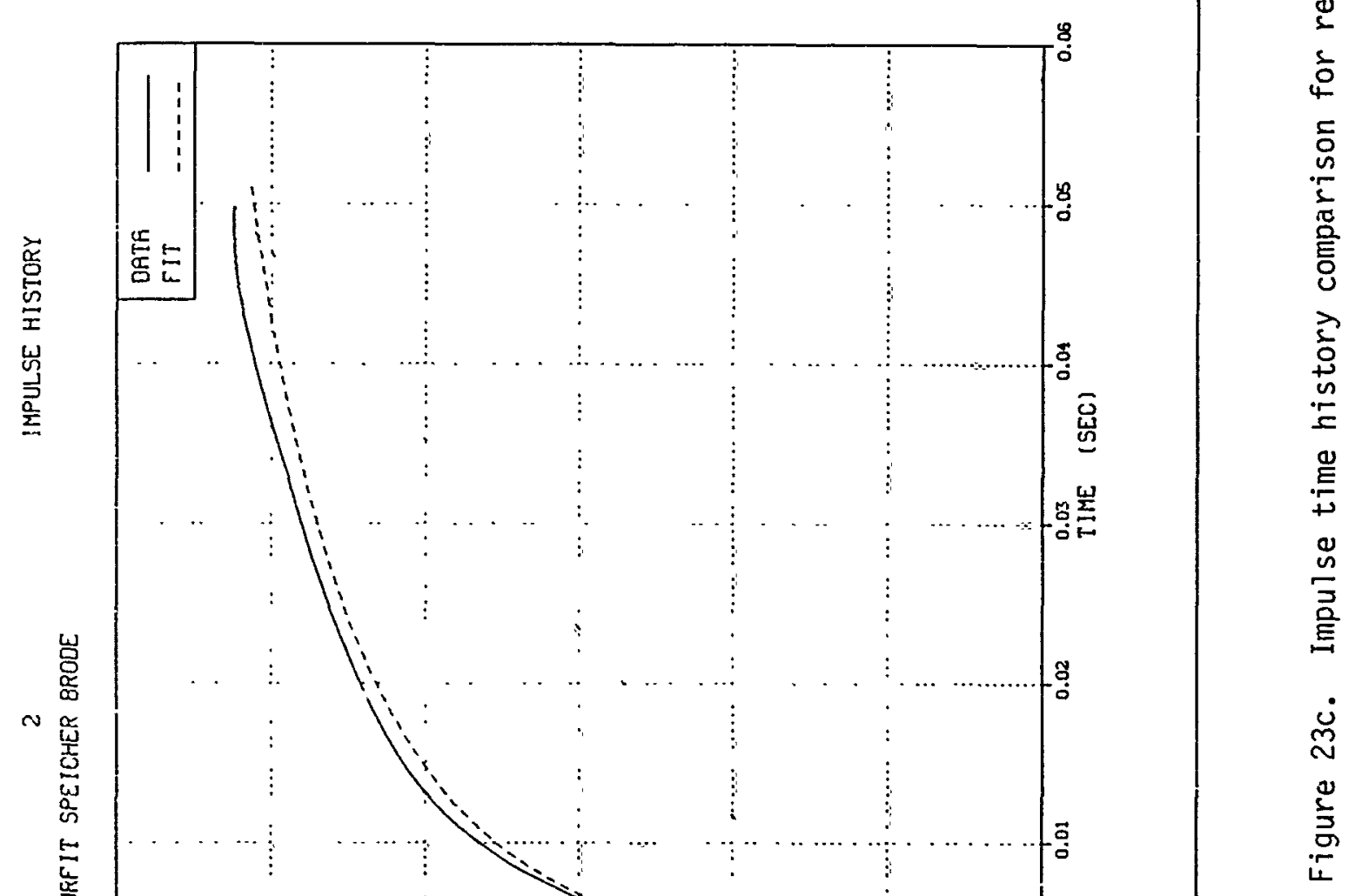




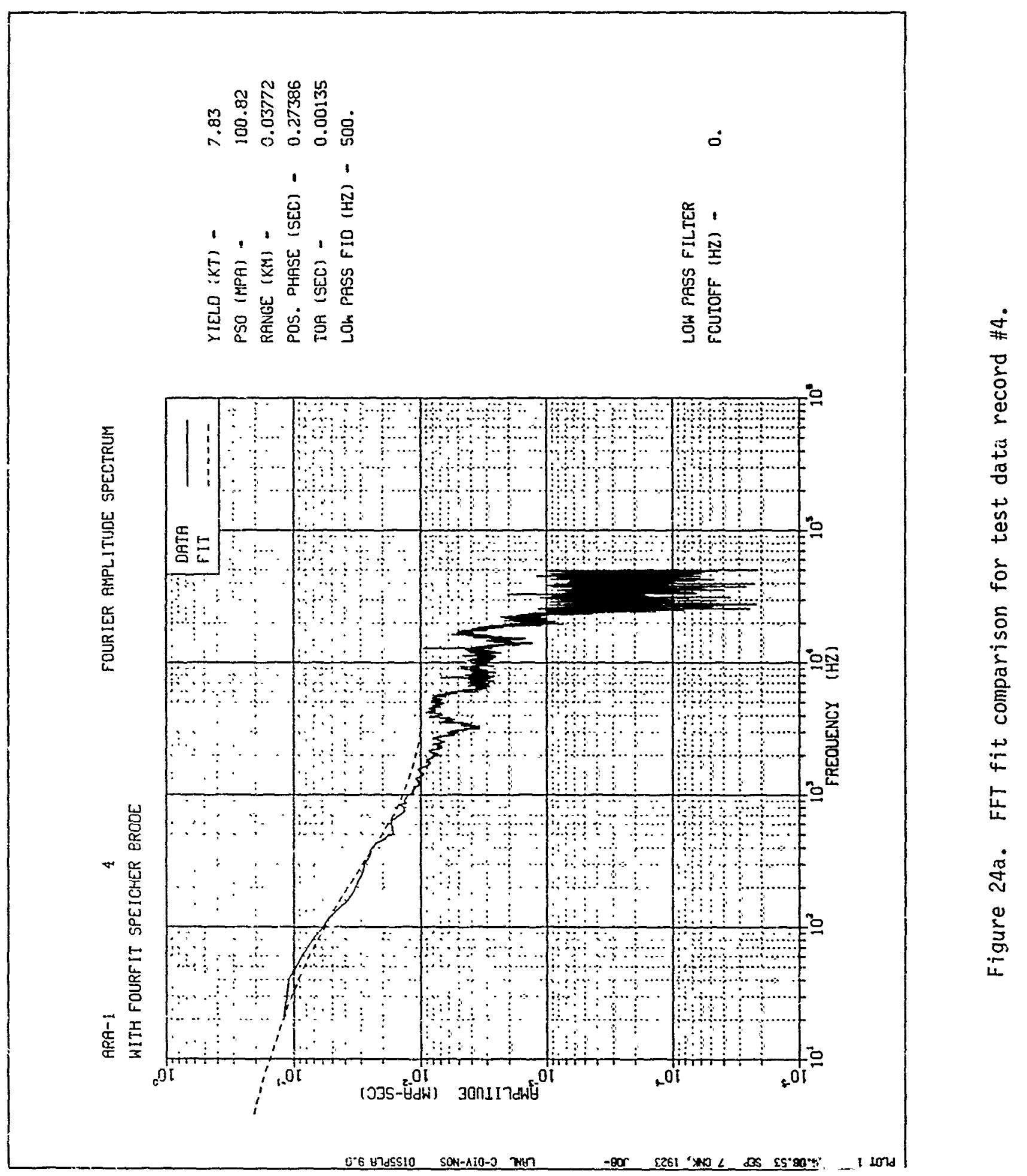




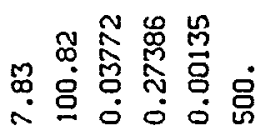

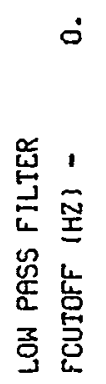

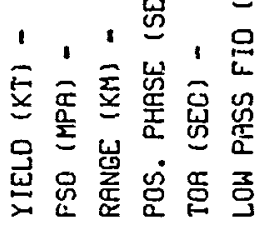

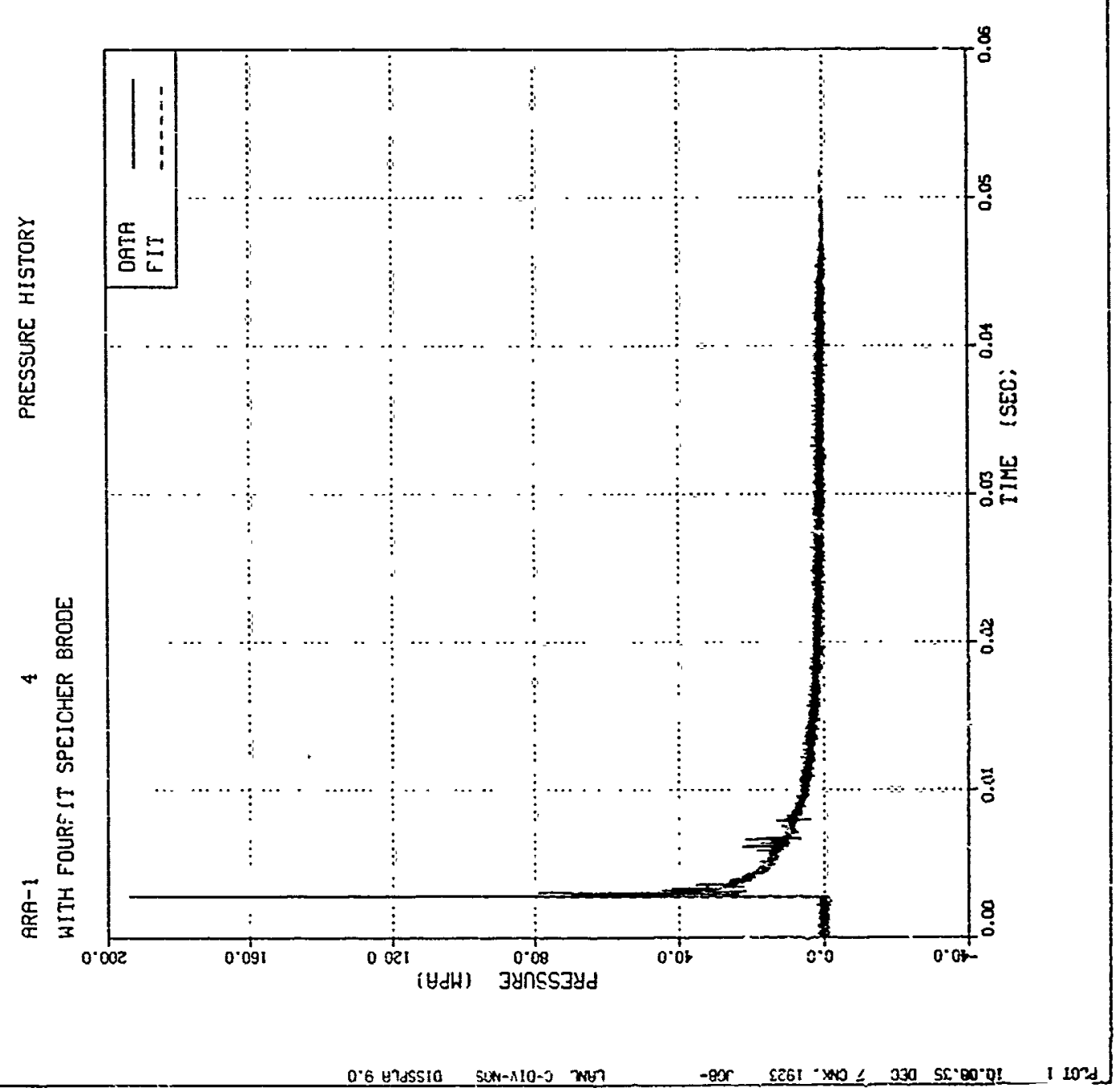

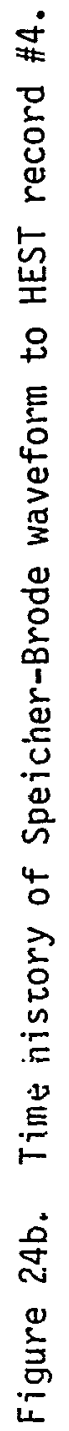




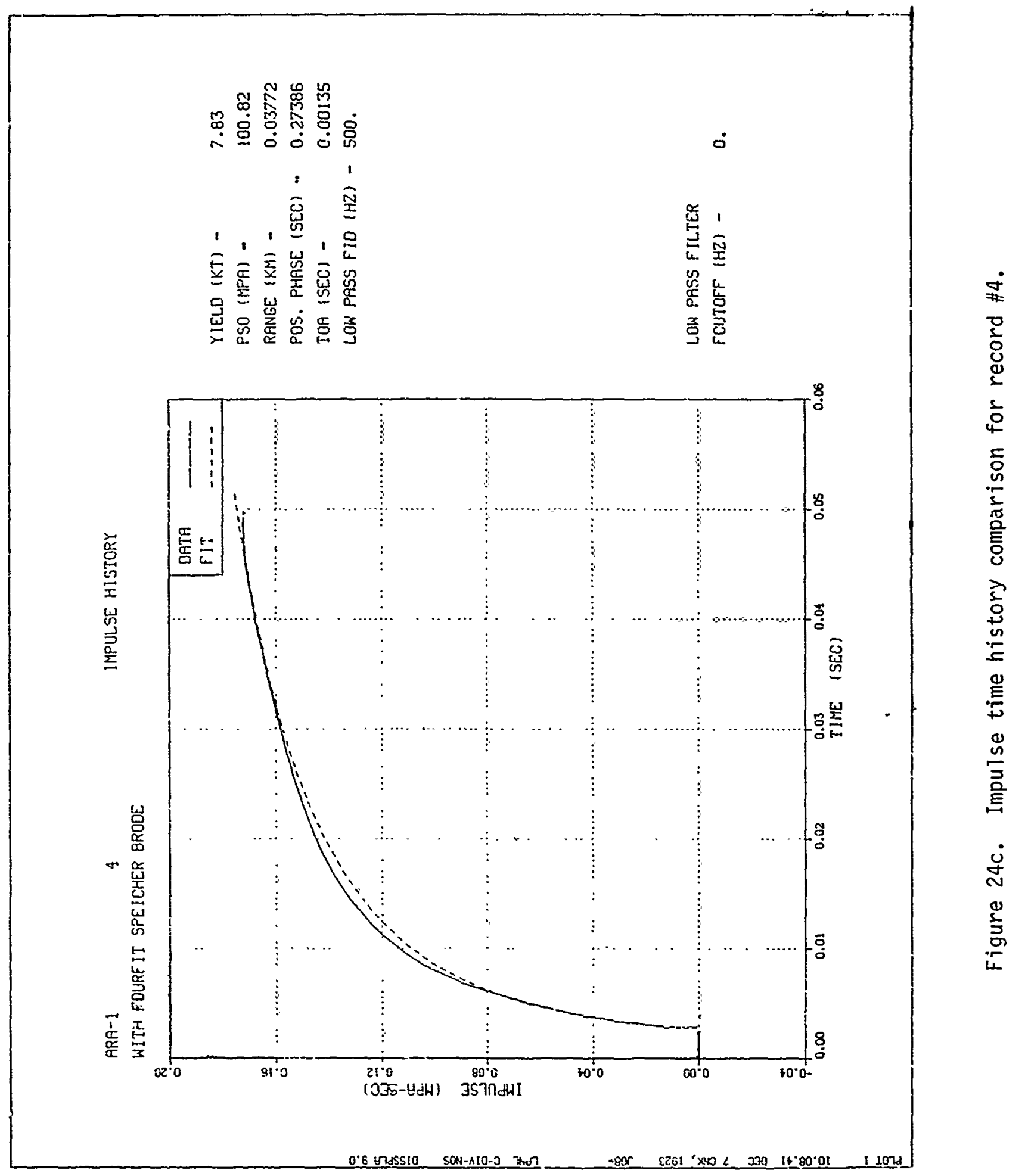




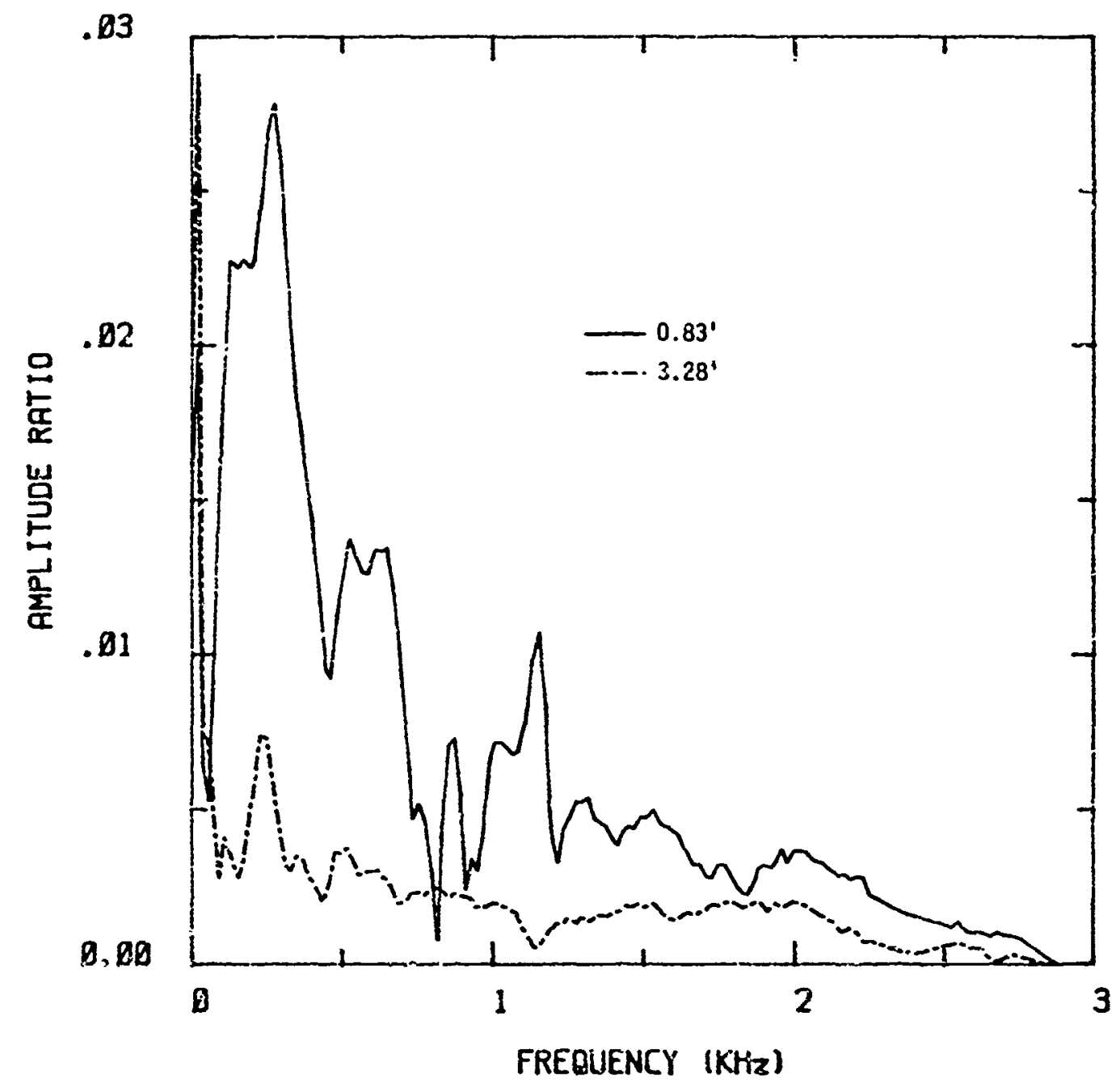

Figure 25. FRF's for vertical soil stress $\left(0.5^{\prime}\right.$ and $\left.5.21^{\prime}\right)$. 


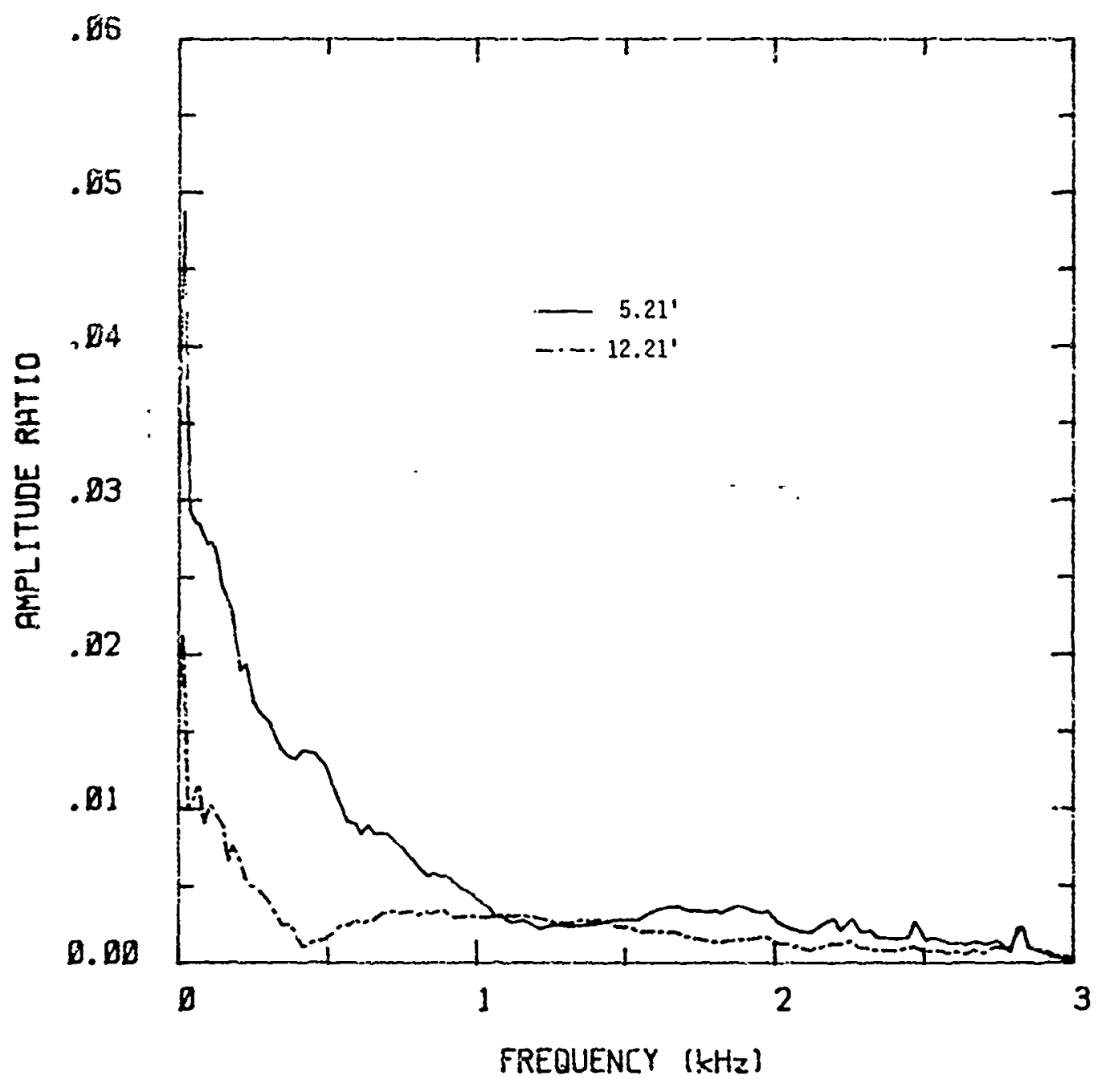

Figure 26. FRF's for vertical soil velocity (5.21' and 12.21'). 


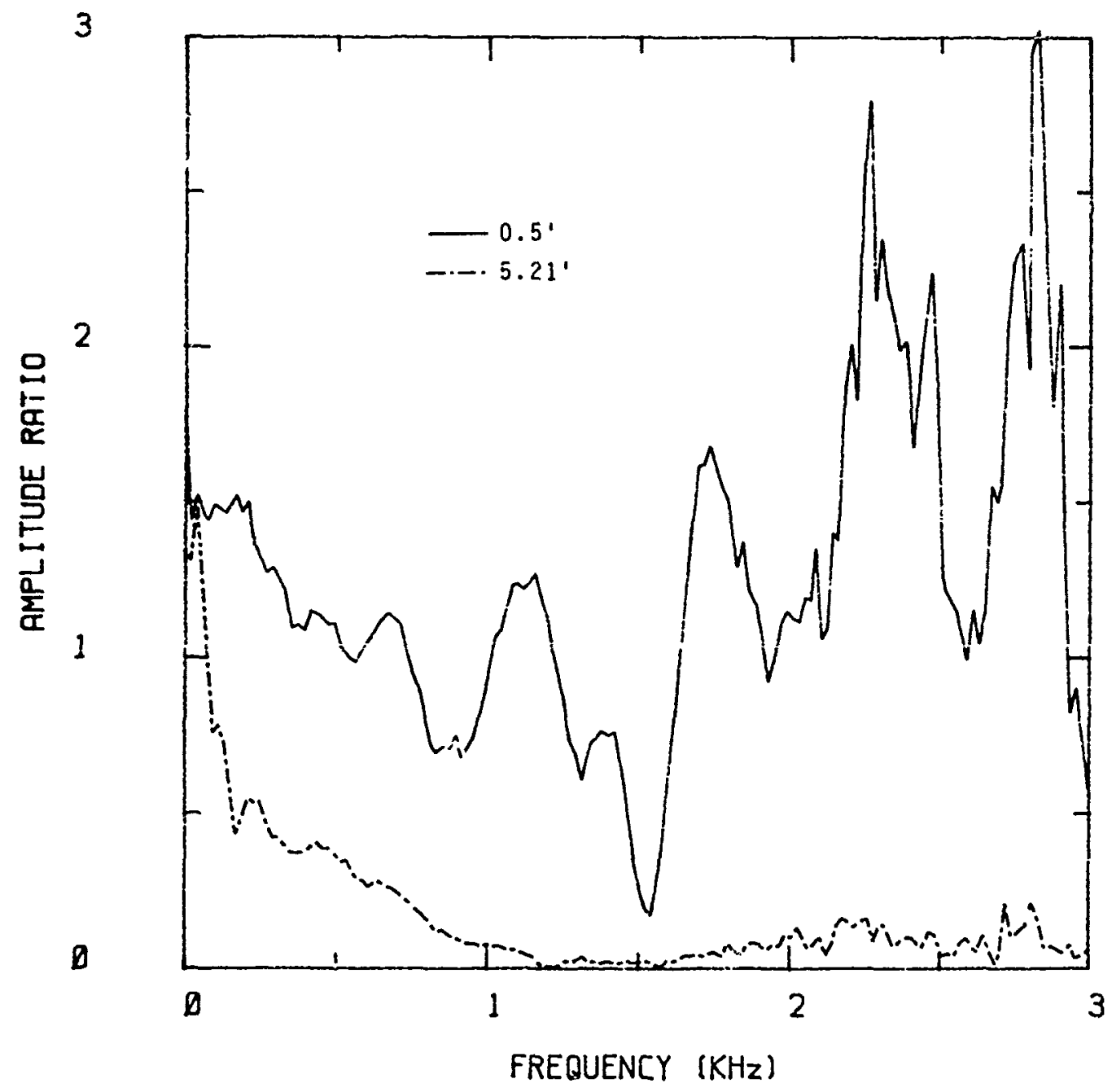

Figure 27. FRF's for vertical structural velocities $\left(0.83^{\prime}\right.$ and $\left.3.28^{\prime}\right)$. 


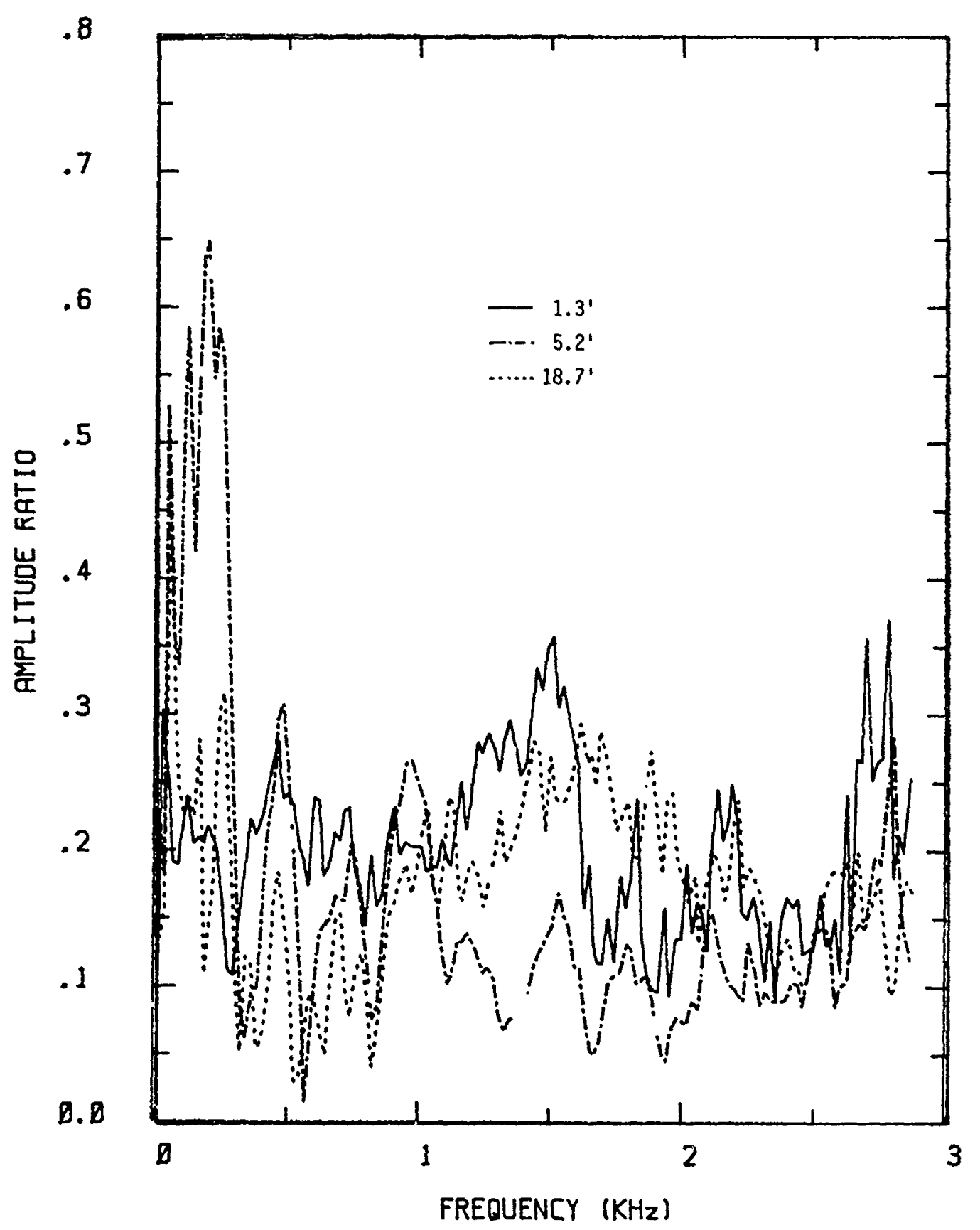

Figure 28. FRF's for vertical structural strains (1.3', 5.2', and 18.7'). 103 


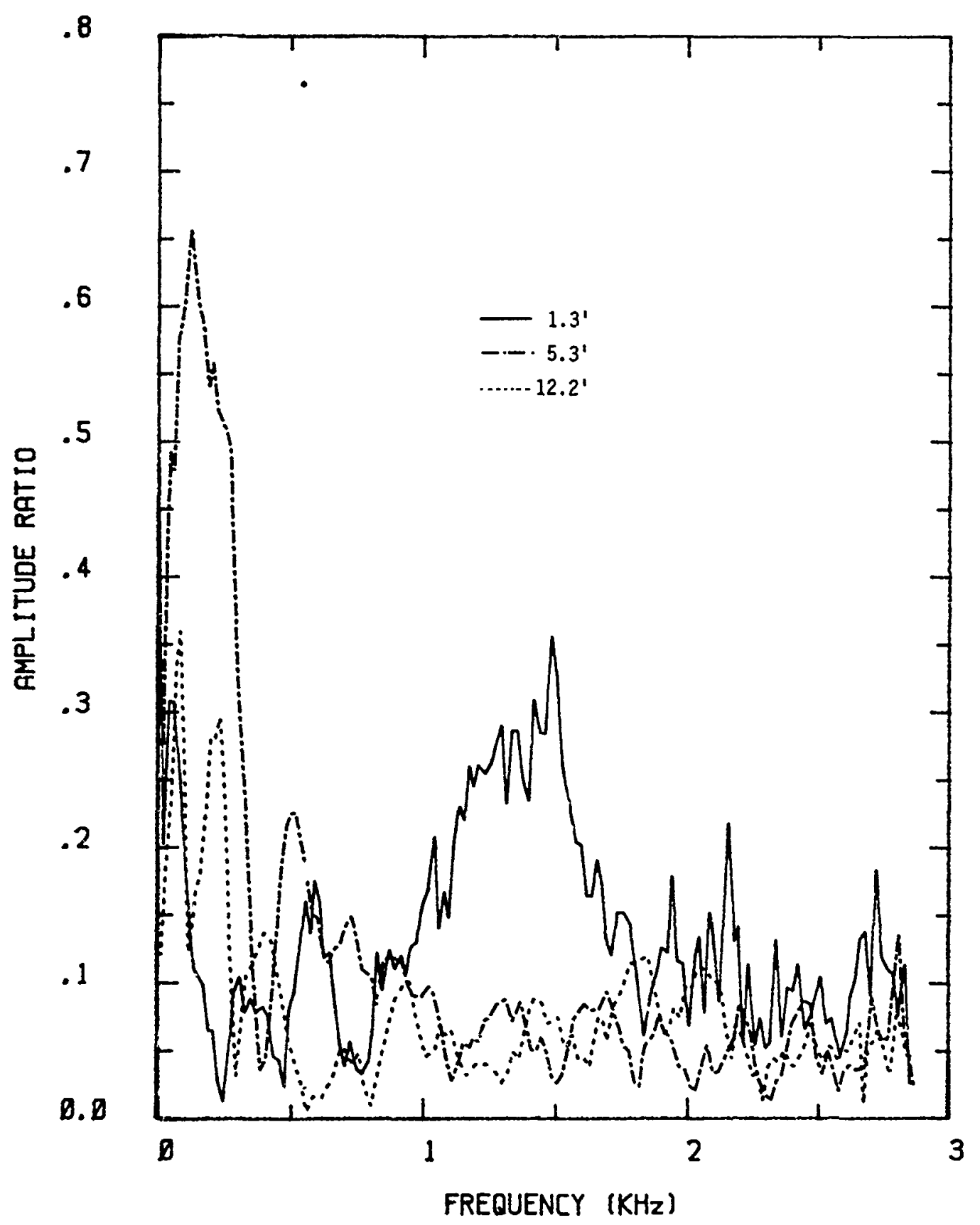

Figure 29. FRF's for structural hoop strains (1.3', 5.3', and 12.2'). 104 


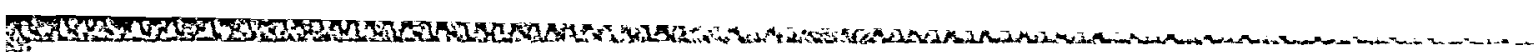

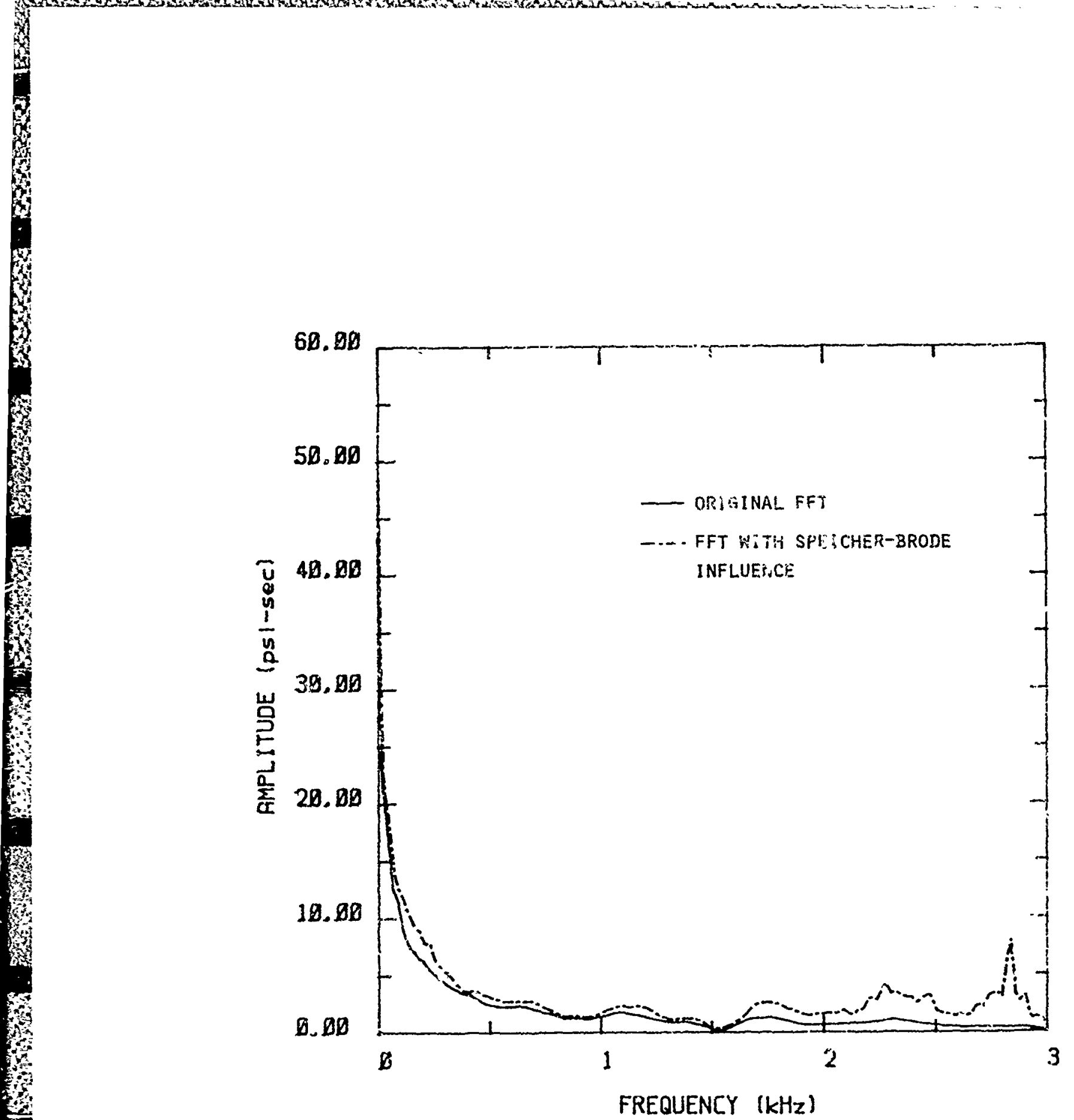

Figure 30. Comparison of origina? FFT to FFT with Speicher-Brode influence for record $\# 6$. 


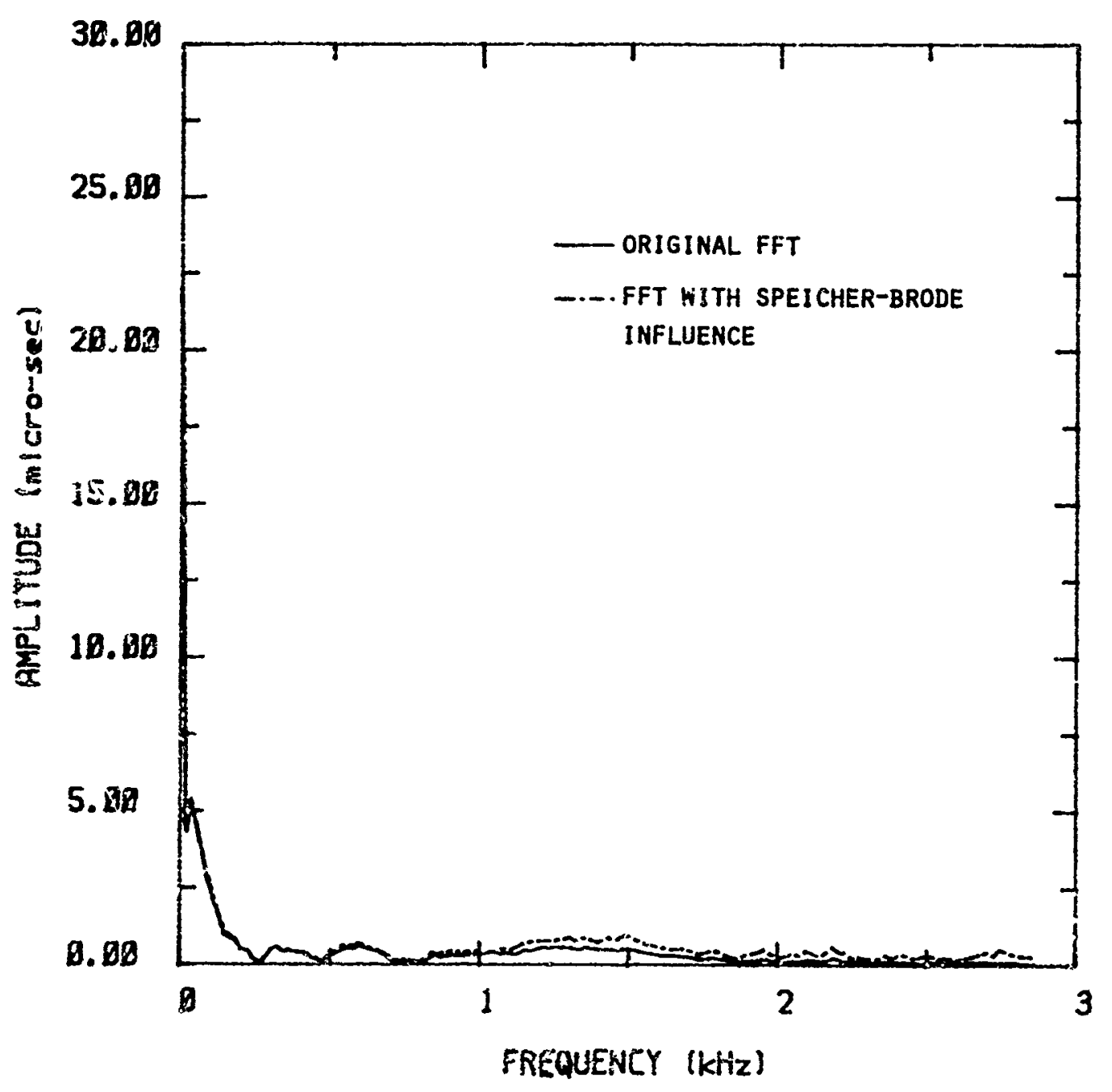

Figure 31. Comparison of original FFT to FFT with Speicher-Brode influence for record \#18. 


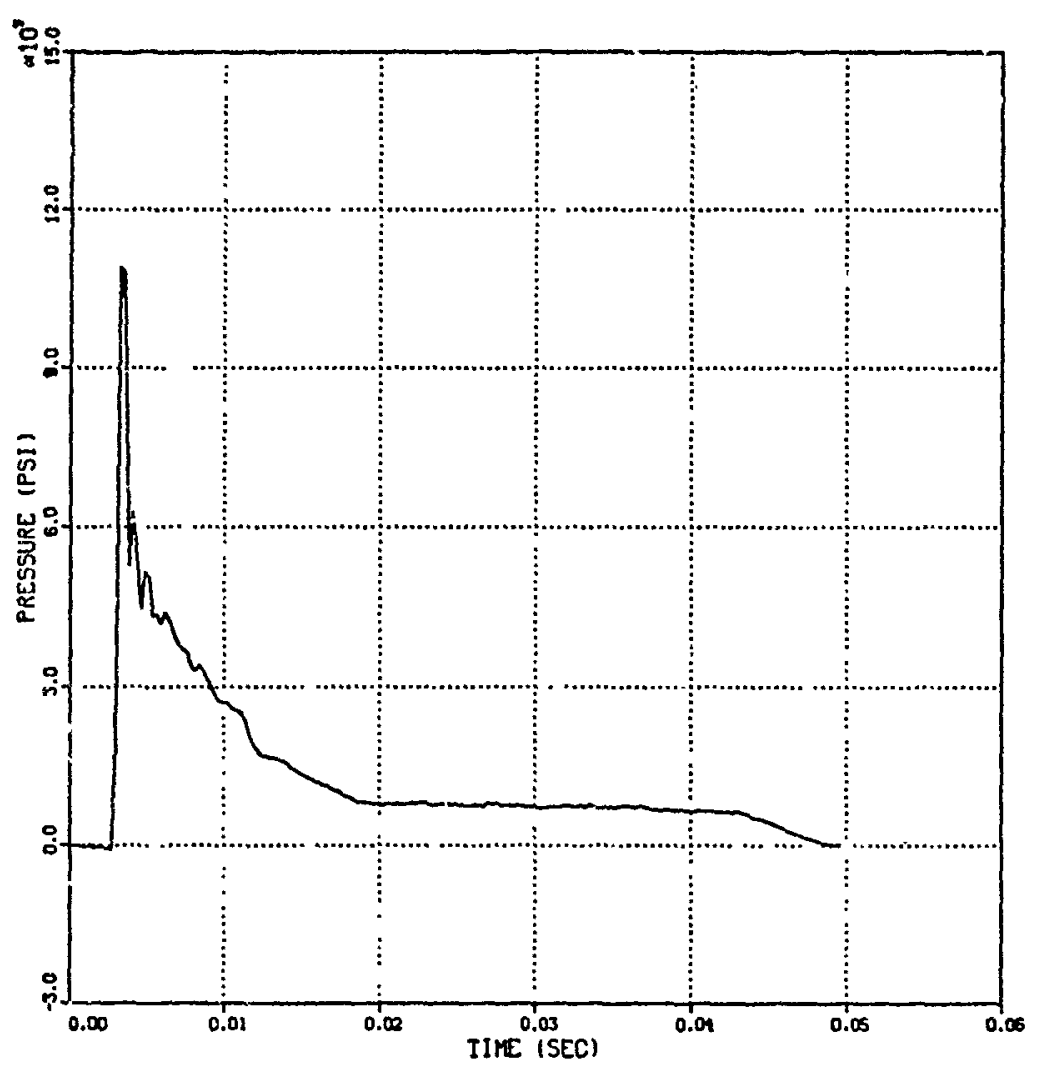

(a) Original time history (from direct inverse FFT)

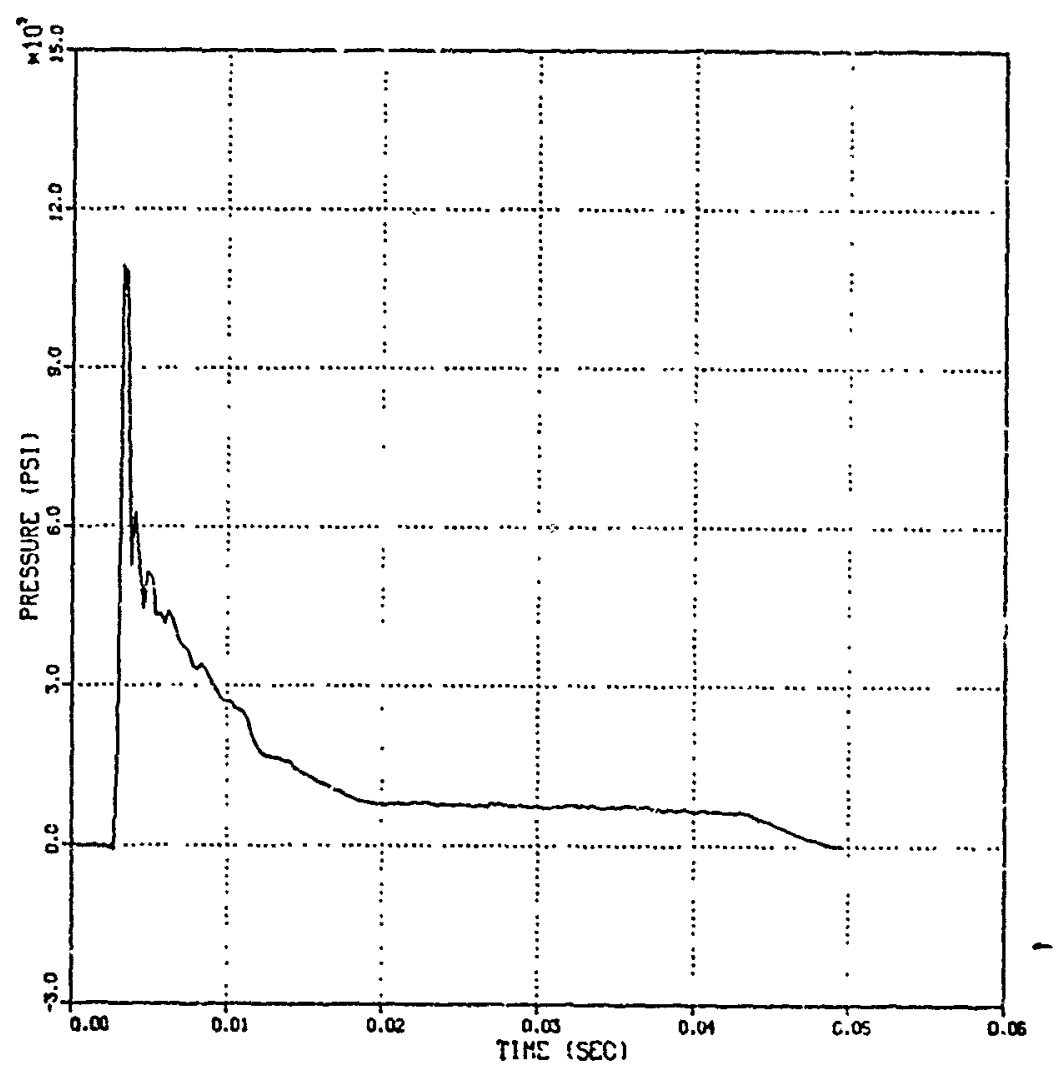

(b) Time history with Speicier-Brode influence

Figure 32. Record Number 5 Time History Comparison 


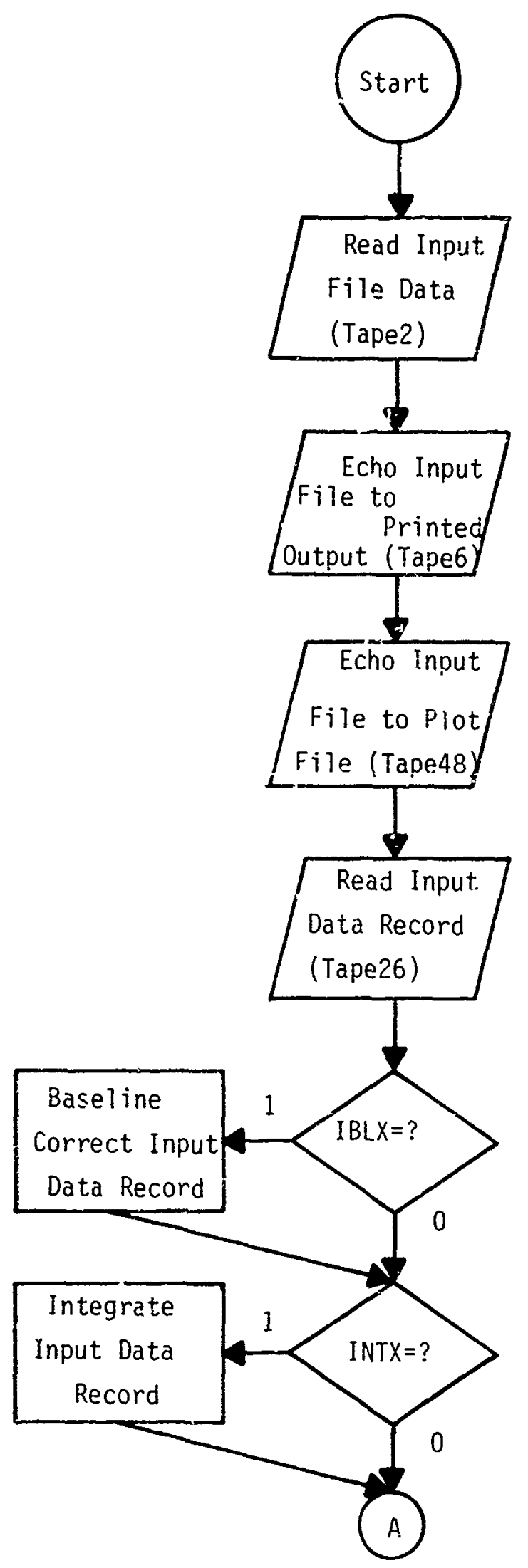

Figure 33. Program FREQRES flow chart. 


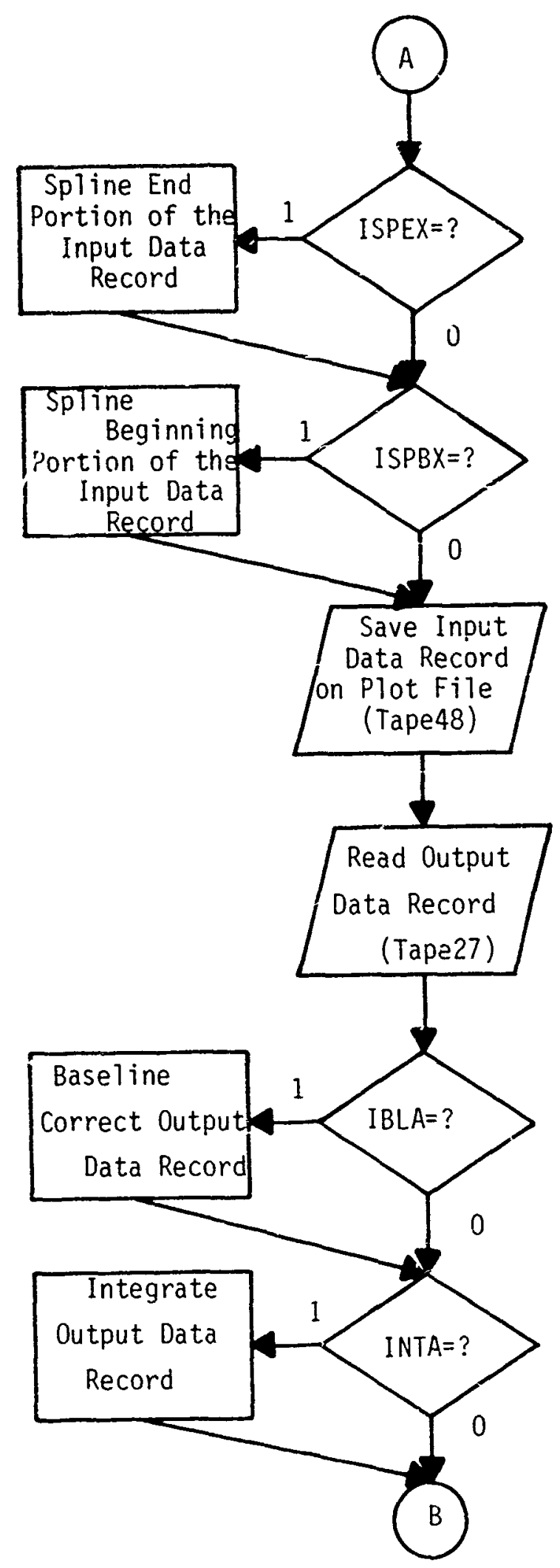

Figure 33. Program FREQRES flow chart (Continued). 


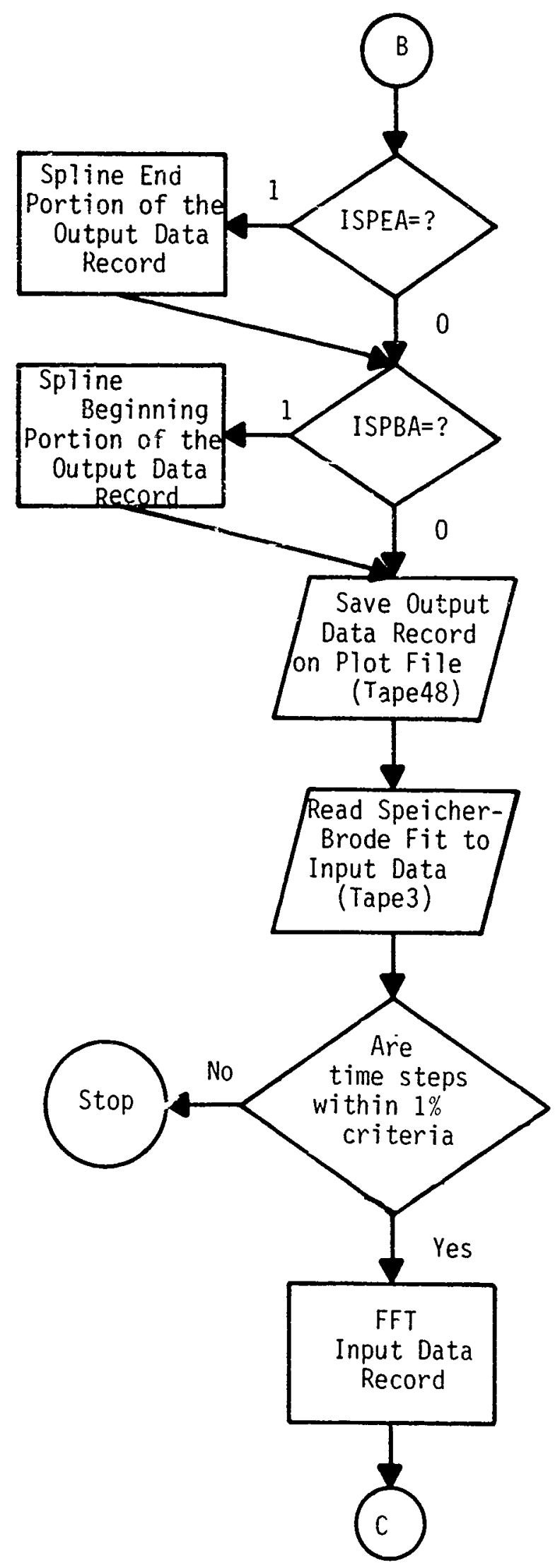

Figure 33. Program FREQRES flow chart (Continued). 


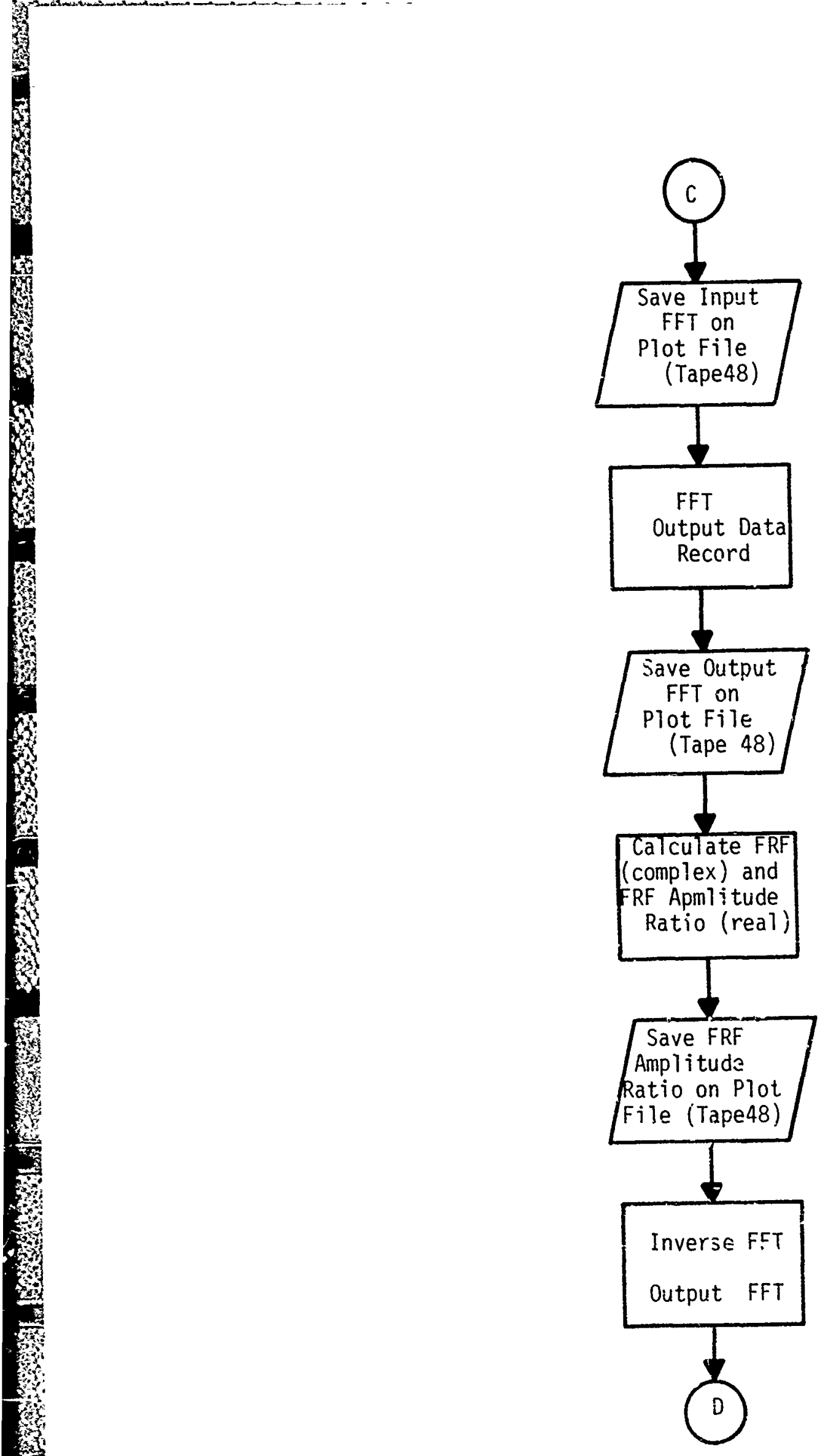

Figure 33. Program FREQRES flow chart (Conitinued). 


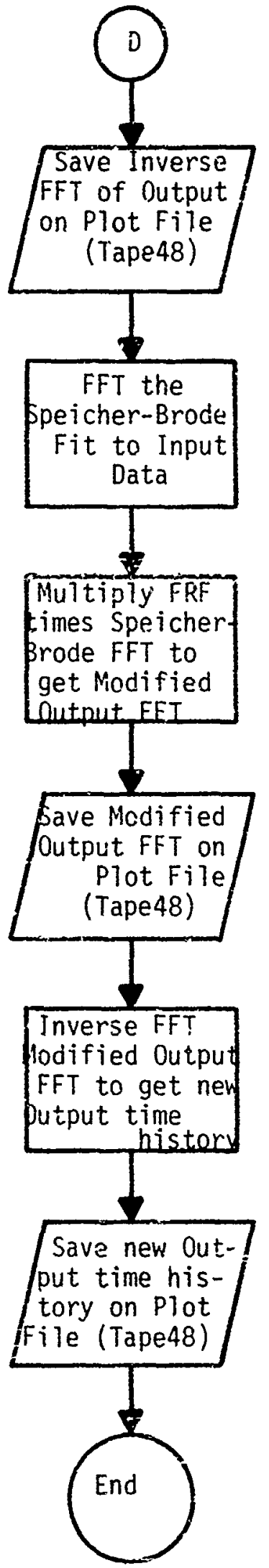

Figure 33. Program FREQRES flow chart (Concluded). 
Table 1. Descriptions of Example Test Data.

Record Number

\section{Description}

HEST pressure on the test article HEST pressure on soil

Vertical soil stress at $0.5^{\prime}$ depth Vertical soil stress at $0.5^{\prime}$ depth Vertical soil siress at $5.21^{\prime}$ depth Vertical structure acceleration at $0.83^{\prime}$ depth Vertical structure acceleration at $3.28^{\prime}$ depth Vertical soil acceleration at 5.21' depth Vertical soil acceleration at 12.21' depth Vertical structure strain at $1.29^{\prime}$ depth Vertical structure strain at $1.29^{\prime}$ depth Vertical structure strain at $3.33^{\prime}$ depth Vertical structure strain at $5.21^{\prime}$ depth Vertical siructure strain at $12.21^{\prime}$ depth Vertical structure strain at 18.71' depth Structure hoop strain at $1.29^{\prime}$ depth Structure hoop strain at $5.29^{\prime}$ depth Structure hoop strain at $12.21^{\prime}$ depth 
Table 2. FREQRES input file variable 7 ist and descriptions.

\begin{tabular}{|c|c|c|c|c|}
\hline 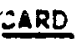 & IMN & FORMAT & VARIA & \\
\hline 1 & $\begin{array}{l}1-5 \\
6-10\end{array}$ & $\begin{array}{l}15 \\
15\end{array}$ & $\begin{array}{l}\text { NEPTS } \\
\text { NSKID }\end{array}$ & $\begin{array}{l}\text { NO. OF POINTS TO BE READ FROM TAPE } \\
\text { SKIP INTERVAL (DEFAULT }=1 \text {, ALL POINTS } \\
\text { FRON TAPE ARE SAVED) }\end{array}$ \\
\hline & $\begin{array}{l}11-20 \\
21-30 \\
31-40\end{array}$ & $\begin{array}{l}\text { E } 10.3 \\
\text { E10.3 } \\
\text { E } 10.3\end{array}$ & $\begin{array}{l}\text { TFAC } \\
\text { XFAC } \\
\text { AFAC }\end{array}$ & $\begin{array}{l}\text { TIME CONVERSION FACTOR (DEFAULT=1.0) } \\
\text { INPUT DATA CONV. FACTOR (DEFAULT }=1.0 \text { ) } \\
\text { OUTPUT DATA CONV. FACTOR (DEFAULT }=1 . \text { ) }\end{array}$ \\
\hline 2 & $1-5$ & 75 & ISPBX & $\begin{array}{l}\text { O: NO SPLINE PERFORHEC ON BESINNING } \\
\text { GF INPUI OATA } \\
\text { 1: BEEINNING OF INPUT DATA WILL BE } \\
\text { SPLINED (DEFAULT=O) }\end{array}$ \\
\hline & $6-15$ & E 10.3 & TSPBX & $\begin{array}{l}\text { IF ISPBX } 1 \text { A SPLINE IS FERFORMED AT } \\
\text { THIS TIME BACK TD TIME ZERO (DEFAULT } \\
\text { IS } 0.0 \text { WHICH MEANS NO SPLINE IS DONE) }\end{array}$ \\
\hline & $16-20$ & 15 & ISPEX & $\begin{array}{l}\text { O NO SPLINE PERFORMED ON END OF } \\
\text { INPUT DATA } \\
\text { 1. ENO OF INPUT DATA WILL BE SFLINES } \\
\text { (CEF SUIT }=0)\end{array}$ \\
\hline & $21-30$ & E 10.3 & TSPEX & $\begin{array}{l}\text { IF ISPEX = T. TIME AT WHIC.A SPLINE } \\
\text { BEGINS FOR INPUT DATA (OEFAULT IS } \\
\text { B5\% DF TTOT) }\end{array}$ \\
\hline & $31-35$ & 15 & ISPBA & $\begin{array}{l}\text { O: NO SPLINE PERFORMED ON EEGINNIAG } \\
\text { OF OUTPUT DATA } \\
\text { 1: BEGINNING OF OUTPUT DATA WILL BE } \\
\text { SPLINED (DEFAULT=O) }\end{array}$ \\
\hline & $36-45$ & E10.3 & TSPBA & $\begin{array}{l}\text { IF ISPBAE } A \text { SPLINE IS PERFORMED AT } \\
\text { THIS TIME BACK TO TIME ZERO (DEFAULT } \\
\text { IS } 0.0 \text { WHICH MEANS NO SOLINE IS DONE) }\end{array}$ \\
\hline & $46-50$ & 15 & ISPEA & $\begin{array}{l}\text { O: NO SPLINE PERFORMED ON END OF } \\
\text { OUTPUY DATA } \\
\text { 1: END OF OUTPUT DATA WILL BE } \\
\text { SPLINED (DEFAULT=O) }\end{array}$ \\
\hline & $51-60$ & E 10.3 & TSPEA & $\begin{array}{l}\text { IF ISPEA=1. TIME AT WHICH SPLINE } \\
\text { BEGINS FOR OUTPUT DATA (DEFAULT } \\
\text { IS B5\% OF TTOT) }\end{array}$ \\
\hline 3 & $1-5$ & 15 & IBLX & $\begin{array}{l}\text { INPUT DATA BASELINE CORRECTION TRIGGER } \\
\text { O: NO BASELINE CORRECTION } \\
\text { 1: BASELINE CORRECTION WITH THE } \\
\text { FOLLOWING PARAMETERS (OEFAULT=O) }\end{array}$ \\
\hline & $6-15$ & E 10.3 & DELPX & $\begin{array}{l}\text { CORRECTION ADDED TO INPUT DATA VALUES } \\
\text { AFTER TIME SBX. IF ESX AND SBX ARE } \\
\text { EOUAL THEN THE FULL VALUE OF CELPX IS } \\
\text { AODED AT ALL TIMES AFTER SBX. IF EBX } \\
\text { IS GREATER THAN SBX THEN THE PLOT IS } \\
\text { ROTATED ABOUT THE POINT DEFINED AT SBX } \\
\text { BY THE AMOIT DITEIPX AT TIME EBX }\end{array}$ \\
\hline & $16-25$ & E 10.3 & SBX & $\begin{array}{l}\text { START TIME FOR BASELINE CORRECTION } \\
\text { (PLOT ROTATION POINT IF EBX > S3X) }\end{array}$ \\
\hline & $\begin{array}{l}26-35 \\
36-40\end{array}$ & $\begin{array}{l}\text { E 10.3 } \\
\text { I5 }\end{array}$ & $\begin{array}{l}\text { EBX } \\
\text { INTX }\end{array}$ & $\begin{array}{l}\text { END TIME FOR BASELINE CORRECTION } \\
\text { INPUT DATA INTEGRATION TRIGGER } \\
\text { O: NO INTEGRATION } \\
1: \text { INTEGRATE INPUT DATA }\end{array}$ \\
\hline
\end{tabular}


Table 2. FREQRES input file variable list and descriptions (Concluded).

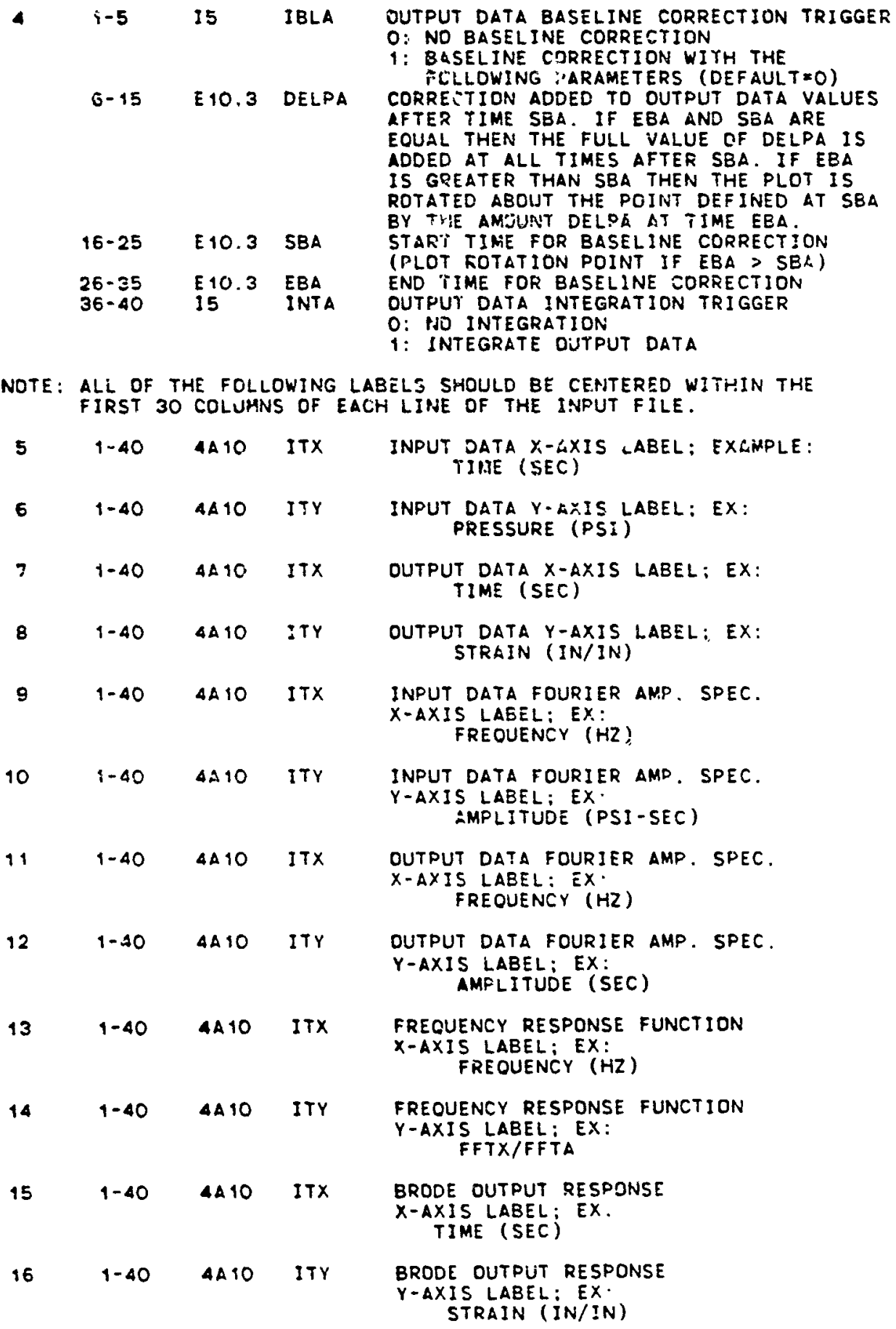


Table 3. Sample output listing from a FREQRES calculation.

FREQRES OUTPUT LISTING

THE NUMBER OF POINTS READ FROM THE DATA RECORO TAPES IS 9970 WITH A SKIP OF 27 CONSIOEREO FOR ANALYSIS

TIME CONVERSION FACTOR

INPUT DATA CONV. FACTOR

OUTPUT DATA CONV. FACTOR

$=.100 E+01$

$=.100 E+01$

8EGINNING PORTION OF INPUT DATA SPLINED FROM TIME EOUAL O.O TO TIME EQUAL $.260 E-02$

FINAL $15 \%$ OF INPUT DATA SPLINED TO ZERO

BEGINNING PORTION OF OUTPUT DATA SPLINED FROM TIME EOUAL 0.0 TO TIME EOUAL $.300 E-02$

FINAL $15 \%$ OF OUTPUT DATA SPLINED TO ZERO

VEQY IMPORTANT NOTICE:

NBPTS FOR THE SPEICHER-BRODE FIT FROM FOURFIT = 392

MUST BE EOUAL TO NPT FROM THIS PROGRAM = 369

IF NBPTS AND NPT ARE NOT EQUAL. THIS PROGRAM WILL

TRUNCATE ONE OF THEM TO MAKE THEM EOUAL.

DTBP FOR THE SPEICHER-BRODE FIT FROM FOURFIT $=.13372120$-03

MUST BE VEFY CLOSE TO DTO FROM THIS PROGRAN $=.13500000 E-03$

IF THEY ARE NOT CLOSE. THIS PROGRAM WILL STOP

OUTPUT RECORD TOTAL IMPULSE $=\quad .649781 \mathrm{E}+02$

FIRST POINT OF OUTPUT FFT $=.648020 E+02$

OUTPUT INVERSE FFT OFFSET $=\quad .129430 E+04$ 


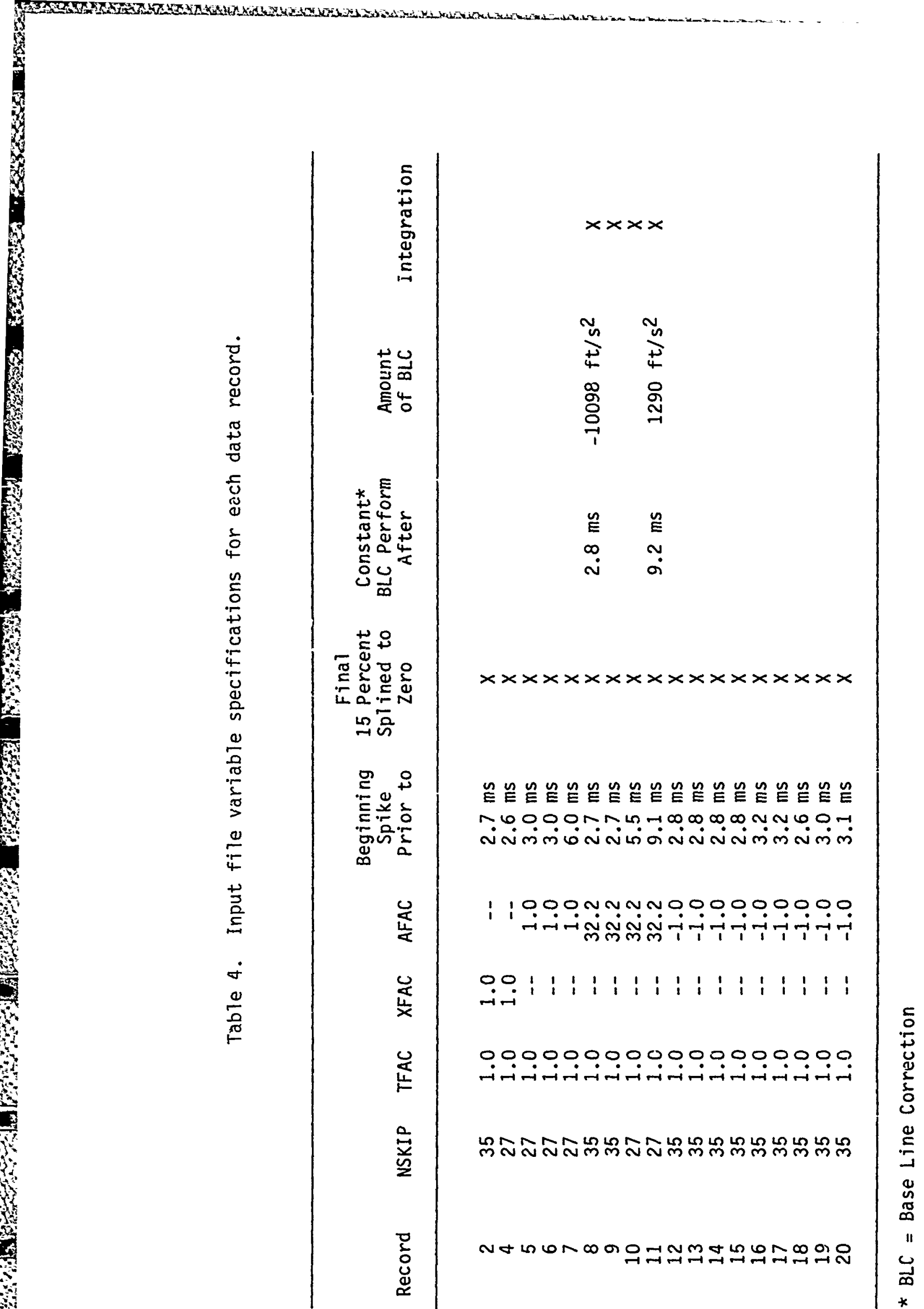


Table 5. Summary of the total impulse, first FFT value, and inverse FFT offset for the test data.

\begin{tabular}{|c|c|c|c|c|}
\hline $\begin{array}{l}\text { Record } \\
\text { Number }\end{array}$ & Totai Impulse & First FFT Value & Inverse & FFT offset \\
\hline $\begin{array}{r}4 \\
5 \\
6 \\
7 \\
8 \\
9 \\
10 \\
11 \\
12 \\
13 \\
14 \\
15 \\
16 \\
17 \\
18 \\
19 \\
20\end{array}$ & $\begin{array}{c}24.93 \mathrm{psi}-\mathrm{sec} \\
64.98 \mathrm{psi}-\mathrm{sec} \\
47.34 \mathrm{ps} \text {-sec } \\
33.74 \mathrm{psi-sec} \\
.5192 \mathrm{ft} \\
.7249 \mathrm{ft} \\
.7842 \mathrm{ft} \\
.4031 \mathrm{ft} \\
.1170 \mathrm{micro} \mathrm{sec} \\
.6474 \mathrm{micro} \mathrm{sec} \\
-14.46 \text { micro sec } \\
8.581 \text { micro sec } \\
48.47 \text { micro sec } \\
5.014 \text { micro sec } \\
24.80 \text { micro sec } \\
10.27 \text { micro sec } \\
-4.586 \text { micro sec }\end{array}$ & $\begin{array}{c}24.87 \mathrm{psi}-\mathrm{sec} \\
64.80 \mathrm{psi}-\mathrm{sec} \\
47.22 \mathrm{psi}-\mathrm{sec} \\
33.65 \mathrm{psi-sec} \\
.5174 \mathrm{ft} \\
.7223 \mathrm{ft} \\
.782 \mathrm{ft} \\
.4020 \mathrm{ft} \\
.1166 \mathrm{micro} \mathrm{sec} \\
.6451 \text { micro sec } \\
14.40 \text { micro sec } \\
8.551 \text { micro sec } \\
48.30 \text { micro sec } \\
4.997 \text { micro sec } \\
24.71 \text { micro sec } \\
10.23 \text { micro sec } \\
4.570 \text { micro sec }\end{array}$ & $\begin{array}{l}516 \text { psi } \\
1294 \text { psi } \\
947 \text { psi } \\
676 \text { psi } \\
10.4 \\
14.5 \\
15.7 \\
8.07 \\
-.39 \\
10.2 \\
-288 \\
173 \\
968 \\
98.4 \\
496 \\
205 \\
-92.1\end{array}$ & $\begin{array}{l}i \\
i \\
i \\
i \\
\mathrm{ft} / \mathrm{s} \\
\mathrm{ft} / \mathrm{s} \\
\mathrm{ft} / \mathrm{s} \\
\mathrm{ft} / \mathrm{s} \\
\text { micro strain } \\
\text { micro strain } \\
\text { micro strain } \\
\text { micro strain } \\
\text { micro strain } \\
\text { micro strain } \\
\text { micro strain } \\
\text { micro strain } \\
\text { micro strain }\end{array}$ \\
\hline
\end{tabular}


Table 6. FREQRES input files.

Input File

TAPE2

TAPE3

TAPE26

TAPE27

\section{Description}

Input file for input variable specification as described in Section 3.1

Speicher-Brode "best-fit" waveform sbtained from TAPE49 of FOURFIT ca?culation

Input data record digitized time history

Output data record digitized time history

Table 7. FREQRES output files.

Output File

TAPE6

TAPE 48
Description

Printed output

Plot file 


\section{DISTRIBUTION LIST}

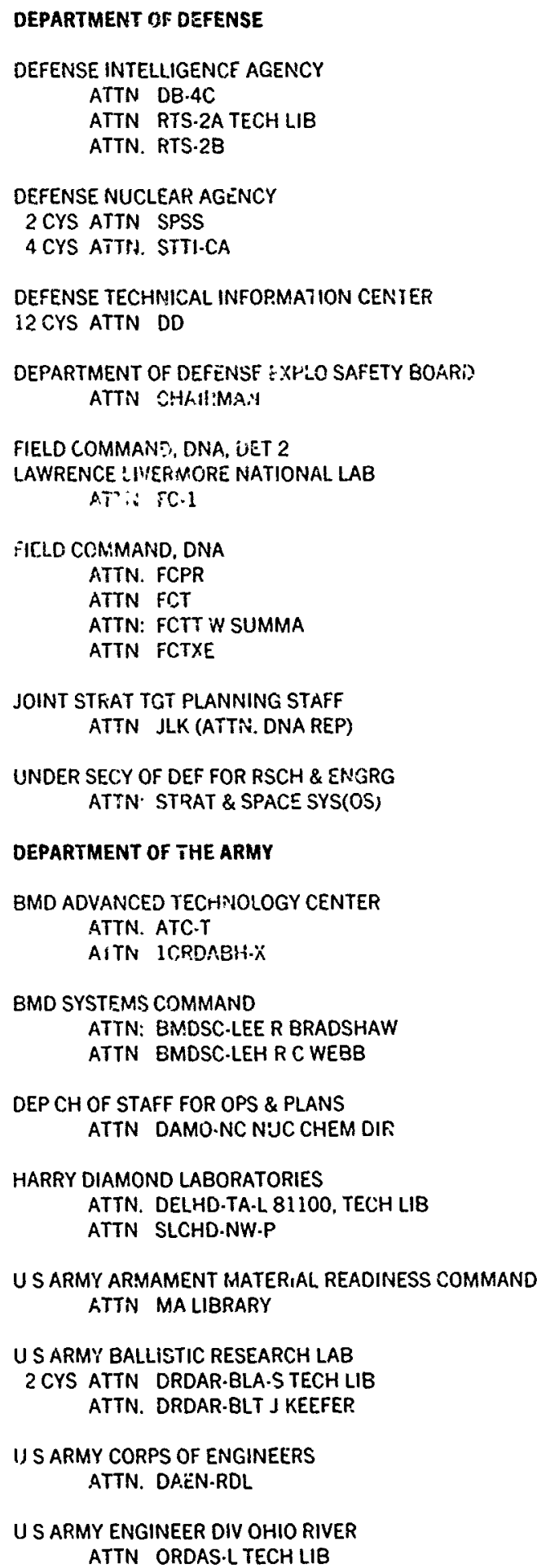

U S ARMY ENGINEER DIV HUNTSVILLE ATTN: HNDED.SR ATTN: HNDEN.FO

U S ARMY ENGR WATERWAYS EXPER STATION ATTN: I STRANGE ATTN: J ZELASKO ATTN. LIBRARY ATTN WESSD J JACKSON ATTN WESSE

U S ARMY FOREIGN SCIENCE \& TECH CTR ATTN. DRXST-SD

U S ARMY NUCLEAR \& CHEMICAL AGENCY ATTN LIBRARY

US ARMY WHITE SANDS MISSILE RANGE ATTN STEWS.TE.N K CUMMINGS

USA MISSILE COMMAND ATTN - DOCUMENTS SEC?ION ATTN: DRSMI-RH

DEPARTMENT OF THE NAVY

DAVID TAYLOR NAVAL SHIP R \& D CTR ATTN TECH INFO CTR CODE. 5221

NAVAL CIVIL. ENG!NEERING LABORATORY ATTN: CODE $[.5]$

NAVAL FACILITIES ENGINEERING COMMAND ATTN CODE 04B

NAVAL POSTGRADUATE SCHOOL ATTN: CODE 1424 LIBRARY

NAVAL REST.ARCH LABORATORY ATTN: CODE 2627 TECH LIB

NAVAL SURFACE WEAPONS CENTER ATTN: CODE F31

NAVAL SURFACE WEAPONS CENTER ATTN TECH LIB \& INFO SVCS BR

NAVAL WFAPONS CENTER ATIN. CODE 266 C AUSTIN ATTN. CODE 343 FKA6A2, TECH SVCS

NAVAL WEAYONS EVALUATION FACILITY ATTN. CLASSIFIED LIBRARY

OFFICE OF NAVAL RESEARCH ATTN. CODE 474

\section{DEPARTMENT OF THE AIR FORCE}

AFRCE-BMS/DEE ATTN DEB 
DEPARTMENT OF THE AIR FORCE (CONTINUED)

AIR FORCE GEOPHYSICS LABORATORY ATTN: LWH H OSSING

AIR FORCE INSTITUTE OF TECHNCLOGY ATTN LIBRARY

AIR FORCE SYSTEMS COMMAND ATTN. DLW

AIR FORCE WEAPONS LABORATORY, AFSC ATTN- NTE M PLAMONDON ATTN: NTED R MATALUCCI ATTN. NTES.C R HENNY ATTN. SUL

BALLISTIC MISSILE OFFICE/DAA ATTN. ENSN ATTN. MGEN A SC.HENKER ATTN PP

DEPUTY CHIEF OF STAFF ATTN: AF/RDQ

FOREIGN TECHNOLOGY OIVISION, AFSC ATTN NIIS LIBRARY

STRATEGIC AIR COMMAND ATTN. NRI/STINFJ

STRATEGIC AIR COMMAND ATTN XPFS

DEPARTMENT OF ENERGY

DEPARTMENT OF ENERGY

ALBUQUERQUE OPERATIONS OFFICE ATTN CTID ATTN R JONES

DEPARTMENT OF ENERGY

OFC OF MIL APPLICATION, GTN ATTN OMA/RD\&T

DEPARTMENT OF ENERGY

NEVADA OPERATIONS OFFICE ATTN DOC CON FOR TECH LIB

UNIVERSITY OF CALIFORNIA

LAWRENCE LIVERMORE NATIONAL LAB ATTN- L-203 R SCHOCK ATTN L.203 T BUTKOVICH ATTN L-658 TECH INFO DEPT LIB ATTN. P COYLE

LOS ALAMOS NATIONAL LABORATORY ATTN. MS P364 RPTS IIB ATTN MS530 G SPILLMAN ATTN R WHITAKER

OAK RIDGE NATIONAL LABORATORY ATTN CENTRAL RSCH LIBRARY ATTN CIVIL DEF RES PROJ
SANOIA NATIONAL LABORATORIES ATTN. LIB \& SEC CLASSIF DIV

SANDIA N.MTIONAL LABORATORIES ATTN. DIV 7111 B VORTMAN ATTN. J BANNISTER ATTN. ORG 7111 L HILL. ATTN- TECH LIB 3141

\section{OTHER GOVERNMENT}

FEDERAL EMERGENCY MANAGEMENT AGENCY ATTN. ASST ASSOC DIR FOR RSCH J KERR ATIN W CHIPMAN/NP.CP

DEPARTMENT OF DEFENSE CONTRACTORS

AEROSPACE CORP ATTN: LIBRARY ACQUISITION M]/199

AGBABIAN ASSOCIATES, INC ATTN・ C BAGGE

ANALYTIC SERVICES, INC (ANSER) ATTN. G HESSELBACHER

APPLIED RESEARCH ASSOCIATES, INC 2 CYS ATTN B BINGHAM ATTN N HIGGINS

APPLIED RESEARCH ASSOCIATES, INC ATTN: D PIEPENBURG

APPIIED RESEARCH ASSOCIATES, INC ATTN. P FRANK

A.FPLIED THEORY, INC ATTN. I TRULIG

AVCO SYSTEMS DIVISION ATTN LIBRARY A830

BDM CORP

ATYN A LAVAGNINO

ATTN. CORPORATE LIB

ATTN. T NEIGHBORS

BDM CORP

ATYN F LEECH

ATTN R HENSLEY

BOEING CO

ATTN AEROSPACE LIB

ATTN M/S 42/37 R CARLSON

BOEING CO

ATTN MS.85.20 D CHOATE

CALIFORINIA RESEARCH \& TECHNOLOGY, INC ATTN KKREYENHAGEN ATTN LIBRARY

CALIFORNIA RESEARCH \& TECHNOLOGY, INC ATTN F SAUER 
DEPARTMENT OF DEFENSE CONTRACTORS (CONTINUED)

CALIFORNIA RESEARCH \& TECHNOLOGY, INC ATTN TECHLIB

CALSPAN CORP

ATTN. LIBRARY

CARPENTER RESEARCH CORP

ATTN: H J CARPENTER

DENVER, UNIVERSITY OF

ATTN. SEC OFCR FOR J WISOTSKI

EG\&G WASH ANALYTICAL SVCS CTR, INC ATTN LIBRARY

GENERAL RESEARCH CORF ATTN TECHNICAL INFORMATION OFFICE

H-TECH LABS, INC ATTN: B HARTENBAUM

IIT RESEARCH INSTITUTE ATTN. DOCUMENTS LIBRARY

INSTITUTE FOR DEFENSE ANALYSES ATTN CLASSIFIED LIBRARY

KAMAN SCIENCES CORP ATTN. L MENTE ATTN: LIBRARY ATTN. R RUETENIK ATTN W LEE

KAMAN SCIENCES CORP ATTN I SHELTON ATTN: LIBRARY

KAMAN SCIENCES CORP ATTN. E CONRAD

KAMAN TEMPO

ATTN DASIAC

KAMAN TEMPO

ATTN. DASIAC

LOCKHEED MISSILES \& SPACE CO, INC ATTN. J WEISNER DEPT 80.82 ATTN: TECH INFO CTR D/COLL, D/90.11, B/106

MARTIN MARIETTA CORP ATTN. G FOTIEO

MCDONNELL DOUGLAS CORP ATTN. R HALPRIN

MCDONNELL DOUGLAS CORP ATTN: M POTTER MS/35.18

MERRITT CASES, INC ATTN J MERRITT ATTN LIBRARY
UNIVERSITY OF NEW MEXICO

NEW MEXICO ENGINEERING RESEARCH INSTITUTE ATTN - N BAUM

PACIFIC.SIERRA RESEARCH CORP ATTN: H BRODE, CHAIRMAN SAGE

PACIFICA TECHNOLOGY ATTN: R ALLEN ATTN: RBJORK

PATEL ENTERPRISES, INC ATTN MPATEL

PHYSICAL RESEARCH, INC ATTN. W MENDES

PHYSICS INTERNATIONAL CO ATTN E EMOORE ATTN: LBEHRMANN

$R \& D$ ASSOCIATES

ATTN- A KUHL ATTN: D SIMONS

ATTN: J LEWIS

ATTN. TECH INFO CTR

ATTN. W WRIGHT

$R \& D$ ASSOCIATES

ATTN: G GANONG

RAND CORP

ATTN PDAVIS

RAND CORP

ATTN B BENNETT

S.CUBED

ATTN. D GRINE

ATTN LIBRARY

ATTN* T RINEY

SCIENCE \& ENGRG ASSOC, INC ATTN. B CHAMBERS

SCIENCE APPLICATIONS INTL CORP ATTN: TECH LIB

SCIENCE APPLICATIONS INTL CORP ATTN. D MAXWELL

SCIENCE APPLICATIONS INTL CORP ATTN. J COCKAYNE ATTN: M KNASEL ATTN. R SIEVERS ATTN W LAYSON

SCIENCE APPLICATIONS INTL CORP ATTN G BINNINGER

SOUTHWEST RESEARCH INSTITUTE ATTN A WENZEL ATTN - W BAKER 
DEPARTMENT OF DEFENSE CONTRACTORS (CONTINUED)

SRI INTERNATIONAL

ATTN: G ABRAHAMSON

STRUCTURAL MECHANICS ASSSOC, INC ATTN. R KENNEDY

TELEDYNE BROWN ENGINEERING

ATIN D ORMOND

ATTN. F LEOPARD

ATTN: J RAVENSCRAFT

TRW ELECTRONICS \& DEFENSE SECTOR

2 CYS ATTN N LIPNER

ATTN: TECH INFO CTR
TERRA TEK, INC

AT?N: LIBRARY

TRW ELECTRONICS \& DEFENSE SECTOR

ATTN: E WONG

ATTN: G HULCHER

ATTN. PDAI

WEIDLINGER ASSOC, CONSULTING ENGRG ATTN: T DEEVY

WEIDLINGER ASSOC, CONSULTING ENGRG ATTN: I SANDLER

ATTN. M BARON

WEIDLINGER ASSOC, CONSULTING ENGRG ATTN: JISENBERG 